\title{
Evaluation of Thermal Probe Method for Estimating the Heat Loss From Underground Heat Distribution Systems
}

Jin B. Fang and Richard A. Grot

U.S. DEPARTMENT OF COMMERCE

Nationl Institute of Standards and Technology

(Formerty National Bureau of Standards)

National Engineering Laboratory

Center for Building Technology

Building Environment Division

Gaithersburg, MD 20899

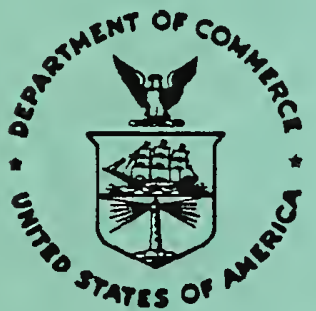

Prepared for

U.S. Department of Energy

Buildings and Community Systems

Building Services Division

Washington, DC 20585
National Bureau of Standards became the National Institute of Standards and Technology on August 23, 1988, when the Omnibus Trade and Competitiveness Act was signed. NIST retains all NBS functions. Its new programs will encourage improved use of technology by U.S. industry.

\section{U.S. DEPARTMENT OF COMMERCE C. William Verity, Secretary NATIONAL INSTITUTE OF STANDARDS AND TECHNOLOGY Ernest Ambler, Director}





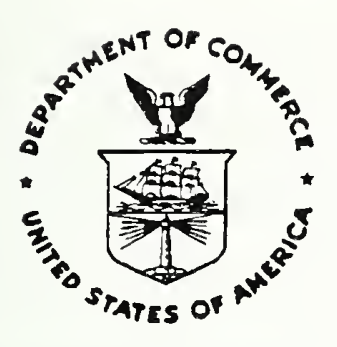

\title{
Evaluation of Thermal Probe Method for Estimating the Heat Loss From Underground Heat Distribution Systems
}

Jin B. Fang and Richard A. Grot

\author{
U.S. DEPARTMENT OF COMMERCE \\ Nationl Institute of Standards and Technology \\ (Formerly National Bureau of Standards) \\ National Engineering Laboratory \\ Center for Building Technology \\ Building Environment Division \\ Gaithersburg, MD 20899
}

December 1988

Prepared for

U.S. Department of Energy

Buildings and Community Systems

Building Services Division

Washington, DC 20585

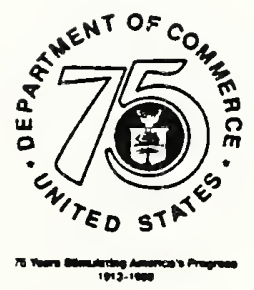



An automated, microcomputer controlled instrumentation system for in situ measurements of the earth temperatures and soil thermal conductivities at different depths is described. The system can also be used on site for calculating the heat losses from the underground district heating pipes. Step-by-step use and operation procedures of the developed heat loss measuring system and computer software package are presented. The heat loss rates and locations of underground pipes are calculated from the measured values of soil thermal conductivity and the earth temperatures around the pipes using the non-linear least squares method. The thermal probe technique was used to estimate the heat loss rates and the depths of buried steam supply and condensate return pipes installed at James Madison University, Harrisonburg, Virginia .

Key Words: computer software; district heating and cooling; earth temperature; heat loss; instrumentation system; nonlinear least squares fitting; soil; temperature probe; thermal conductivity; thermal probe; underground heat distribution system. 
TABLE OF CONTENTS

Page

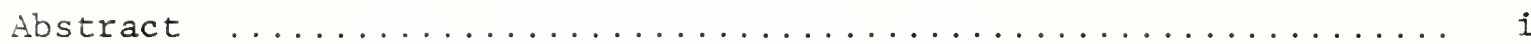

1. Introduction $\ldots \ldots \ldots \ldots \ldots \ldots \ldots \ldots \ldots \ldots \ldots \ldots \ldots \ldots$

2. Temperature Distribution Near Buried Pipes $\ldots \ldots \ldots \ldots \ldots \ldots \ldots$

3. Transient Needle Method for Determination of Soil Thermal

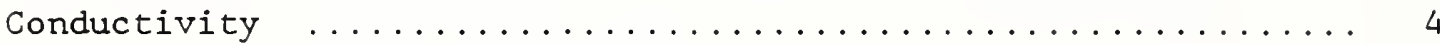

4. Description of the Instrumentation System $\ldots \ldots \ldots \ldots \ldots \ldots$

4.1 Autoranging DC Power Supply $\ldots \ldots \ldots \ldots \ldots \ldots \ldots \ldots \ldots \ldots \ldots \ldots \ldots \ldots \ldots \ldots$

4.2 Terminal Boxes and Analog Interface Card .......... 7

4.3 Data Acquisition System Board $\ldots \ldots \ldots \ldots \ldots \ldots \ldots \ldots$

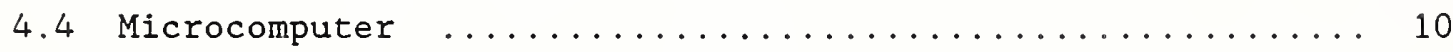

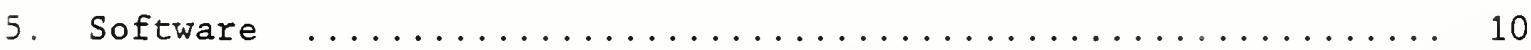

6. Measurement Equipment and Procedures................ 11

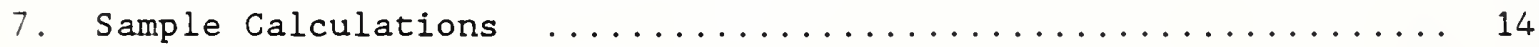

8. Conclusions and Recommendations $\ldots \ldots \ldots \ldots \ldots \ldots$

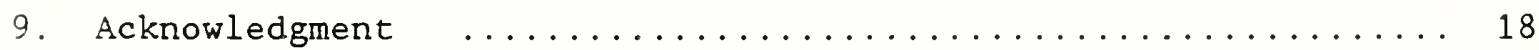

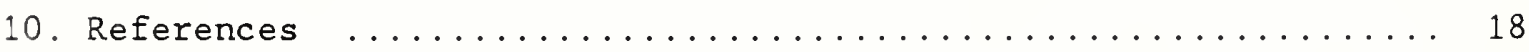


Appendix A - Descriptions of Major Subroutine Subprograms..........25

Appendix B - Operation Procedure of the Instrumentation System......26

Appendix A - A Listing of the Computer Programs...................

LIST OF FIGURES AND TABLE

Figure 1. Schematic of a two-pipe underground heat distribution

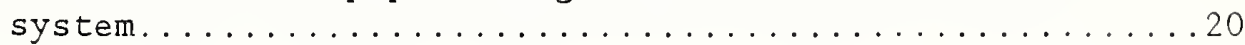

Figure 2. Two underground pipes encased in a metallic conduit......21

Figure 3. Sectional View of a Laboratory Conductivity Probe $\ldots . \ldots 22$

Figure 4. Construction Details of a Temperture Probe ............23

Table 1. Pin Connections between Connector J2 of the Power Supply

and Connector $\mathrm{J} 1$ of the Data Acquisition System Board......24 



\section{INTRODUCTION}

A centralized heating plant generates steam, hot water or chilled water and delivers these process fluids through a network of pipelines buried underground or installed above the ground. The supply and distribution of energy by means of a district heating and cooling system can be more efficient and economical than a number of smaller units. The system can also effectively utilize a variety of fuels including municipal refuse and industrial waste heat to provide energy at lower prices, with greater opportunities for associated urban development compared to other alternative energy systems. District heating and cooling is considered as one of the most viable means to help attain energy independence. However, these advantages are not realized unless the operating cost due to heat loss through the underground system is low.

To determine the performance of underground distribution system, there is interest to develop procedures for estimating heat losses and heat gains from the system. These procedures will provide necessary information for optimum design of insulated piping networks and indicate when significant deterioration of pipe insulation and metal conduits occur. The information can serve as a basis for determining the necessity and priority of pipeline repair or replacement. Several types of measurement techniques such as condensate production rate [1] and shallow earth temperature [2, 3] measurements have been used for estimating the heat loss from a section of buried pipeline. Presently, there is no easy-to-use in situ method to quantify pipe heat losses accurately without major disruptions of normal operation of the pipelines. 
This report describes a thermal probe technique developed for in situ measurements of soil thermal conductivity and heat loss from a directly buried conduit heat distribution system in which two insulated pipes encased in one or two metal conduits are installed in direct contact with the earth. This technique uses heat transfer theory, nonlinear least squares method, and measured thermal conductivity of the surrounding soil to convert the earth temperature profile around the underground pipes into heat loss values. This report also describes the detailed construction and step-bystep operation of an automated instrumentation system. The system is controlled by a microcomputer to measure soil thermal conductivity and earth temperatures in the vicinity of the underground heat distribution system. An application of the thermal probe technique to estimate the heat loss rates and locations of buried steam and condensate pipes installed on the James Madison University campus in Virginia is described.

\section{TEMPERATURE DISTRIBUTION NEAR BURIED PIPES}

A heat conduction model is employed to describe the temperature distribution in the soil above and around a pair of underground pipes. Figure 1 shows a schematic of the two-pipe, direct buried conduit underground heat distribution system. The derivation of expressions describing the temperature field near the buried pipes is based on two assumptions. The thermal conductivity of soil is assumed to be independent of temperature and the depth of a pipe is large compared to its pipe radius. With these simplifying assumptions, the heat conduction equation derived under steady-state conditions, with negligible moisture migration effects, and subject to boundary conditions of 
constant temperature for the ground surface and outer pipe wall, can be solved using the method of images [4]. Thus, the earth temperature disturbance caused by the heating or cooling of an underground pipe buried at a finite depth from the ground surface can be expressed by

$$
T-T_{0}=\frac{Q_{i}}{4 \pi k} \ln \left[\frac{\left(X-b_{i}\right)^{2}+\left(Y+a_{i}\right)^{2}}{\left(X-b_{i}\right)^{2}+\left(Y-a_{i}\right)^{2}}\right]
$$

where $T$ is the temperature of the soil at a given location, $T_{0}$ is the undisturbed soil temperature, $Q_{i}$ is the heat loss or heat gain of the $i-t h$ pipe per unit length, $k$ is the thermal conductivity of the soil, $X$ and $Y$ are the Cartesian coordinates of any arbitrary point in the temperature field, and $b_{i}$ and $a_{i}$ are the horizontal distance and vertical depth of the center of the $i-t h$ pipe.

The underground temperature field around a two-pipe system with each pipe encased in a metallic conduit can be obtained by superimposing the contribution of each pipe to give

$$
T=\sum_{i=1}^{2} \frac{Q_{i}}{4 \pi k} \ln \left[\frac{\left(X-b_{i}\right)^{2}+\left(Y+a_{i}\right)^{2}}{\left(X-b_{i}\right)^{2}+\left(Y-a_{i}\right)^{2}}\right]+T_{0}
$$

This non-linear multivariable function can be solved to give the heat losses $\left(Q_{1}, Q_{2}\right)$, locations $\left(b_{1}, b_{2}\right)$ and depths $\left(a_{1}, a_{2}\right)$ of the pipes using the method of non-linear least squares, provided the earth temperature and thermal conductivity data are available. In the field, the locations of the underground pipes may not be well known. In order to improve the estimate of pipe heat loss, one of the unknown parameters is removed by introducing a known separation distance, $d$, between the centers of the pipes (see figure 1). This separation distance can be obtained from either the pipeline 
layouts in the architectural drawings or by measurement where the pipes are accessible in the nearby manholes.

The temperature of the soil surrounding two underground pipes installed in a single metallic conduit (see figure 2) is given by

$$
T=\frac{Q t}{4 \pi k} \ln \left[\frac{(X-b) 2+(Y-a) 2}{(X-b)^{2}+(Y-a)^{2}}\right]+T_{O}
$$

where $Q_{t}$ is the total heat loss per unit length of the pipes, and $b$ and $a$ are the horizontal distance and the depth of the center of the conduit, respectively. This equation is a simplified case of equation 1 . With the use of non-linear least squares technique, this equation can be solved to yield the combined heat loss from the pipes, and the location and depth of the conduit based on the soil temperature and thermal conductivity data.

\section{TRANSIENT NEEDLE METHOD FOR DETERMINATION OF SOIL THERMAL CONDUCTIVITY}

The advantage of the transient needle method is both the soil thermal conductivity and diffusivity can be determined simultaneously from the test data without knowledge of the heat capacity of the soil. The instantaneous temperature rise at a point on the surface of a long heated cylinder or needle, which has smaller diameter compared to its length and is dissipating heat into an infinite homogeneous medium, can be approximated by [5]

$$
T_{S}=\frac{Q}{4 \pi k L}\left[\ln (t)+\ln \left(\frac{4 \alpha}{r^{2}}\right)-\gamma\right]
$$

where $T_{S}$ is the surface temperature of the cylinder or needle, $Q / L$ is the power input per unit length, $t$ is the elapsed time, $r$ is radial distance 
from the line heat source, $\gamma$ is Euler's constant (0.5772), and $k$ and $\alpha$ are soil thermal conductivity and diffusivity, respectively.

From this equation, it is apparent that if temperature is plotted versus $\ln (t)$, the curve with $t$ greater than some certain value becomes asymptotic to a straight line having the slope equal to $\mathrm{Q} /(4 \pi \mathrm{kL})$ and the intercept equal to $\ln \left(4 \alpha / r^{2}\right)-\gamma$ on the $\ln (t)$, axis. The soil thermal conductivity and diffusivity can be determined from the slope and intercept values of the least squares method regression line, which best fits the experimental temperature-time data. If $S$ is the slope and $I$ is the intercept of the extrapolated straight line on the $\ln (t)$ axis, the thermal conductivity (k) and thermal diffusivity $(\alpha)$ of soil can be calculated from the following equations:

$$
\begin{aligned}
& k=\frac{Q}{4 \pi L S} \\
& \alpha=\frac{r^{2}}{4} \exp \left(\frac{I}{S}+\gamma\right)
\end{aligned}
$$

\section{DESCRIPTION OF THE INSTRUMENTATION SYSTEM}

A microcomputer based instrumentation system was developed for in situ measurements of the soil temperature and thermal conductivity, and the heat loss rates of the heat supply and the return pipes. The instrument can be operated in an interactive mode and contains computer routines for data storage on a floppy disk, and for on-line data analysis and plotting. The thermal conductivity measuring system is a microcomputer-controlled unit providing programmable power to thermal conductivity probes, and measuring 
both the output voltages of the thermocouples attached on the probe wall surface and the electrical power consumed by the probe heater. The measuring system consists of a $200 \mathrm{~W}$ autoranging DC power supply, two terminal boxes each having eight analog input connections, a sixteen-channel analog interface card, a data acquisition board, and a portable microcomputer. This instrumentation system requires a constant $120 \mathrm{~V} / \mathrm{AC}$ power source and is controlled entirely by the computer software. The computer is also used to calculate the soil thermal conductivity and diffusivity for each thermocouple input. The performance specifications of the major hardware are as follows:

\subsection{Autoranging DC Power Supply}

The programmable DC power supply (Hewlett Packard Model 6024A and option 002) 1 can provide output voltage ranging from 0 to $60 \mathrm{~V}$, 0 to $10 \mathrm{~A}$ output current, and $200 \mathrm{~W}$ autoranging power output from $120 \mathrm{~V} / \mathrm{AC}$ source. The power supply is equipped with a system interface board for remote monitoring and control of its output voltage and current. It can be remotely programmed to provide the output power varying over a wide and continuous range of voltage and current combinations. These output power characteristics are necessary for electrical heating of the thermal conductivity probe.

1. Certain trade names or company products are mentioned in the text here and in subsequent chapters to specify adequately the experimental procedure and equipment used. In no case does such identification imply recommendation or endorsement by the National Institute of Standards and Technology, nor does it imply that the products are necessarily the best available for the purpose. 
The power supply has front panel controls, plus a voltage and a current meter for continuous display of the output levels. It is furnished with a builtin adjustable overvoltage protection circuit to safeguard against excess voltage and current output. The power supply will shut down if either condition is met. All connections between the interface board and external circuits are made with a 50-pin connector, which is modified to fit a $37-p$ in connector in the rear panel of the power supply.

\subsection{Terminal Boxes and Analog Interface Card}

The computer interface system for temperature measurement consists of two terminal boxes and an analog/digital interface board (Omega White Box Analog Interface and Control for IBM Personal Computer, Part No. WB-AIO-B16). The terminal box can accomodate a wide range of DC voltage and sensors, and has a cold junction compensation device for thermocouples. Its function in the system is to read the thermocouples of the temperature probes and thermal conductivity probes. It can accept up to 8 analog inputs with a peak continuous operating voltage of $50 \mathrm{~V} / \mathrm{DC}$ and a maximum current of $1 \mathrm{~A}$. In order to determine the thermal conductivity of the soil and the heat loss of the underground pipes, thermocouples (type $\mathrm{T}$ ) are used to measure the earth temperatures. The thermocouple wire leads are connected to the terminal blocks in the terminal boxes, and then to two 26-pin analog connectors for a 16-channel analog interface card by an analog ribbon cable. The terminal box also provides ports for input and output for each of the 8 digital lines for digital control. 
The analog interface card contains an analog-to-digital converter with 14 bit resolution, 16 analog input channels, and 16 digital lines for digital inputs or outputs. This card was plugged into one of the empty expansion slots of the microcomputer. As suggested in the user's manual, the analog cable from the terminal box with the lower serial number was connected to the 26-pin connector for analog channels 1 to 8, while the other terminal box was connected to analog channels 9 to 16 . The interface card accepts $\mathrm{mV}, \mathrm{V}$, $\mathrm{mA}$ and thermocouple inputs with an uncertainty of less than 0.048 of range, and has the filter delay time varying from 0.015 to 0.4 second per channel. It is capable of handling up to 16 thermocouple inputs and digitalizing into temperature values at a rate of 0.5 seconds per channel. The scan time for consecutive readings of the entire 16 thermocouple channels using this analog interface card was found to be approximately 13 seconds. The measurement errors due to type $T$ thermocouples and the cold junction compensation device at $25^{\circ} \mathrm{C}$ are estimated to be $\pm 0.8^{\circ} \mathrm{C}$ and $\pm 0.02^{\circ} \mathrm{C}$, respectively. To facilitate transporting and operating of the instruments, the programmable DC power supply and two terminal boxes were housed in a rugged metal case.

\subsection{Data Acquisition System Board}

A general purpose single board data acquisition system (Data Translation, Model DT 2801 board) was plugged directly into one of the expansion slots of an IBM PC compatible computer. This board served the purpose of controling the autoranging DC power supply using the digital-to-analog converter of the board to control the voltage and amperage levels of the power regulator, and the analog-to-digital data acquisition module to monitor the performance of 
the power supply. Certain special functions of the power supply are controlled and monitored using the digital input and output ports on the board. Prior to plugging the board into the backplane of the computer, the jumpers on the board were installed or removed according to functions of analog and digital conversion in selecting various board parameters as given in the user's manual. The board parameters selected are the analog input voltage ranging 0 to $+5 \mathrm{~V}$, bipolar input mode, single-ended inputs, and the board base address assigned at 2EC (HEX) port address. The board can be programmed from the IBM PC compatible to perform analog-to-digital (A/D) and digital-to-analog (D/A) conversions, and digital input and output transfers.

The board has an A/D converter for 16 single-ended or 8 differential analog input channels with 12 -bit resolution or 0.0248 of the analog input range, and two D/A converters with the same resolution. It contains a programmable gain amplifier to permit gains of 1,2, 4 and 8 to be selected by software so that a wide range of input signal levels can be accommodated. The board also has two 8-line digital I/O ports, which can be used separately to read or write 8-bit data, or changed simultaneously for 12 or 16-bit data transfers, and an on-board programmable clock with a base frequency of 13.7 $\mathrm{kHz}$ to provide clock pulses to control the operations of $\mathrm{A} / \mathrm{D}$ and $\mathrm{D} / \mathrm{A}$ converters. The board for data acquisition has two connectors: a 62-pin PC I/O bus connector, which was made connections automatically to the PC bus when it was installed into the backplane of the PC, and a 50-pin connector. The 50-pin connector is accessible from the rear panel of the PC to connect all analog and digital inputs and outputs to the board. The system accuracy 
of the board is estimated to be within $\pm 0.05 \%$ of full scale input range, and with power off, the board can accept a maximum input voltage of $\pm 20 \mathrm{~V}$. Details of the pin connections between the 37 -pin rear panel connector $\mathrm{J} 2$ of the programmable DC power supply and the 50-pin connector J1 of the data acquisition DT2801 board are given in Table 1.

\subsection{Microcomputer}

A portable computer (XPC Compact model) is used as the base of automated operations for the instrumentation system. The major components of this IBM PC compatible are as follows:

(1) A 8088 CPU board with $640 \mathrm{~KB}$ RAM memory and six expansion board slots.

(2) A Hercules compatible video card and an Intel 8087 math-coprocessor.

(3) Two $360 \mathrm{~KB}$ double-density, double-sided, 5-1/4" disk drives.

(4) A parallel printer port, a serial I/O port and a $4.77 \mathrm{MHz}$ clock with battery backup.

(5) A keyboard and a monochrome display monitor.

In addition to these basic components, the portable system contains a printer (Epson, model FX-86e). A nominal $110 \mathrm{~V} / \mathrm{AC}$ power source is required for the entire automated instrumentation system.

\section{SOFTWARE}

A software package called the 'Underground Piping Heat Loss Diagnostics' has been developed to control all operations of the microcomputer-based automated thermal probe system. The software is written in such a way that all 
acquisition, storage and analysis of test data can be performed in an interactive manner.

The computer programs are written in FORTRAN and assembly language, and consists of a main program (HEAT) and thirty eight subroutines. In addition to coordinating all operations of the instrumentation and data acquisition system, the main program provides a main menu for selecting types of thermal measurements and calculations. Various functions of major subroutine subprograms are described briefly in Appendix A and a listing of the source code of the computer program is given in Appendix $C$.

\section{MEASUREMENT EQUIPMENT AND PROCEDURES}

In addition to the instrumentation and data acquisition system described previously, the major equipment employed for measurement of the heat loss from underground pipes include a mobile drilling rig, thermal conductivity and temperature probes, and a $120 \mathrm{~V} / \mathrm{AC}$ generator to provide a constant power supply. The drilling rig is mounted on a two-wheel, single axle trailer (General Equipment Co. 550 Dig-R-Mobile) and equipped with a motorized auger powered by a 7 horse power gasoline engine. The drill bit used with the auger for boring into the ground is a $7 / 8$ in. diameter drill attached to 3 ft and $6 \mathrm{ft}$ long extension rods of 1 inch diameter.

The thermal conductivity probe is a hollow stainless steel sheath with both ends closed that contains an electric heater and thermocouples (type $T$ ) installed at the interior wall of the sheath. For field measurements, two types of the 1 in. $(25 \mathrm{~mm})$ diameter probes used are $4.3 \mathrm{ft}(1.3 \mathrm{~m})$ long with 
2 thermocouples positioned at $1.3 \mathrm{ft}(0.4 \mathrm{~m})$ and $2.0 \mathrm{ft}(0.62 \mathrm{~m})$ from the lower end of the probe, and $6.6 \mathrm{ft}(2 \mathrm{~m})$ in length with 3 thermocouples separately installed at $1.4 \mathrm{ft}(0.42 \mathrm{~m}), 2.8 \mathrm{ft}(0.84 \mathrm{~m})$ and $4.1 \mathrm{ft}(1.25 \mathrm{~m})$ from the lower end. In order to check the operations of the developed instrumentation system and to determine the thermal property of soil samples taken from the field, a laboratory probe (Geotherm, Inc.) $1 / 8$ inch ( $3 \mathrm{~mm}$ ) diameter 4 inch (100 mm) long is used for measuring soil thermal conductivity. A typical commercial built laboratory probe containing a single thermocouple is shown in Figure 3. The thermal time constants, which is the. time necessary to pass the startup transient, for the laboratory and field probes are typically 100 and 1000 seconds, respectively.

Figure 4 shows the construction details of a temperature probe. The temperature probe was fabricated from a nominal $3 / 4$ in. (19 $\mathrm{mm}$ ) steel pipe of 1 inch $(27 \mathrm{~mm})$ outside diameter by $7 \mathrm{ft}(2.1 \mathrm{~m})$ in length. Six thermocouples are installed on the outer wall surface at $1 \mathrm{ft}(0.3 \mathrm{~m})$ intervals starting at $3 / 4$ in. (19 $\mathrm{mm})$ from the lower end closed with a plug. The type $T$ thermocouple junction was attached to the exposed surface of a $1 / 4$ inch ( $6 \mathrm{~mm})$ diameter by $1 / 4$ in. $(6 \mathrm{~mm})$ thick teflon plug threaded into the temperature probe. This steel probe can eliminate probe deformation problems encountered at high temperatures in comparison to the temperature probe constructed from a flexible pvc pipe used in previous field measurements [2]. In field measurements, ground holes are drilled up to 6 feet in depth at 1 ft intervals along a line perpendicular to the buried pipes for an extension of at least $4 \mathrm{ft}$ on both sides of the heat supply pipe. To minimize the oversizing of the hole caused by side-to-side movement of the drill, a 
special auger guide is utilized in ground boring. A ground hole having an outside diameter smaller than the thermal conductivity probe will minimize thermal contact resistance between the probe and the earth.

The thermal conductivity probe is pushed down manually one of the selected holes to assure good probe contact with the earth. The microcomputer-controlled instrumentation system is used in conjunction with the probe to provide programmable electric power to heat the probe; read thermocouples; probe electrical current and voltage, and calculate soil thermal conductivity and thermal diffusivity for each thermocouple location. The step-by-step use and operation procedures of the instrumentation system are given in Appendix B.

The instrumentation system can also be used to determine soil thermal properties in the laboratory. The thermal conductivity of a sand sample was determined using the developed instruments and a standard $1 / 8$ in. ( $3 \mathrm{~mm}$ ) diameter laboratory probe. The measured values were found to be comparable, with a deviation within 58 , with those obtained by a commercially available, microcomputer-controlled thermal property analyzer (Underground Systems, Inc.) on the same sample.

In field measurement of earth temperatures, the temperature probe is inserted carefully into the same hole to ensure again good probe-soil thermal contact, following the disconnections of probe power plug and thermocouple input and the manual removal of the thermal conductivity probe from the hole. The connections required are the thermocouple inputs from the probe to a terminal box. The instrumentation system can accomodate two temperature 
probes at different locations and can measure up to twelve earth temperatures of six separate depths simultaneously. The system is used in connection with the temperature probes to read thermocouple outputs; display and record the earth temperatures and relative locations of all thermocouples installed on the probe surfaces. The operation procedures of the instrumentation system for temperature measurement are presented in Appendix B.

The instrumentation system is then instructed to perform calculations based on the earth temperature data for determining the heat loss rates and the locations of two insulated pipes using the non-linear least squares method. The pipe heat loss rates are printed on the computer screen along with the horizontal distance and vertical depth of the underground pipes. The final display is also recorded on a floppy disk. The detailed operations of the instrumentation system for heat loss calculations are given in Appendix B.

For measurement of soil moisture content, a 3 -in. (76 mm) diameter helicoid bore auger is used to drill and excavate soil samples at various depths. Each soil sample taken with a scoop is sealed in a plastic wrap and placed in a glass container. The moisture content of soil sample is determined by measuring the loss in mass of the sample after drying in an electric oven maintained at $100 \pm 3^{\circ} \mathrm{C}\left(212 \pm 5^{\circ} \mathrm{F}\right)$ for a week to a constant mass $( \pm 0.58)$ in the laboratory.

\section{SAMPLE CALCULATIONS}

A set of test data obtained from a field measurement [2] performed on a directly buried conduit steam distribution system installed at the James Madison University campus, Harrisonburg, Virginia, was used to evaluate the 
heat loss calculation routines. This underground system consists of a nominal 6-in. (152 mm) steam pipe and a 3 -in. (76 mm) condensate return pipe laid side by side with a separation distance of $13 \mathrm{in.}(0.33 \mathrm{~m})$ between the pipe centers, and buried approximately 4 ft $(1.22 \mathrm{~m})$ below the ground surface. The carrier pipes were installed in a $36 \mathrm{in.}(0.91 \mathrm{~m})$ wide by 30 in. $(0.76 \mathrm{~m})$ high rectangular trench filled with protexulate insulation (Protexulate Inc.), which is a mineral powder loose-fill insulating material, and covered with the earth. The earth temperatures were taken for 58 measuring locations in a plane normal to the pipes. These measuring points were distributed horizontally at $1 \mathrm{ft}(0.31 \mathrm{~m})$ intervals covering a total distance of $11 \mathrm{ft}(3.35 \mathrm{~m})$ on both sides of the steam pipe and vertically at $1 \mathrm{ft}(0.31 \mathrm{~m})$ intervals between depths 1 to $5 \mathrm{ft}(0.31$ to $1.52 \mathrm{~m})$. The average value of measured soil thermal conductivities at the test site was found to be $0.524 \mathrm{Btu} / \mathrm{h} \cdot \mathrm{ft} \cdot \mathrm{F}(0.907 \mathrm{~W} / \mathrm{m} \cdot \mathrm{C})$.

Based on these earth temperature and thermal conductivity data obtained from the thermal probe method and the separation distance between the pipes as the input data, the heat loss rates and locations of the underground pipes are calculated using the computer code in option 3 of the main menu. The final results of the computer outputs for these sample calculations are given below:

$\begin{array}{lcc} & \text { Pipe No. } 1 & \text { Pipe No. } 2 \\ \text { Heat Loss Rate, Btu/h.ft } & 183.9(185.5) & -90.3(-91.8) \\ \text { Horizontal Distance, inch } & 72.4(72.5) & 59.4(59.5) \\ \text { Vertical Depth, inch } & 47.9(47.9) & 53.2(53.3)\end{array}$


It is not possible to verify the calculated heat loss values of the steam and the condensate return pipes since the actual values are unknown. However, the estimated depths and locations of the underground pipes are in good agreement with the values found in the pipeline layouts of the architectural drawings. In order to check the validity of this calculation procedure, the numerical values in parenthese in the above table are the DATAPLOT software package implemented on an UNIVAC $1100 / 80$ computer for statistical anlaysis and are also listed for comparison. It can be seen that the heat loss rates and locations of both buried pipes calculated from this computer code agree reasonably well with those obtained from the DATAPLOT software package.

\section{CONCLUSIONS AND RECOMMENDATIONS}

An automated instrumentation and real time data acquisition system controlled by an IBM PC compatible computer was constructed for in-situ measurements of soil thermal properties and earth temperatures at various depths. The heat loss from an underground insulated piping system in district heating and cooling can be measured using the developed instrumentation system. A step-by-step use and operation procedure of this instrument and the computer software package for field and laboratory thermal measurements are presented. The developed hardware and computer software were tested under actual use conditions and found generally to provide satisfactory performance.

The steady-state solutions describing the temperature distribution in the earth around two directly buried pipes installed in separate metallic conduits or a single conduit are given. The solution models the pipes as line heat sources and treats the ground surface and the outer pipe walls as isothermal surfaces. It is particularly applicable for the case when the 
pipe depth is large compared to the pipe radius. Using the method of nonlinear least squares, the equation describing the local earth temperature, which is a nonlinear multivariable function, can be solved to give the heat loss rates, the depths and locations of the buried pipes. The necessary input data include soil thermal conductivity and the earth temperatures obtained from the thermal probe technique, and the separation distance between pipes. The developed computer programs are implemented on the microcomputer and give proper computing speed and adequate accuracy on the calculated results. Sample calculations based on the test data obtained from field measurements conducted on a directly buried conduit steam distribution system installed at the James Madison University, Harrisonburg, Virginia are presented. The calculated pipe depths and locations are generally consistent with the actual values found in the pipeline layouts of architectural drawings, and the estimated heat loss rates agree reasonably well with those by the DATAPLOT software package installed on a mainframe computer for statistical analysis.

The use of thermal probe technique exhibits a considerable promise for estimating the heat loss from an underground heat distribution system. Continuous measurements of earth temperatures and thermal conductivities, and processing and analysis of test data can be carried out rapidly and effectively in the field. Further work is recommended to validate and improve this measurement technique by using tests involving a pair of long insulated pipes with known heat losses and pipe depths. A series of tests will have to be conducted for pipes buried in soils exposed to various surface moisture conditions. Comparison of the pipe heat losses measured by the thermal probe method with those determined by other techniques such as 
the calorimetric method [2] on a section of buried pipes is needed for improved accuracy of this method. It is recommended to apply the thermal probe technique for measuring the heat loss through piping system anchors and supports on the site, which appears to be possible.

\section{ACKNOWLEDGMENT}

This work was sponsored by the Building Services Division, U.S. Department of Energy through an interagency agreement with the National Institute of Standards and Technology. The authors wish to express their appreciation to Mr. Prakash B. Kunjeer of the U.S. Department of Energy for guidance and assistance throughout the project. The authors would like to thank Douglas Pruitt of NIST for his assistance in constructing the automated instrumentation system, and Sandra Foltz of NIST for her help in developing the computer programs used in this study.

\section{REFERENCES}

1. Pan Am World Services, Inc., "Heat Distribution Systems Life-Cycle Cost Analysis - Comparison Between Direct Buried and Shallow Trench Systems," Report 130319, July 1985.

2. Kusuda, T., Fang, J. B. and Ellis, W. M., "A Method for Measuring Heat Loss from Underground Heat Distribution Systems," Thermal Insulation: Materials and Systems, ASTM STP 922, F. J. Powell and S. L. Matthews, Eds., American Society for Testing and Materials, Philadelphia, PA, 1987, pp. 52-68.

3. Beck, J. V. and Karnitz, M. A., "Parameter Estimation Study of Heat Loss from Underground Steam Pipelines," ORNL/TM-9928, Oak Ridge National Laboratory, Oak Ridge, TN, June 1986. 
4. Eckert, E. R. G. and Drake, R. M., 'Analysis of Heat and Mass Transfer,' McGraw-Hill Book Co., New York, 1972.

5. Carslaw, H. S. and Jaeger, J. C., "Conduction of Heat in Solids," Oxford University Press, London, 2nd Edition, 1959.

6. Boggs, S. A. and Radhakrishna, H. S., "Soil Thermal Resistivity and Thermal Stability Measuring Instrument - Volume 4: Abridged Operating Instructions for the Thermal Property Analyzer," EL-2128, Electric Power Research Institute, Palo Alto, CA, November 1981. 


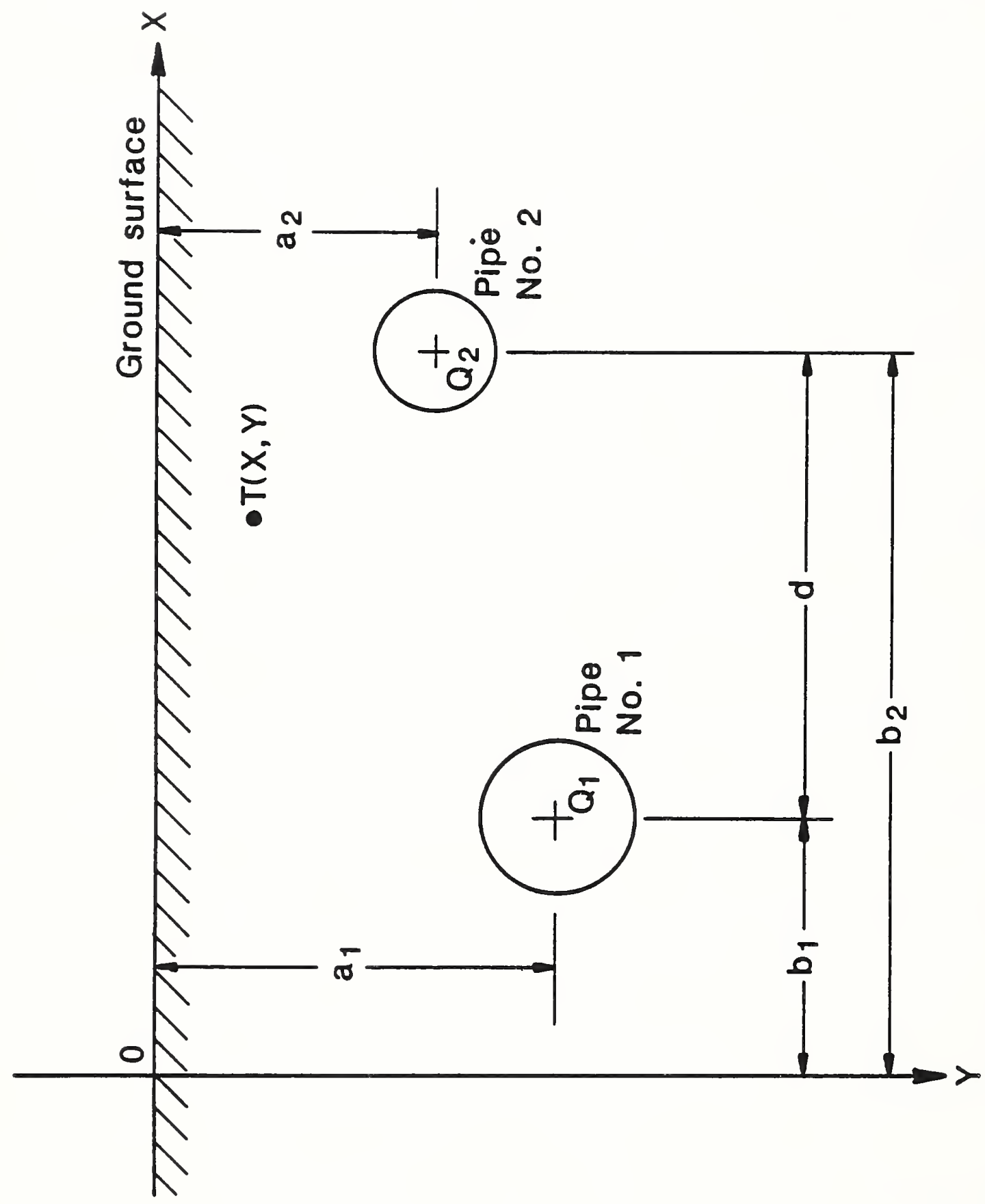

ह 


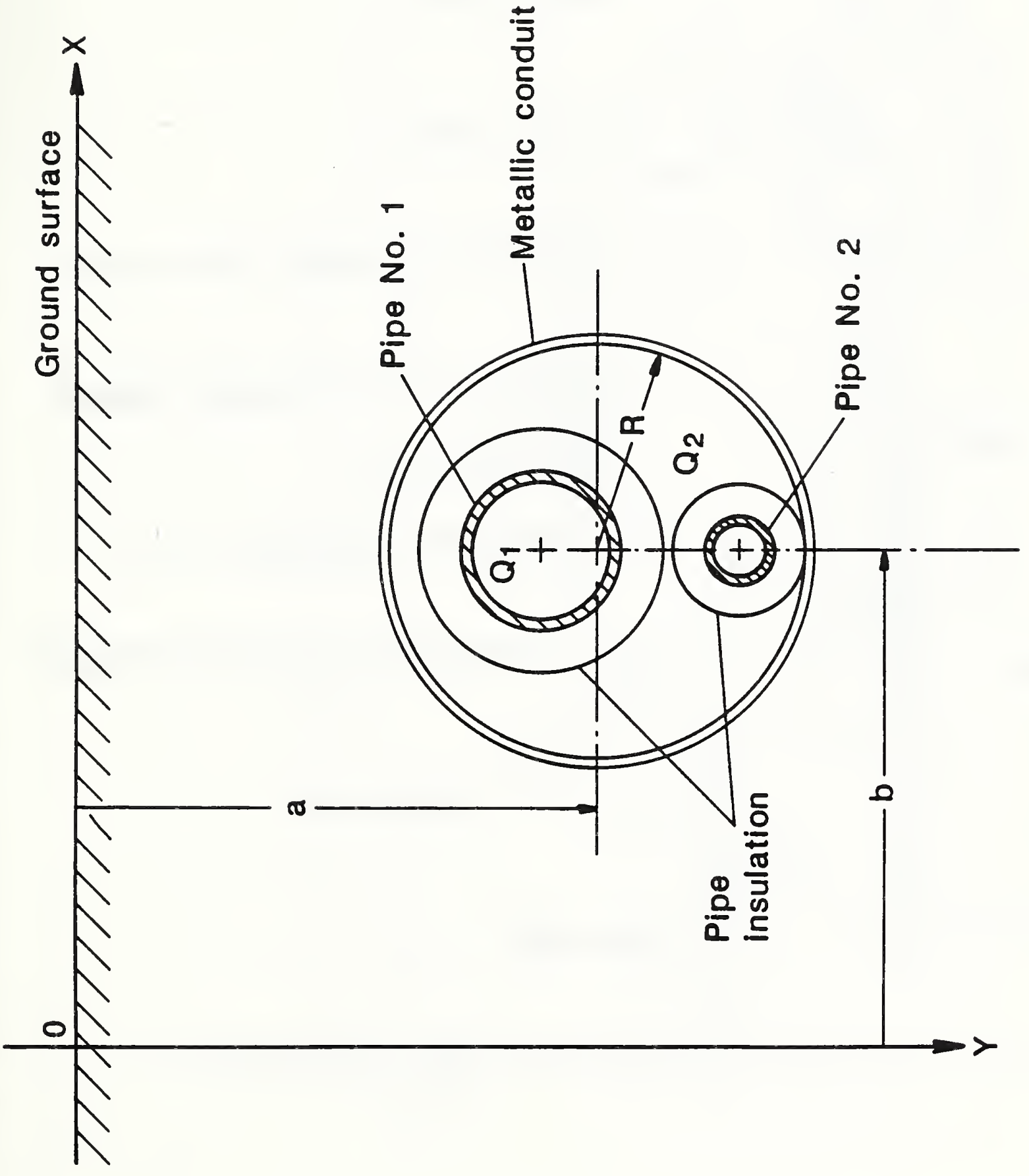

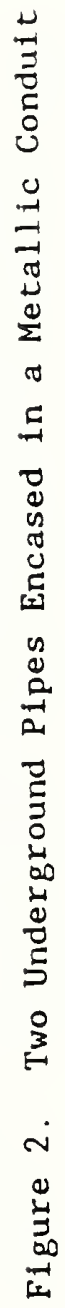




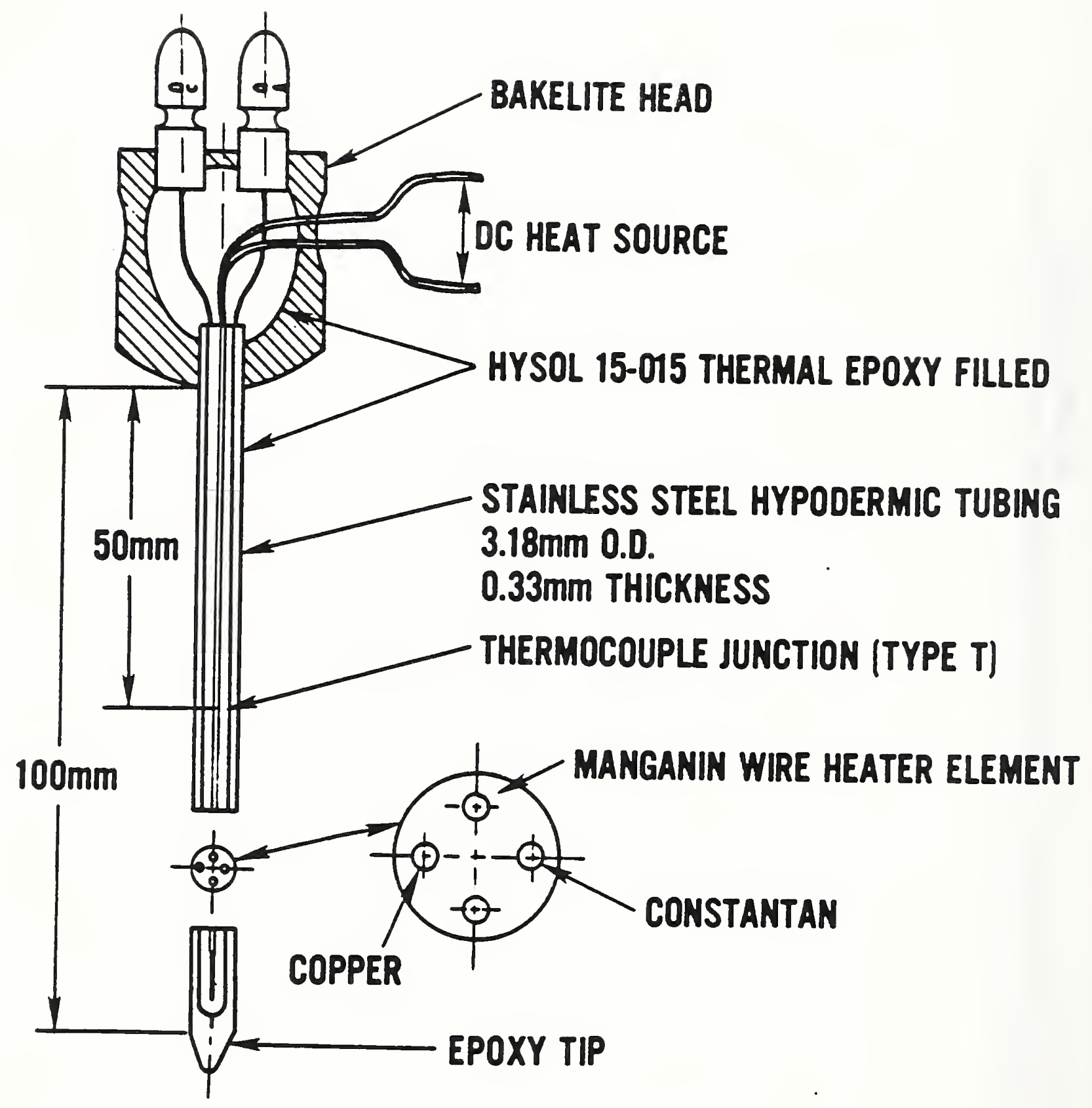

Figure 3. Sectional View of A Laboratory Thermal Conductivity Probe 


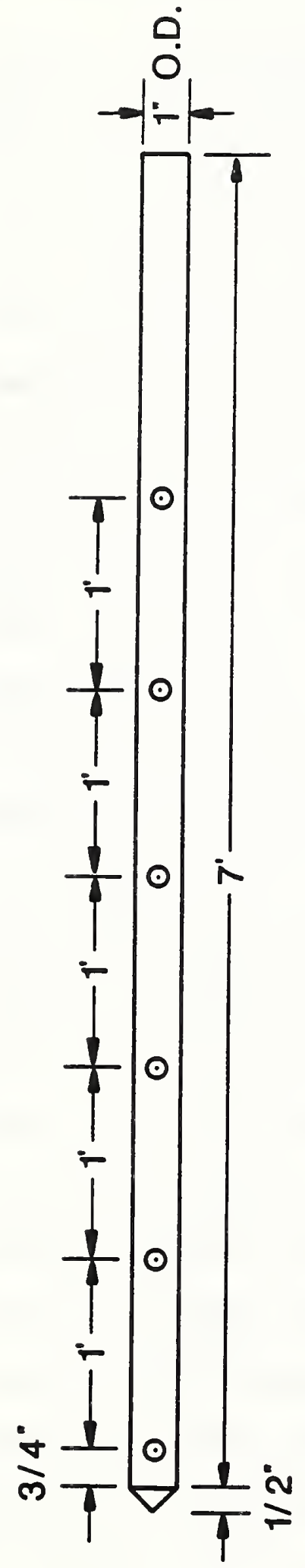

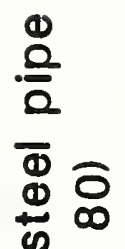

\& $0^{\circ}$

ले

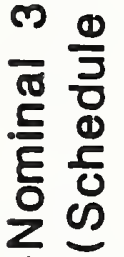

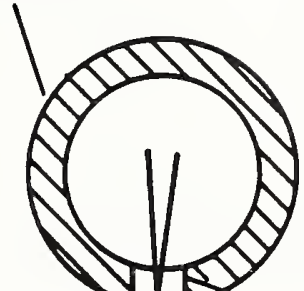

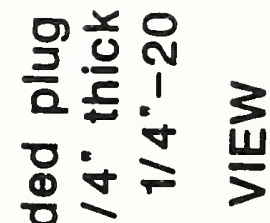

$\stackrel{\mathbb{\Phi}}{\Phi} \times \stackrel{\oplus}{\mathbb{N}}$

$\frac{1}{0}$

\&

등 융

ए

L

岳

1
1
1
0
0
0
0

동음

돈

药

등 을

1 㐫 O

응트

슨은 
Table 1. Pin Connections Between Connector J2 of the DC Power Supply and Connector $\mathrm{J} 1$ of the Data Acquisition System Board

\section{J2 POWER SUPPLY}

Pin No.

1

24

22

25

3

5

6

20

4

23

7

10

29

30

31

16

17

18

19

35

36

37

34
Description

Outboard Sense

CC Volt Prog

- Sense

CV Volt Prog

Current Monitor

Voltage Monitor

Power-on Preset

$-15 \mathrm{~V}$ Reg.

+15V Reg.

+5V Reg.

Power Supply Common

Control Isolator Bias

$\overline{\text { Remote Reset }}$

$\overline{\text { Remote Trip }}$

Remote Inhibit

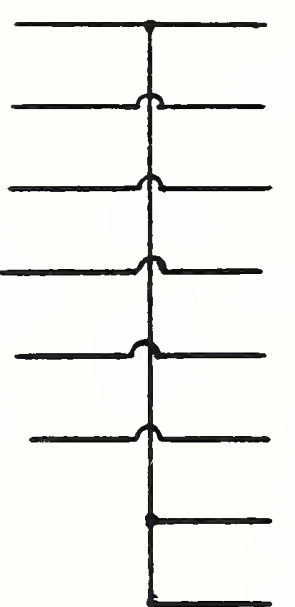

DAC O GND

DAC O Out

DAC 1 GND

DAC 1 out

Channel 0

Channel 1

Amp Low

AGND

AGND

DGND

$26,27,32,37,42,47,48$
23

22

25

24

1

3

18

17

21

28

29

30

38

39

40

44

41

43 
Appendix A. Descriptions of Major Subroutine Subprograms

Subroutine THERMA is used to read up to four thermocouples installed in a thermal conductivity probe, to calculate the thermal conductivity and diffusivity of soil surrounding each thermocouple location, and to store the test data in a file named by the user. Subroutine TEMPER reads earth temperatures from up to sixteen thermocouples positioned at different locations and various depths, and records both detailed and briefly summarized results of temperature measurements on two data files. Subprogram HLCALC performs calculations of the heat loss from underground pipes based on least squares fitting of the earth temperature data to a theoretically derived non-linear equation describing the underground temperature field. Subroutine LMMNL determines the parameters in the non-linear function based on the Levenberg, Marquardt and Morrison algorithm modified for one or more independent variables, and FUNVAL evaluates the function and its partial derivatives with respect to the parameters. Subroutine INITAL is used to initialize the analog interface card and DEGREE reads temperatures from thermocouple outputs. Subprogram POWERON resets and performs operations of the programmable DC power supply for the probe heater, and POWON calculates the electrical current of the desired power level and turns on the power to the thermal conductivity probe. Subroutine RDPOW reads the electrical current and voltage levels from the programmable DC power supply, and CONSTPOW regulates the electric power applied to the probe to be within \pm $0.08 \mathrm{~W}$ of the desired value. Subroutine TEMPDT calculates the time to start and to terminate power to the probe heater, and reads the probe surface temperatures from up to four thermocouple input channels. Subprogram CALC computes soil thermal conductivity and diffusivity and coefficient of 
correlation and finds maximum and minimum values for graph plotting. Subroutines SETTEM, GTEMP, PLTTEM and PLTCHR are used for plotting temperature versus logarithm of time to the screen. Subroutine HILITE is used to highlight a cell by setting its attributes to reverse video while returning the previously highlighted cell attributes to normal. Subroutines CLOCK reads the system clock and PRTCLK writes time and date to the screen.

Appendix B. Operation Procedure of the Instrumentation System

The system connections required include the main power cords to the computer and the programmable DC power supply, a probe power plug and thermocouple inputs, analog card inputs, and the programmable DC power supply remote control. After the instrumentation system is setup and the DOS (Diskette Operating System) disk is inserted into drive $A$, both the computer and the programmable DC power supply are turned on to load the computer operating system. In response to the prompts from the computer, the user enters the date and time, and then inserts a formatted new blank disk into drive B. Replacing the DOS disk with the program disk, the user types 'HEAT' and presses the ENTER key to start the program. Pressing the ENTER key always terminates the input line and using the CTRL-C key terminates program execution of 'HEAT' and returns to the operating system.

In a few seconds, the screen will show the title of the software package, 'Underground Piping System Heat Loss Diagnostics. The main menu is displayed after depressing of the ENTER key. The main menu lists all of the options available for the user. The options are as follows: 1. Determine the soil thermal conductivity, 2. Measure the ground temperatures, 3. Calculate 
heat losses from buried pipes, 4. Exit. Using the arrow keys on the numeric key pad to move the cursor up and down, the user makes a selection of the desired option, which is displayed and highlighted on the screen, and presses the ENTER key. Option 4 in the main menu is used to exit from the program to the operating system.

\section{B.1 Thernal Conductivity Measurement}

The user selects option 1 for measuring the thermal conductivity of soil surrounding an underground heat distribution system. A test setup file must exist before a thermal conductivity measurement can be performed. By answering questions and typing data on the keyboard, the user either creates a new setup file or uses an existing one created and stored previously on the disk. The following is an example of a setup file created interactively in which typical input data are enclosed in parentheses.

FILE NAME to be 1 to 10 alphanumeric characters long (B:SETUP 01)

PROBE SERIAL NUMBER to be any 2 digit number (01)

RESISTANCE/UNIT LENGTH of the probe heater in milli-ohms/cm (60)

EFFECTIVE LENGTH of the probe heater in $\mathrm{cm}$ (102)

EFFECTIVE RADIUS of the probe heater in $\mathrm{cm}(0.546)$

NUMBER OF THERMOCOUPLES in the probe to be 2 digit number (02)

START TIME is the time necessary to pass the startup transient of the probe and begin measuring thermal conductivity in seconds (1000)

FINISH TIME at which the power to the probe is to be turned off in seconds (1900)

TIME INCREMENT to be the scanned time in seconds (20) 
POWER LEVEL of the probe heater in Watts/cm $(0.19)$

This sample file sets a test using a 1 in. (25 mm) diameter by $4.3 \mathrm{ft}$

$(1.3 \mathrm{~m})$ long field probe containing two thermocouples and an electric heater having an electrical resistance of $60 \mathrm{mohm} / \mathrm{cm}$, an effective length of 102 $\mathrm{cm}$, and an effective radius of $0.546 \mathrm{~cm}$. The thermal conductivity measurement will start at 1000 seconds after the power is supplied to the probe heater, and finish at 1900 seconds. The probe heater will be operated at a power level of $0.19 \mathrm{~W} / \mathrm{cm}$. Temperatures will be scanned, displayed on the screen and recorded on an output file every 20 seconds. The numerical values of probe parameters such as the resistance per unit length and the effective radius and length of the probe heater, can be found from the technical data relating to probe specifications provided by the manufacturer.

The power level to be applied to the probe heater for a given test is determined on the basis of the probe electrical resistance/unit length, which is dependent upon the thermal conductivity of soil at the test site. Boggs and Radhaknishna [6] developed the thermal property analyzer for measuring soil thermal resistivity and selected its power level based on the anticipated soil thermal conductivity to use one of three probe powers/unit length, which is suitable for soils of high, medium, or low the rmal conductivity. The guidelines for selecting the power level are as follows:

Expected Thermal Conductivity

Btu/h.ft.F $\quad \underline{W / m . C}$
Suggested Power Level Per Unit Length

$\mathrm{W} / \mathrm{cm}$
0.36
High $=>0.96$
1.7 

Medium
$0.48-0.96$
$0.83-1.7$
0.19
Low $=<\quad 0.48$
0.83
0.10

Each thermal conductivity probe has a characteristic time constant which is the time required to pass the startup transient. The start time for acquiring the taest data should be equal to this time constant, and the finish time for data acquisition should be limited to within three times of this time constant.

An existing file can also be chosen as the setup file, and its contents are then read by the computer and displayed on the screen. The thermal conductivity test can be run automatically after the user interacts with the system to either select the setup file or input the probe parameters, and to name an output file for summarizing the measured results. The instrumentation system will display the start and finish times of the power supply to the probe, write the current time to the screen, read, display and record the time and surface temperatures of the probe every scan. The electric power is applied to the probe heater after a period of 200 seconds elapses for all thermocouples to attain an equilibrium state. The thermal conductivity measuring system regulates and measures the electrical current and voltage from the programmable DC power supply, and displays the desired and the actual power levels for the probe heater. For each time increment, both the time and each thermocouple temperature are continuously displayed on the screen and recorded on the output file.

When the test is finished, the best fitted values of thermal conductivity and diffusivity of soil based on equation 4 at each thermocouple location 
are printed on both the screen and the output file, along with the coefficient of correlation. A plot of temperature versus log of time during the test for all thermocouples attached on the probe surface can be seen on the screen by pressing the ENTER key. After this plotting is completed, the program stops for the user to view the graph. The user can choose to replot the temperature data over a different time span between the new start and finish times. A negative response by typing a " $N$ " or " $n$ " to the recalculation of thermal conductivity and diffusivity question returns the system to the main menu after pressing the ENTER key.

\section{B.2 Earth Temperature Measurement}

In the main menu displayed on the computer screen, option 2 is selected for measuring the earth temperatures at different depths using the arrow and ENTER keys. By responding to the program questions, the user either creates a new index file or uses an existing one stored on the disk. The details of a thermocouple index file to be created prior to executing the temperature data acquisition program, or a temperature measurement are given below. Typical user inputs are enclosed in parentheses.

FILE NAME to be 1 to 12 characters long (B:INDEX1) NUMBER OF THERMOCOUPLES to be a number between 1 and 12 (02) PROBE NUMBER to be any 2 -digit number (01)

THERMOCOUPLE NUMBER* to be any number between 1 and 12 (01) HORIZONTAL DISTANCE* of thermocouple from a reference pint in inches (12.0) VERTICAL DEPTH* of thermocouple from the groun surface in inches (12.0) THERMOCOUPLE NUMBER to be any 2 -digit number (03) 
HORIZONTAL DISTANCE in inches (12.0)

VERTICAL DEPTH in inches (36.0)

Note: Record numbers 4 to 6 are repeated for each additional thermocouple. This input data file states that the temperature measurement will be made using a temperature probe having two thermocouples positioned at a horizontal distance of $1 \mathrm{ft}(0.30 \mathrm{~m})$ from a reference point on the plane normal to buried pipes, and at depths of 1 and $3 \mathrm{ft}(0.30$ and $0.91 \mathrm{~m})$ from the ground surface, respectively.

A list of thermocouple arrangements will be displayed on the computer screen as soon as an index file is created from the user inputs or existent from the previous inputs. Soil temperature measurements are then performed automatically following a new output file named by the user. Upon updating the time and date to the screen, the system reads thermocouple outputs, and writes the thermocouple number, its temperature reading and location to both the screen and the output file. The measured values of earth temperatures can be updated or omittted by entering either " $\mathrm{"} \mathrm{or} \mathrm{"N"} \mathrm{from} \mathrm{the} \mathrm{key} \mathrm{board}$ when determining if another scan is needed.

To obtain more data on temperature distribution around the buried pipes, additional temperature probes are connected and carefully inserted into holes, and the preceding procedure of acquiring temperature data will be repeated. Depth temperature measurements need to be conducted on the thermally undisturbed soil situated far from the pipes. After acquiring sufficient data on the earth temperatures above and on both sides of the buried pipes, the user initiates the system to select the temperatures 
obtained from a probe located the farthest distance from the pipes as the undisturbed earth temperatures at various depths. Summary results of temperature measurements are automatically recorded on another new output file named by the user, and the system then returns to the main menu. This output file to be used for pipe heat loss calculations contains a tabulation of the earth temperature, the horizontal distance and depth of the measuring point, and the undisturbed earth temperature at the measurement depth, for each measuring point.

\section{B. 3 Heat Loss Calculations}

Estimates of the heat loss from a two-pipe system, and of the horizontal locations and depths of the underground pipes are carried out by selecting option 3 in the main menu. The program heading, 'Buried Pipes Heat Loss Calculation Program' will appear on the screen. The user is then prompted by the system to determine if an existing data file stored in the disk is to be used or if a new data file should be created. The following information should be contained in an input data file in which the values in the parentheses are typical user inputs.

INPUT DATA FILE NAME = a file name of 1 to 12 alphanumeric characters (B : DATAFL1)

DISTANCE BETWEEN CENTERS OF PIPES (inch) = a 2 to 9 -digit number with a decimal point $(13.00)$

NUMBER OF MEASURING LOCATION ( $\mathrm{xxx}$ ): to be any 3 -digit number (002) SOIL THERMAL CONDUCTIVITY $(\mathrm{Btu} / \mathrm{h} \cdot \mathrm{ft} \cdot \mathrm{F})=\mathrm{a} 2$ to 9 -digit number with a decimal point $(0.5240)$ 
PROVIDE THE MODE OF INPUT OF TEST RESULTS:

1 = DATA OBTAINED DIRECTLY FROM OTHER SUBPROGRAMS AND FILES

$2=$ DATA INPUT THROUGH AN INTERACTIVE MANNER

MODE OF DATA INPUT ( 1 or 2 ) = a 3 -digit number (002)

MEASURING LOCATION NUMBER* (xxx): any 3-digit number (001)

THE EARTH TEMPERATURE* (DEG F) = a 2 to 8 -digit number with a decimal

point $\quad(94.700)$

HORIZONTAL DISTANCE* (inch) = a 2 to 8 -digit number with a decimal

point $\quad(72.000)$

VERTICAL DISTANCEx (inch) = a 2 to 8 -digit number with a decimal point $(12.000)$

UNDISTURBED EARTH TEMPERATURE* (DEG F) = a 2 to 8-digit number with decimal point ( 76.500$)$

MEASURING LOCATION NUMBER ( $\mathrm{xxx}):(002)$

THE EARTH TEMPERATURE $($ DEG F $)=(135.300)$

HORIZONTAL DISTANCE $($ inch $)=(72.000)$

VERTICAL DEPTH (inch) $=(36.000)$

UNDISTURBED EARTH TEMPERATURE $($ DEG F) $=(70.000)$

Note: The last 5 records in the input data file are repeated for each additional measuring location.

The values in the parentheses shown in this input data file are typical user inputs. If an existing file, which was created for summarizing the results of earth temperature measurements at the end of main menu option 2 , is employed as the input data file, the user will be prompted to enter the file name. Its contents are then accessed and copied by the computer to a new 
file named by the user. The system prompts the user to supply the following information:

PROVIDE THE TYPE OF PIPE CONFIGURATION:

1 = TWO PIPES LOCATED INSIDE A SINGLE METALliC CONDUIT

2 = TWO PIPES INSTALLED IN SEPARATE CONDUIT

TYPE OF PIPE CONFIGURATION (1 or 2) = a 3 -digit number (002)

INPUT THE INITIAL PARAMETER ESTIMATES:

HEAT LOSS FROM PIPE NO. $1(\mathrm{Btu} / \mathrm{h} \cdot \mathrm{ft})=\mathrm{a} 2$ to 10 -digit number with a decimal point $(200.0)$

HORIZONTAL DISTANCE OF PIPE NO. 1 (inch) = a 2 to 10 -digit number with a decimal point (76.0)

VERTICAL DEPTH OF PIPE NO. 1 (inch) = a 2 to 10 -digit number with a decimal point $(48.0)$

The numerical values in the parentheses are user inputs utilized to serve as an example. A data file can be established as the input file prior to execution of this heat loss calculation program. This existing file should contain data to specify the distance between the centers of the pipes, the number of data points, the soil thermal conductivity, the earth temperatures and their measuring locations, undisturbed earth temperatures, the type of pipe configuration, the initial estimates of the heat loss and the location of pipe No. 1, and the heat loss and vertical depth of pipe No.2. The contents of this file are read by the computer and displayed on the screen. The user names an output file to be created, and gives a diagnostics file a name to obtain detailed results of calculations or simply presses the RETURN key if a diagnostic file is not needed. The computer system performs 
calculations to determine statistically the values of the parameters in a theoretical expression (equation 2 or 3 ) for the temperature field around the underground system, and to estimate the heat losses and the locations of two insulated pipes based on the non-linear least squares method. A system warning will appear on the screen if the number of iterations exceeds the maximum allowable number of 50. When the calculations are finished, the pipe heat loss rates are printed on the screen along with the horizontal distance and vertical depth of the underground pipes. The final display is also written to the output file. The program then returns to the main menu awaiting further instructions. 


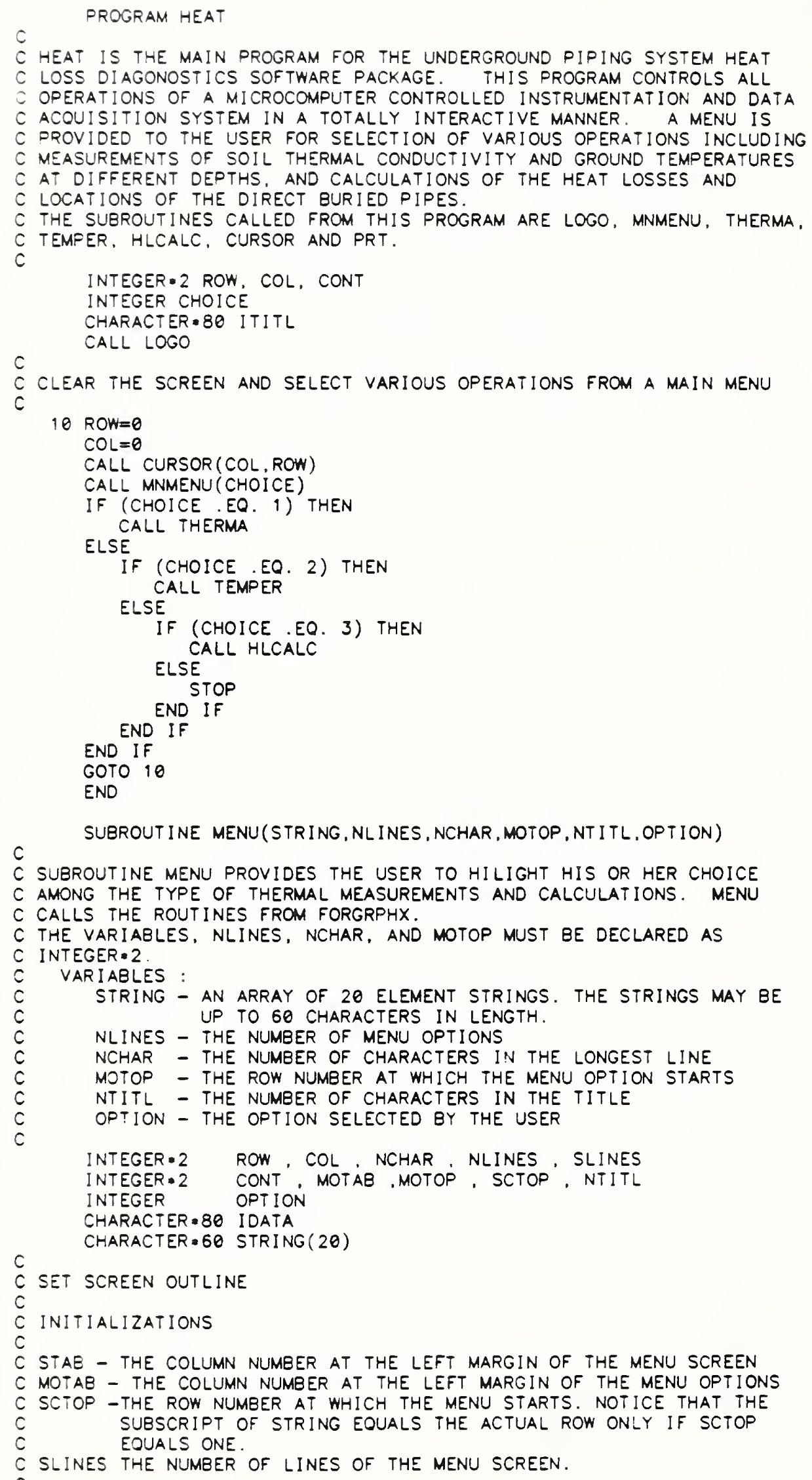




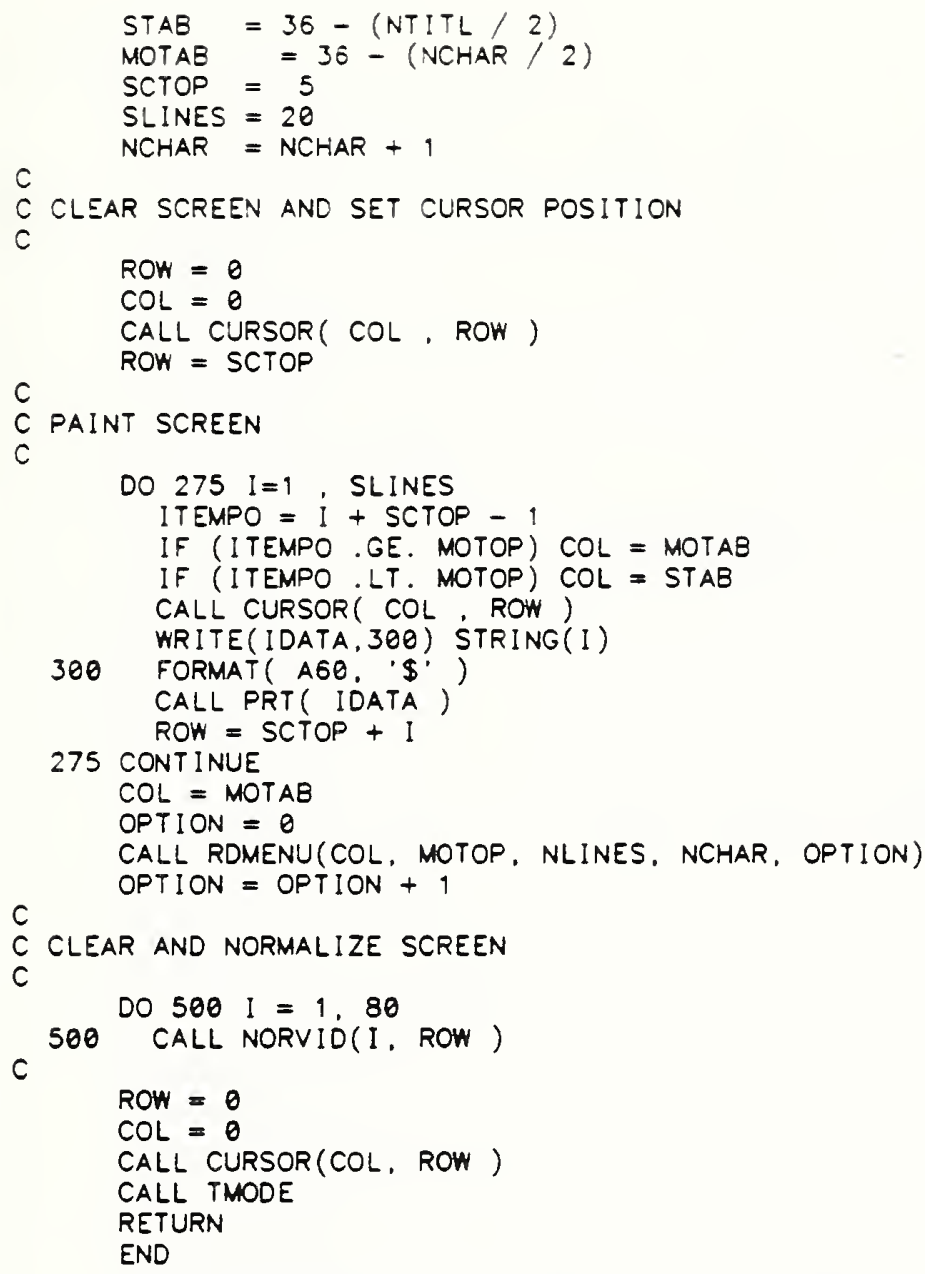




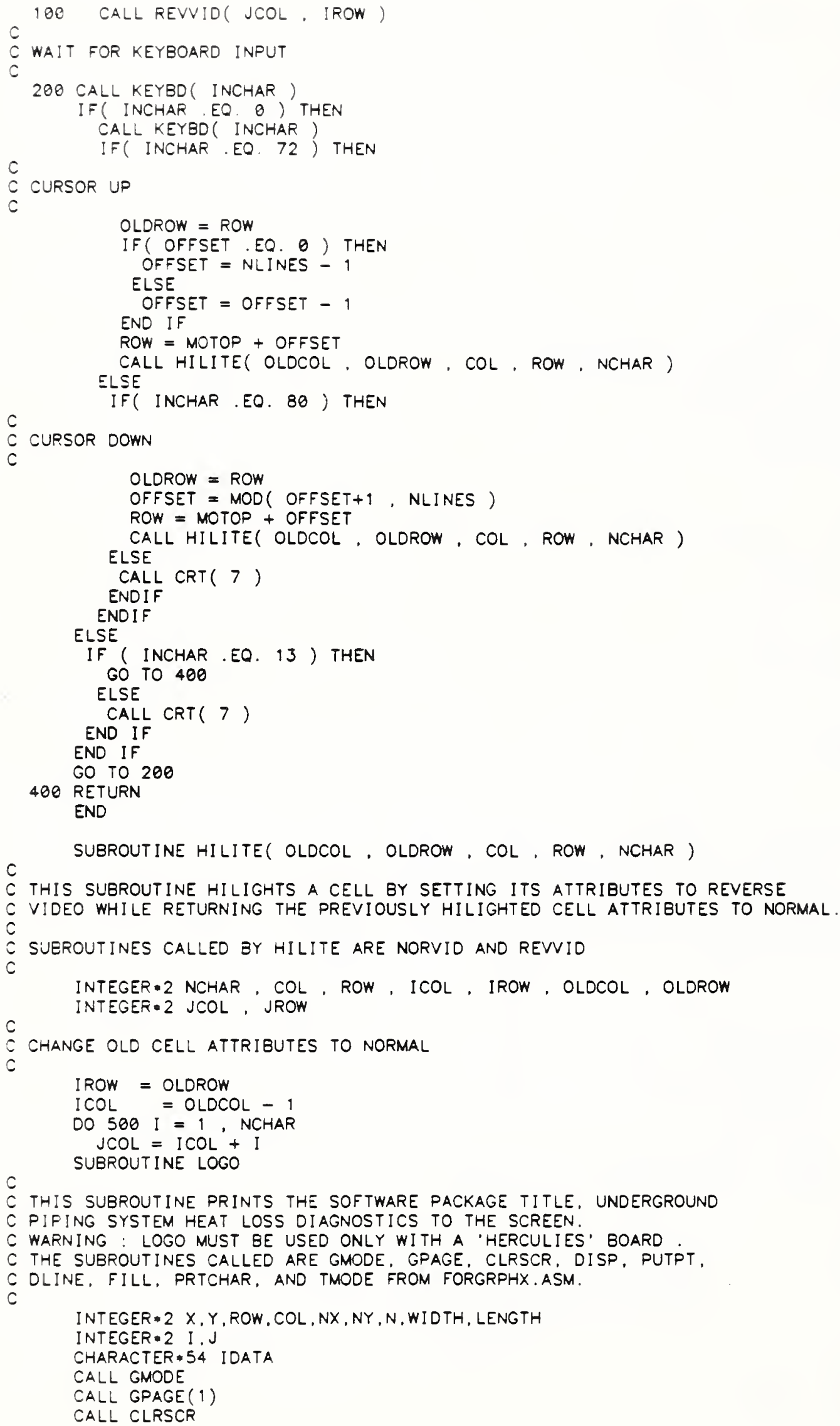




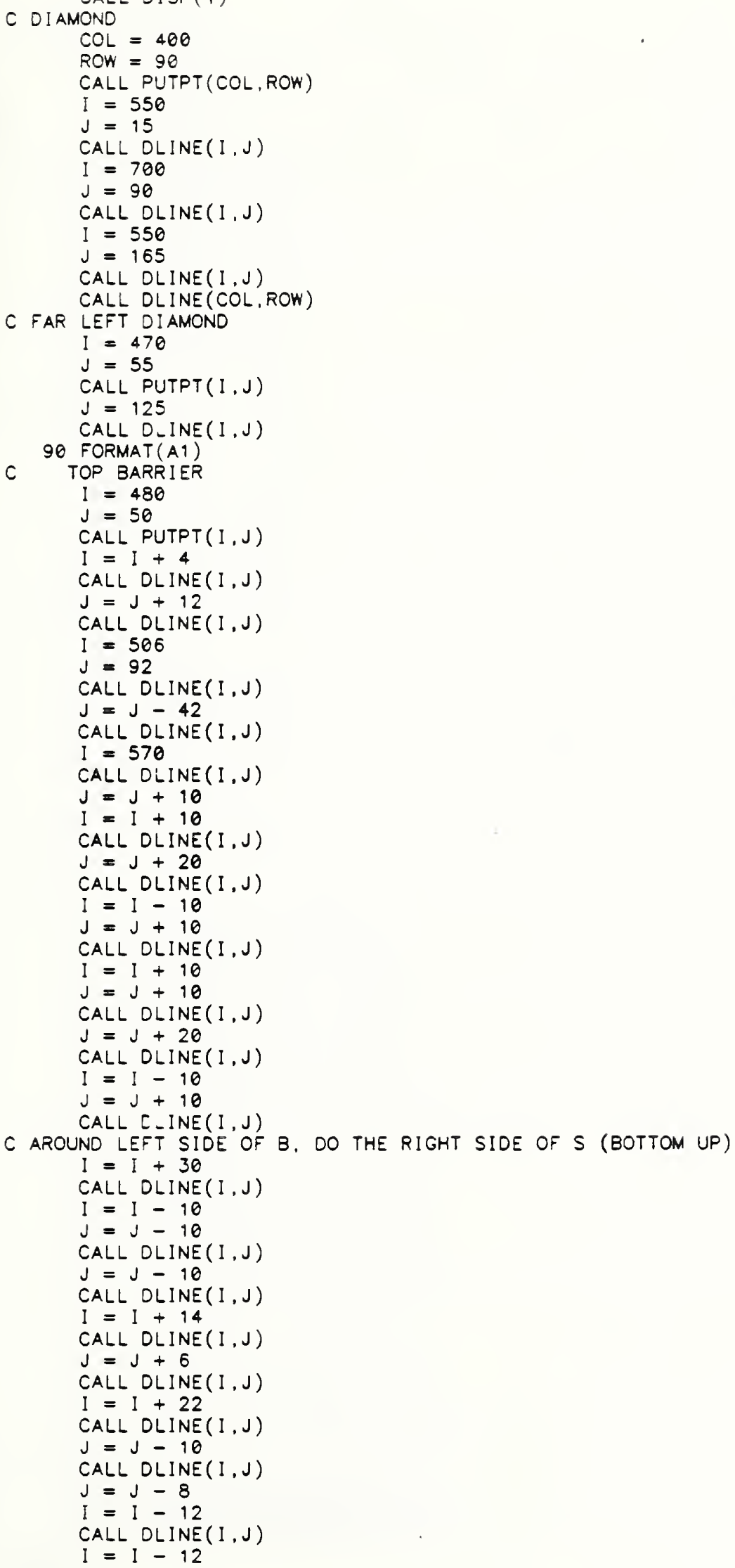




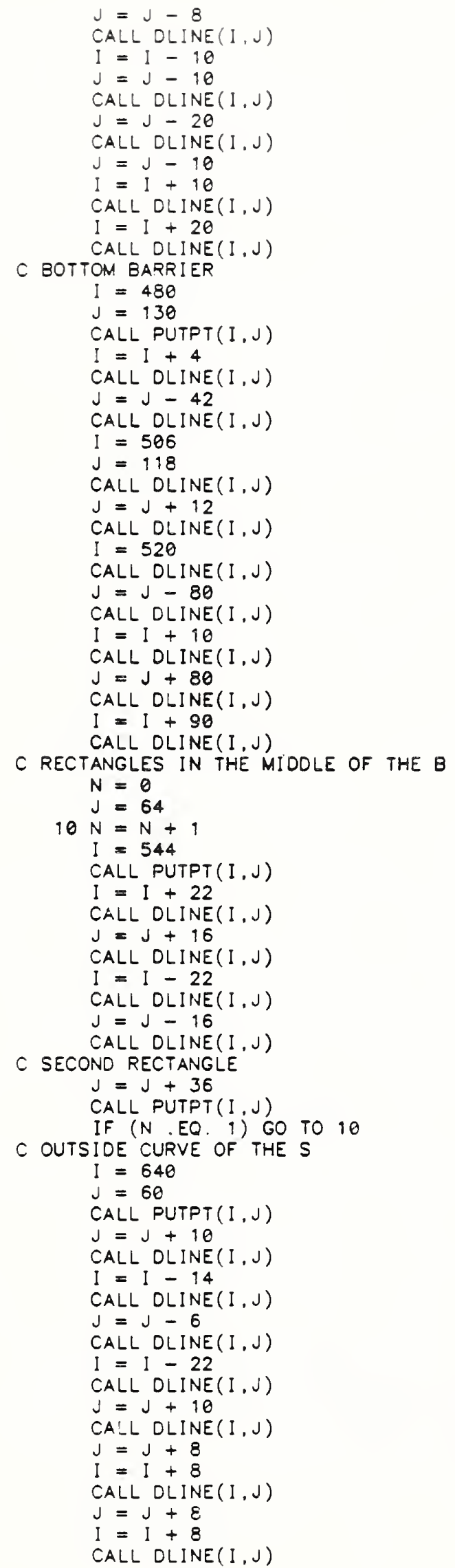




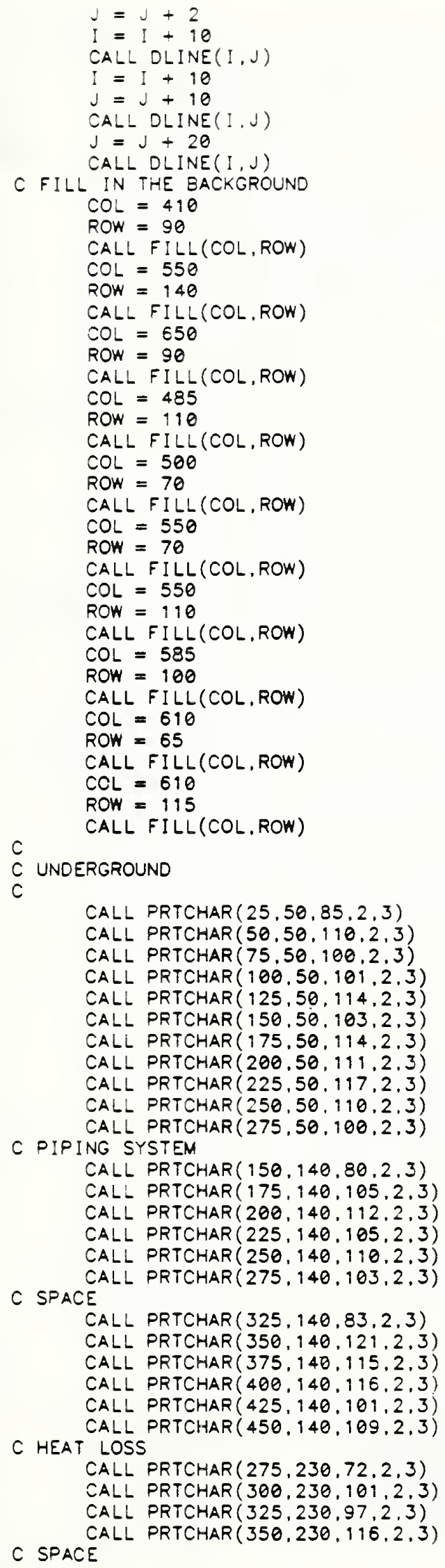




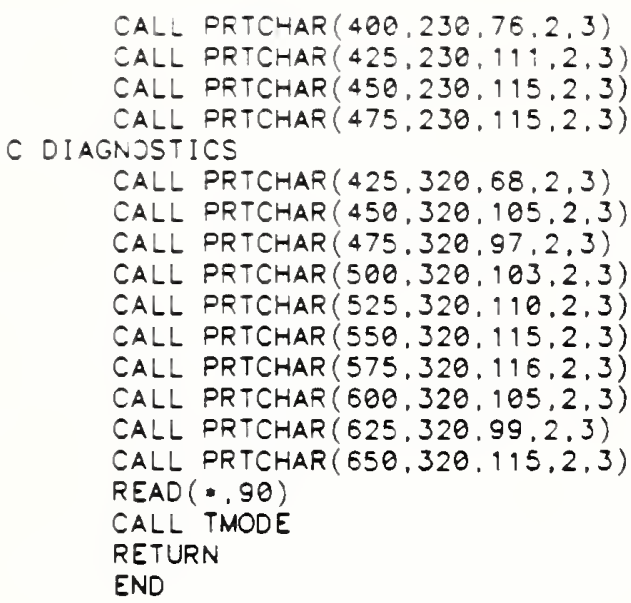




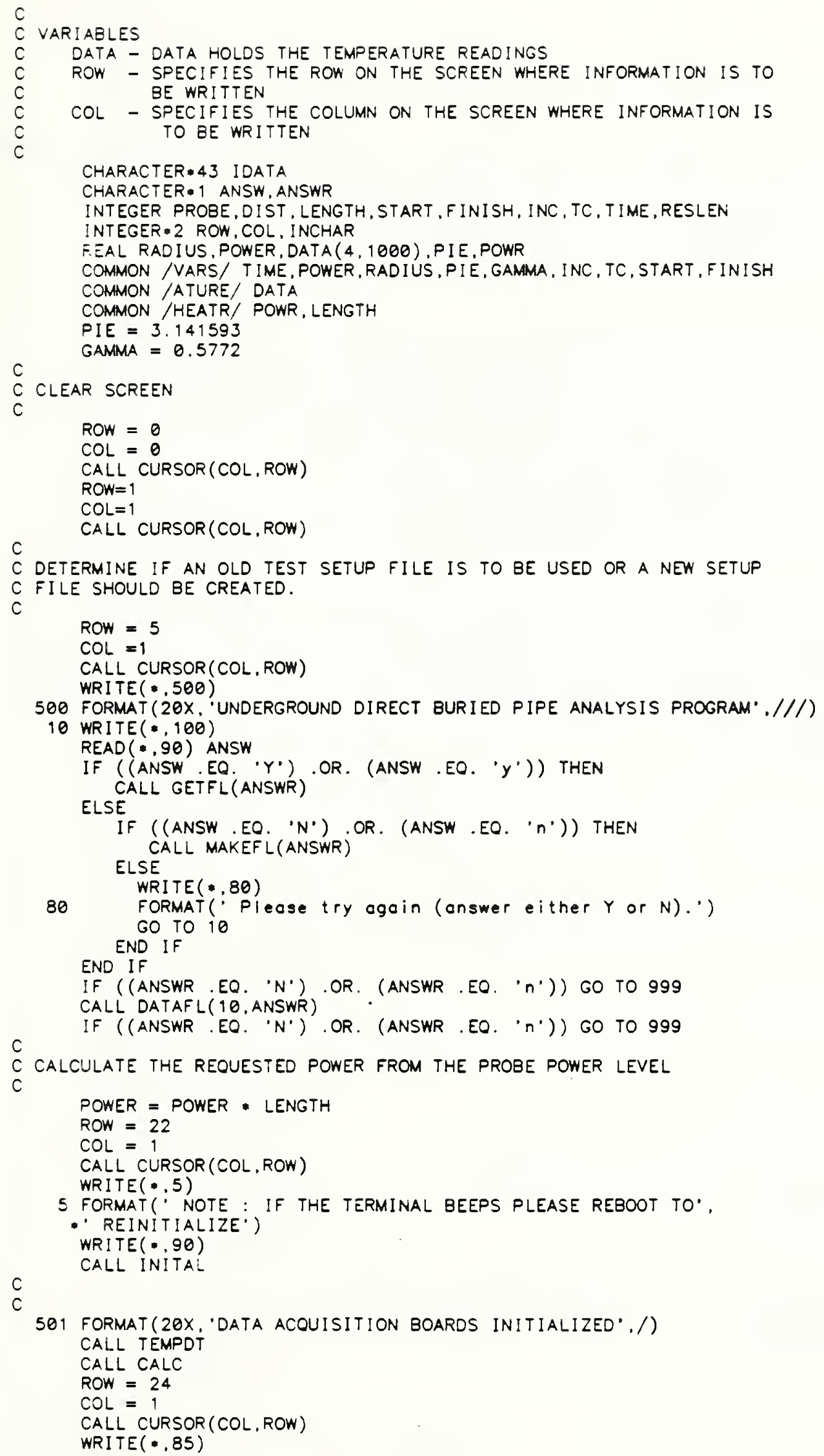




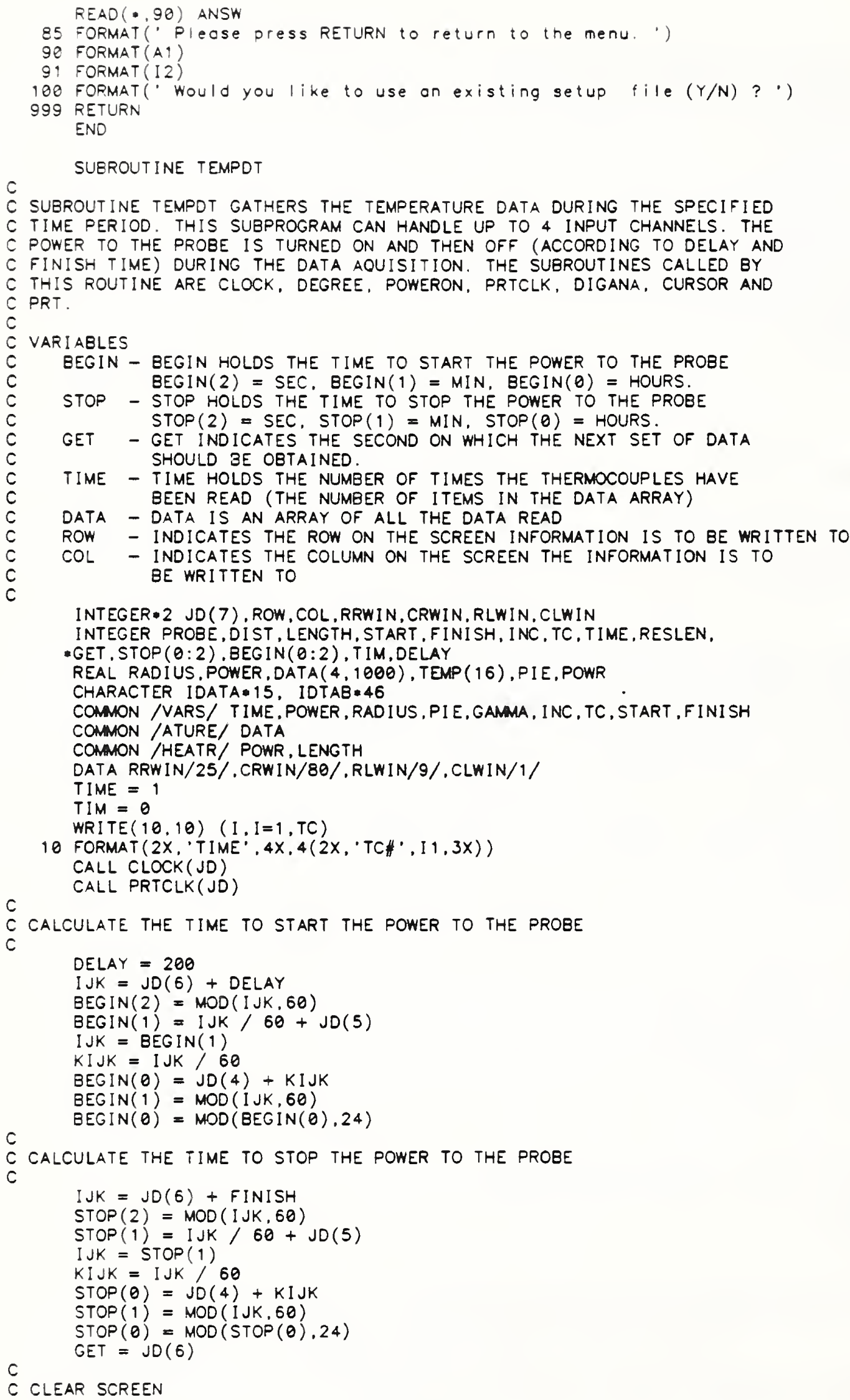

INTEGER 2 JD ( 7), ROW, COL, RRWIN, CRWIN, RLWIN, CLWIN

INTEGER PROBE, DIST, LENGTH, START, FINISH, INC, TC, TIME, RESLEN, 


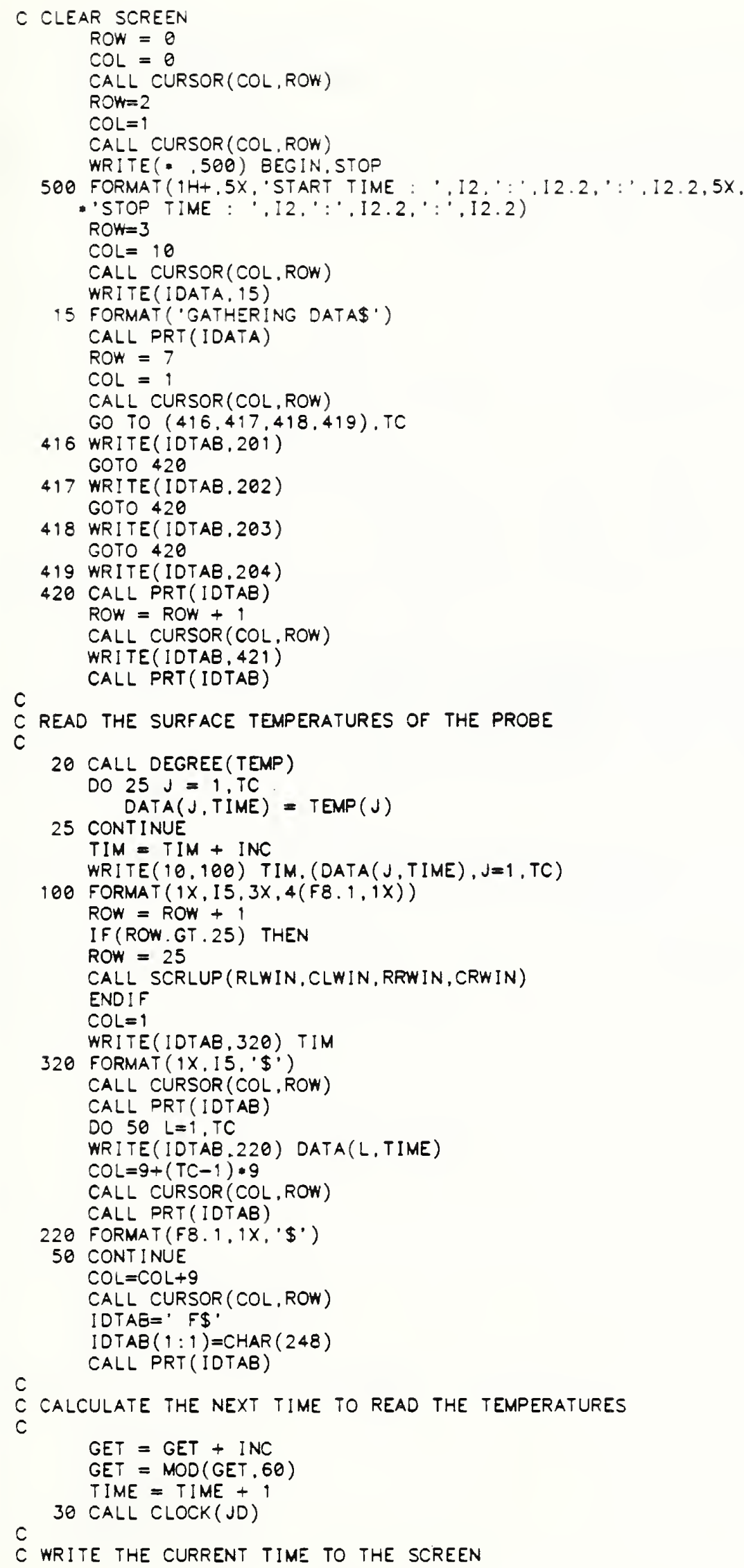


CHECK TO SEE IF IT IS TIME TO TERMINATE THE PROGRAM, READ A TEMPERATURE OR WAIT FOR TIME TO ADVANCE.

IF ( (JD(4). EO BEGIN(0)).AND. (JD(5) .EO. BEGIN(1)) . AND.

- (JO(6) EO. BEGIN(2))) CALL POWERON(POWER, POWR)

IF (JD(4).GT.STOP(O)) GO TO 40

IF (JD(4).EO.STOP(0).AND.JD(5).EO.STOP(1).AND.JD(6).GT.STOP(2))

- GO TO 40

IF (JD(4).EO.STOP(0).AND.JD(5).GT.STOP(1)) GO TO 40

IF (JD(6) . EO. GET) GO TO 20

GO TO 30

C TURN OFF THE POWER TO THE HEATER

40 JDATA $=0$

ICHAN $=0$

CALL DIGANA (JDATA, ICHAN, IGAIN, I ERROR)

ICHAN = 1

CALL DIGANA (JDATA, ICHAN, IGAIN, I ERROR)

TIME = TIME - 1

201 FORMAT(" TIME

202 FORMAT (' TIME

203 FORMAT. TIME

204 FORMAT(" TIME

421 FORMAT (

RETURN

END

C

SUBROUTINE CALC

C THIS SUBROUTINE CALCULATES THE THERMAL CONDUCTIVITY AND THERMAL

C DIFFUSIVITY OF SOIL AT EACH THERMOCOUPLE LOCATION. THE SUBROUTINES C CALLED ARE CURSOR AND PRT IN THE FILE 'FORGRPHX. ASM'.

C

REAL PIE, GAMMA, RADIUS, POWER, SLOPE (4), INTER (4), DATA (4, 1000).

- TICK, KS (4), ALPHA (4), POWR

CHARACTER 80 IDATA

CHARACTER 1 ANS

INTEGER 2 ROW, COL, $X, Y$

INTEGER LENGTH, START, FINISH, INC, TC, TIME, TIMHTR, DELAY, NSYMB (4)

COMAON /VARS/ TIME, POWER, RADIUS, PIE, GAMMA, INC, TC, START, FINISH

COMMON /ATURE/ DATA

COMAON /HEATR/ POWR. LENGTH

COMMON /PLTDAT/ YMAX, YMIN, XMAX, XMIN

C

DATA NSYMB/4,254,88,43/

C CLEAR SCREEN

DELAY $=200$

2 ROW $=0$

$\mathrm{COL}=0$

CALL CURSOR ( $C O L, R O W)$

WRITE (IDATA.570) START

570 FORMAT (10X, 'Stort $=$ '. I4, Seconds $\$$ ')

ROW $=3$

$\mathrm{COL}=1$

CALL PRT (IDATA)

H.RITE $(10,580)$ START

580 FORMAT ( $10 x$. 'Start $=$ '.14,' Seconds')

ROW $=5$

$\mathrm{COL}=5$

CALL CLISSOR (COL, ROW)

WRITE(IJATA, 100)

CALL PRT (IDATA)

ROW = ROW + 1

WR ITE (IDATA, 150)

CALL CURSOR (COL, ROW)

CALL PRT(IDATA)

ROW = ROW + 1

WRITE(IDATA, 160)

CALL CURSOR (COL, ROW)

CALL PRT (IDATA) 


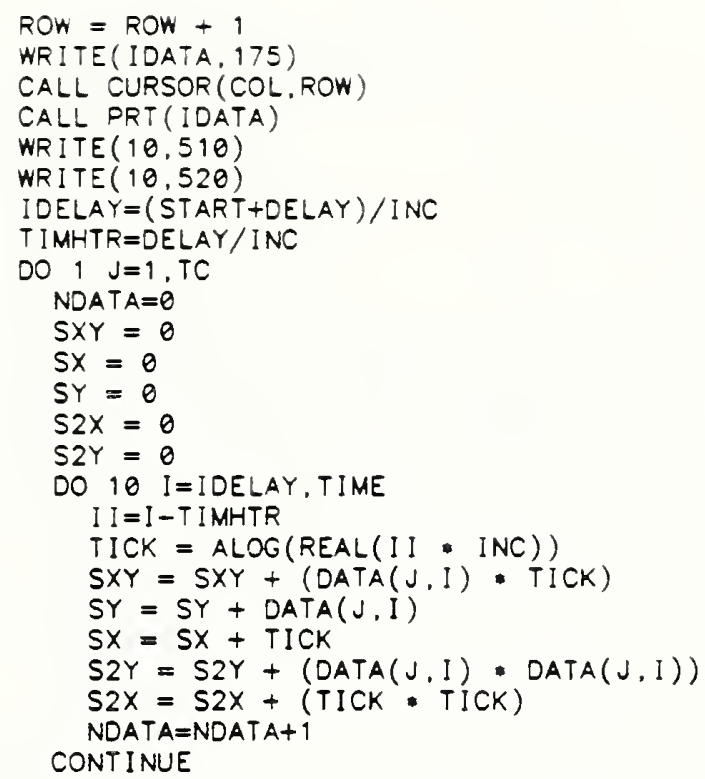




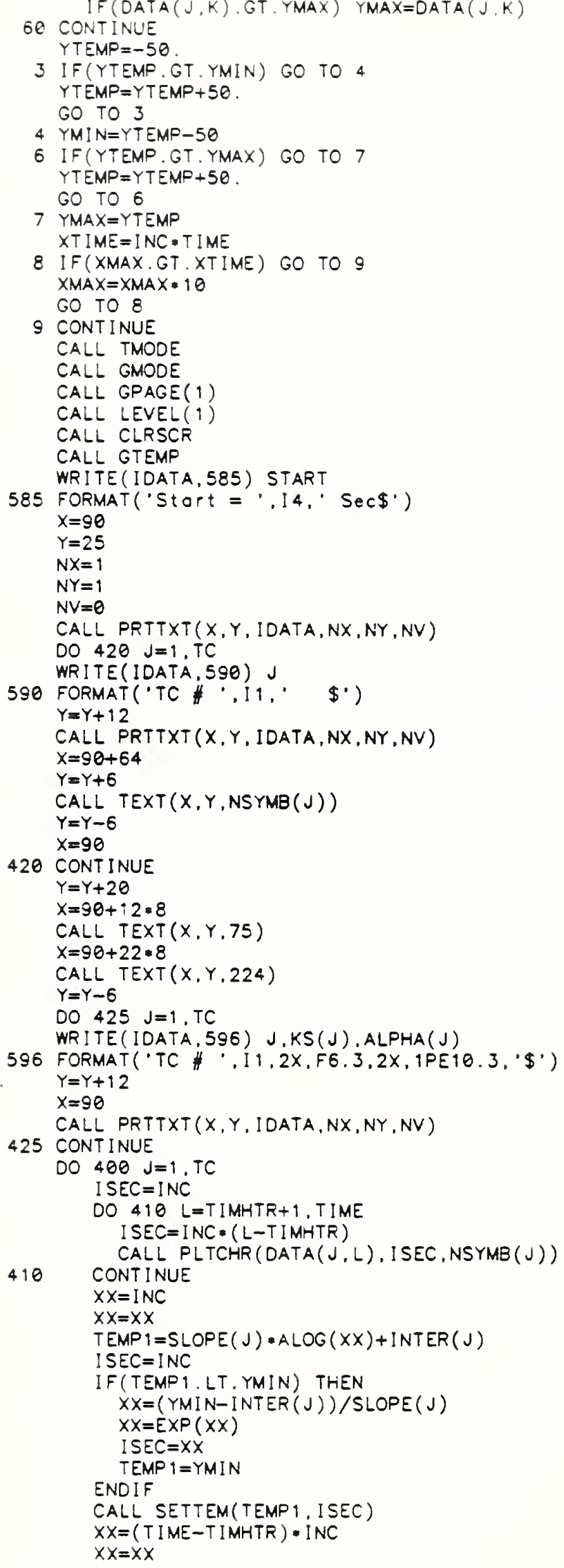




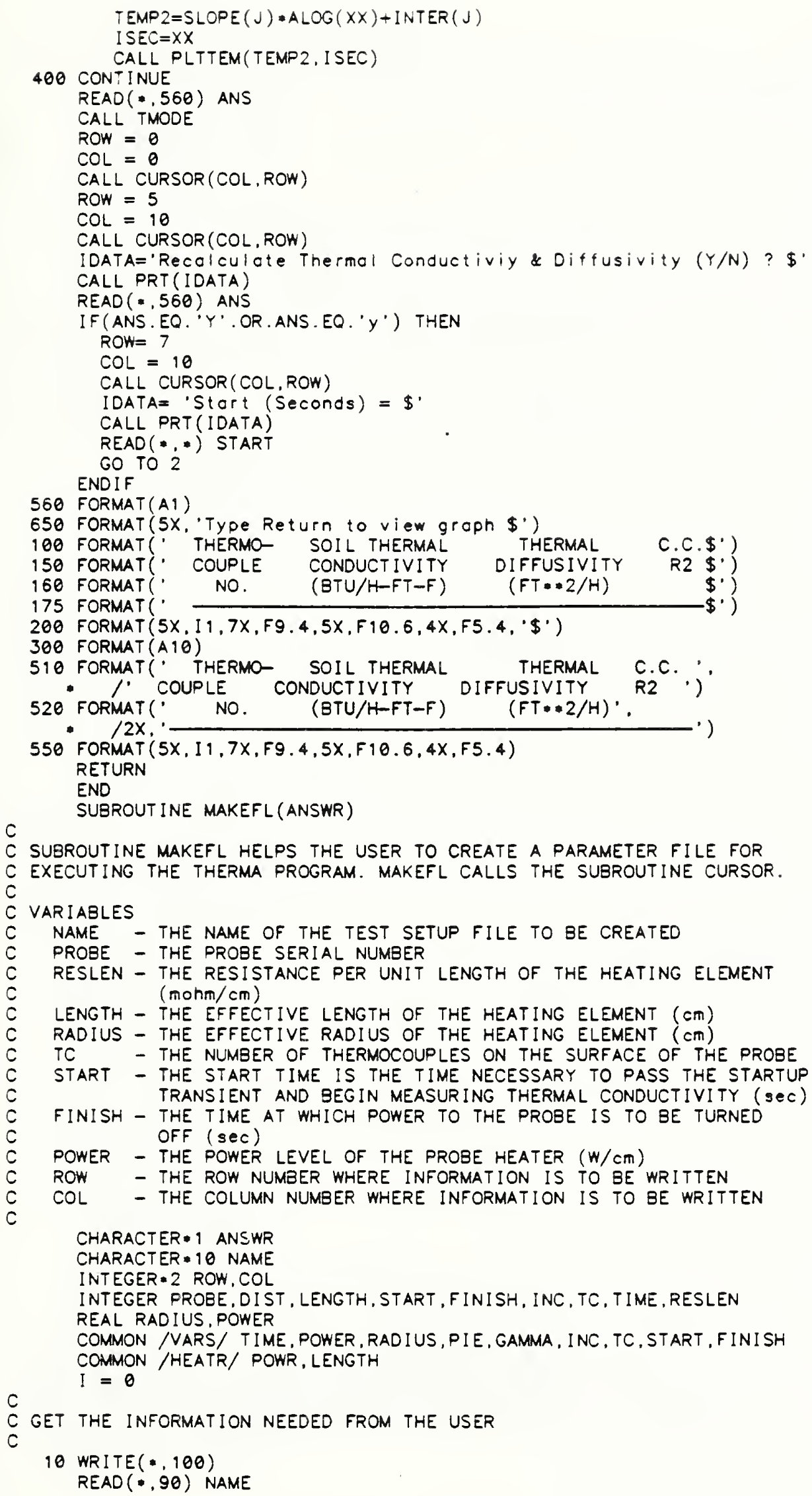




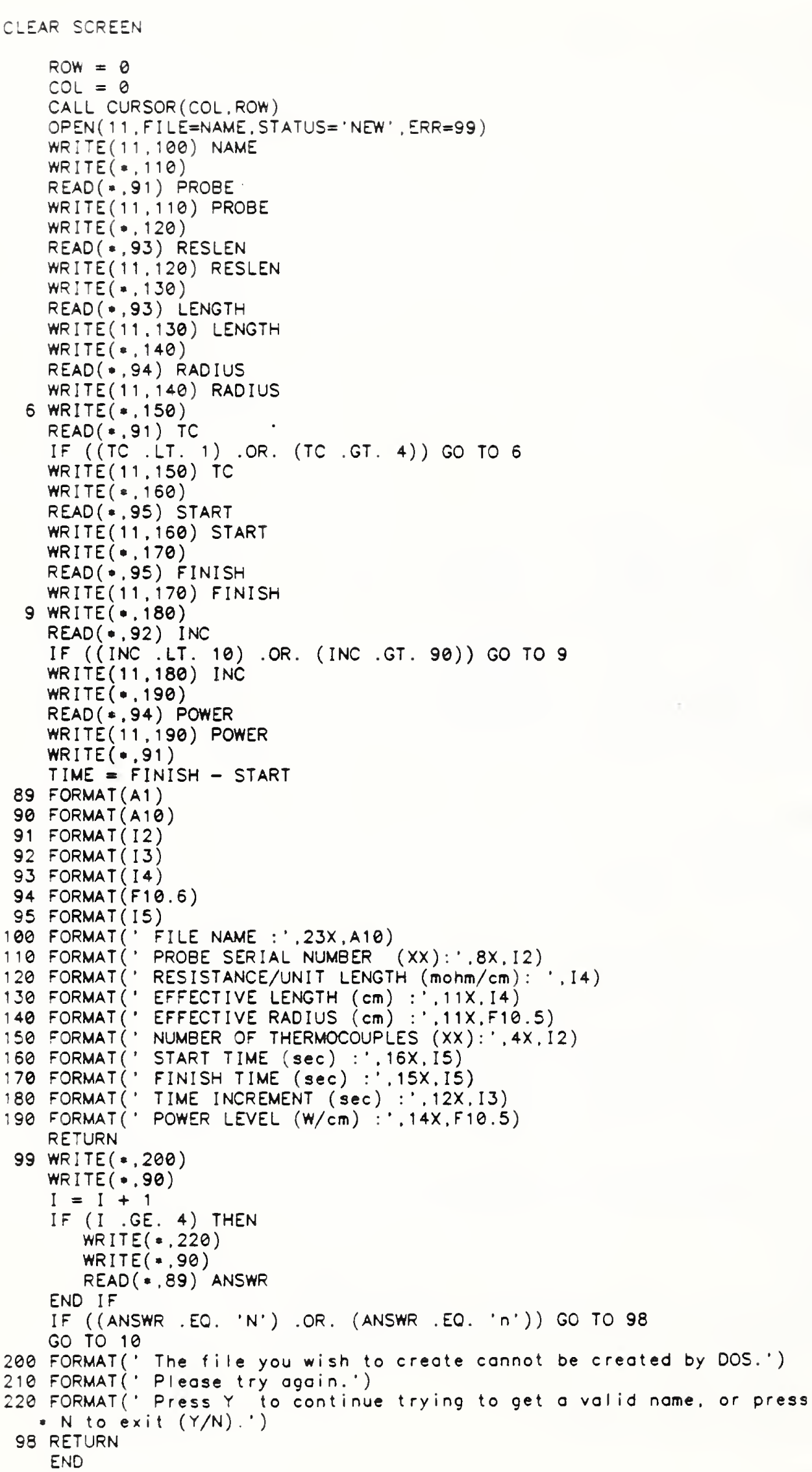




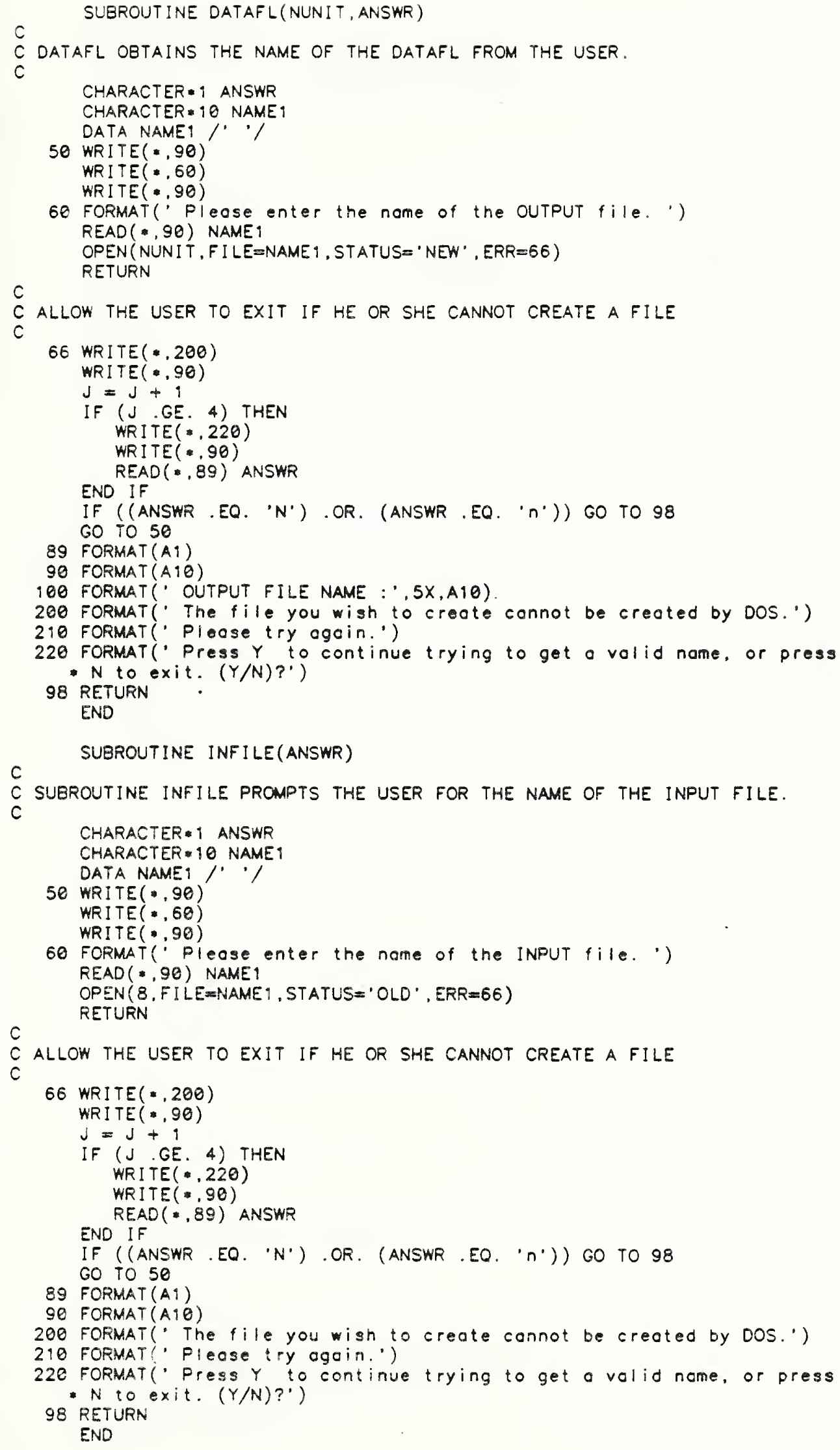




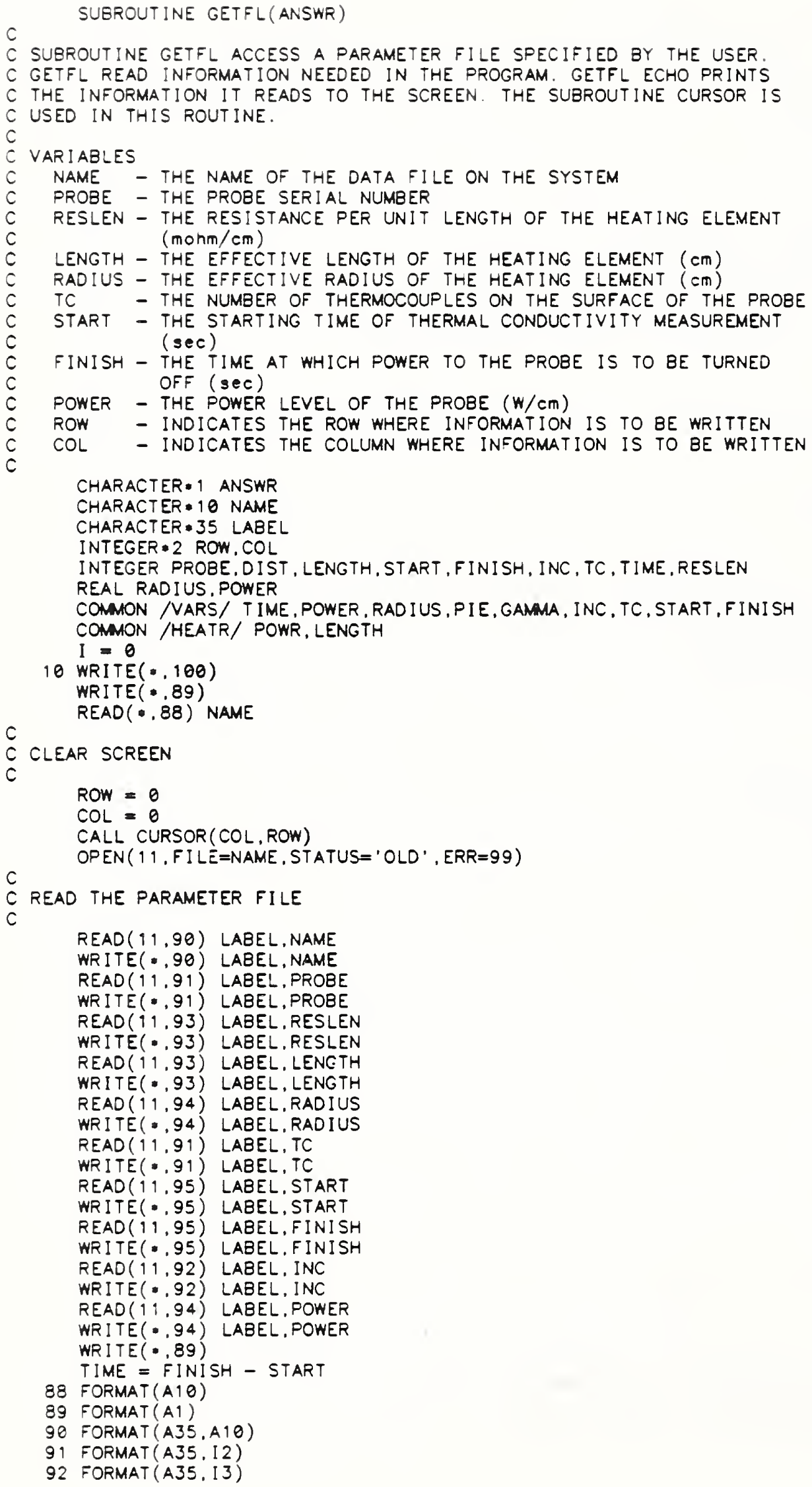




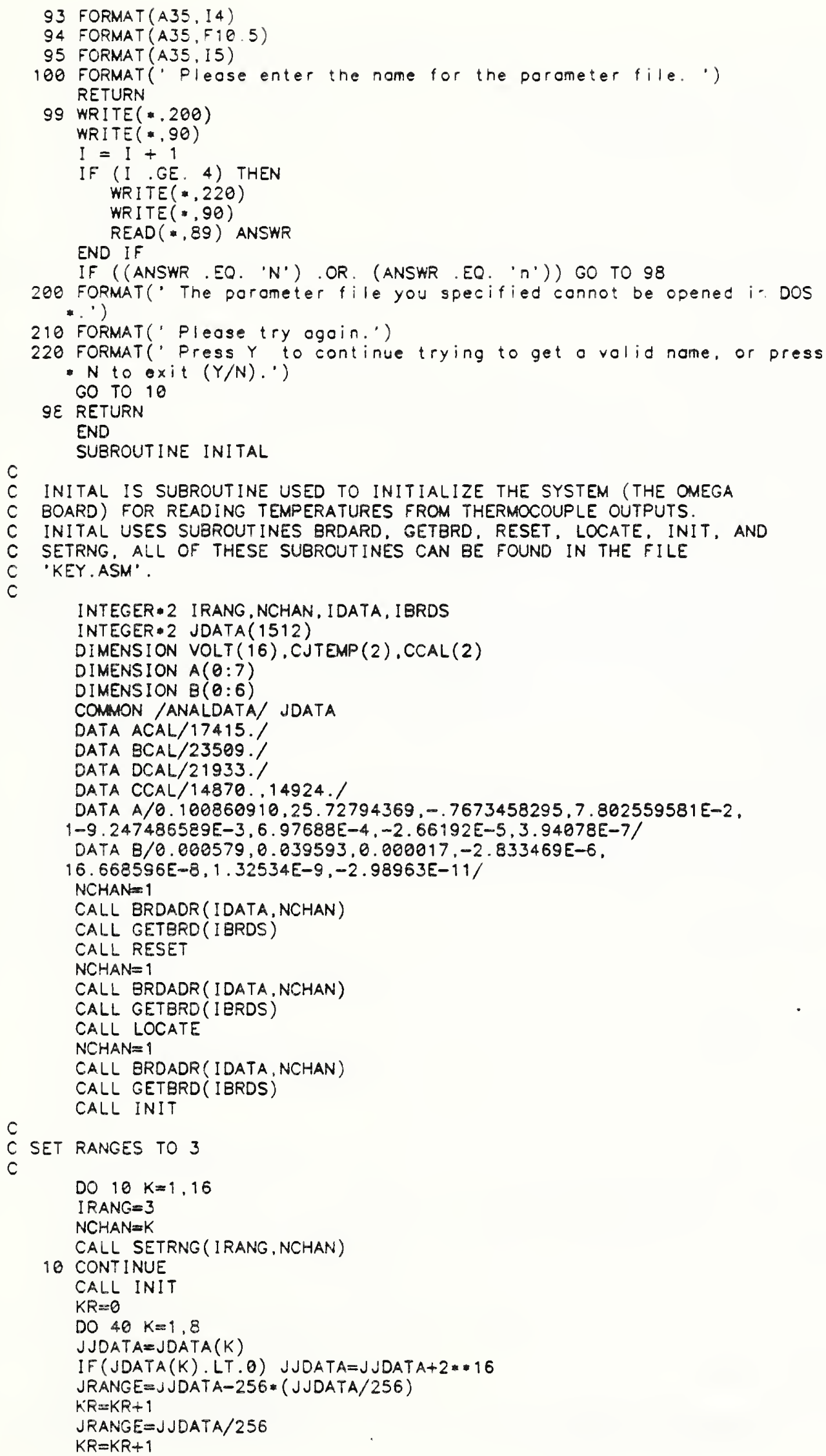




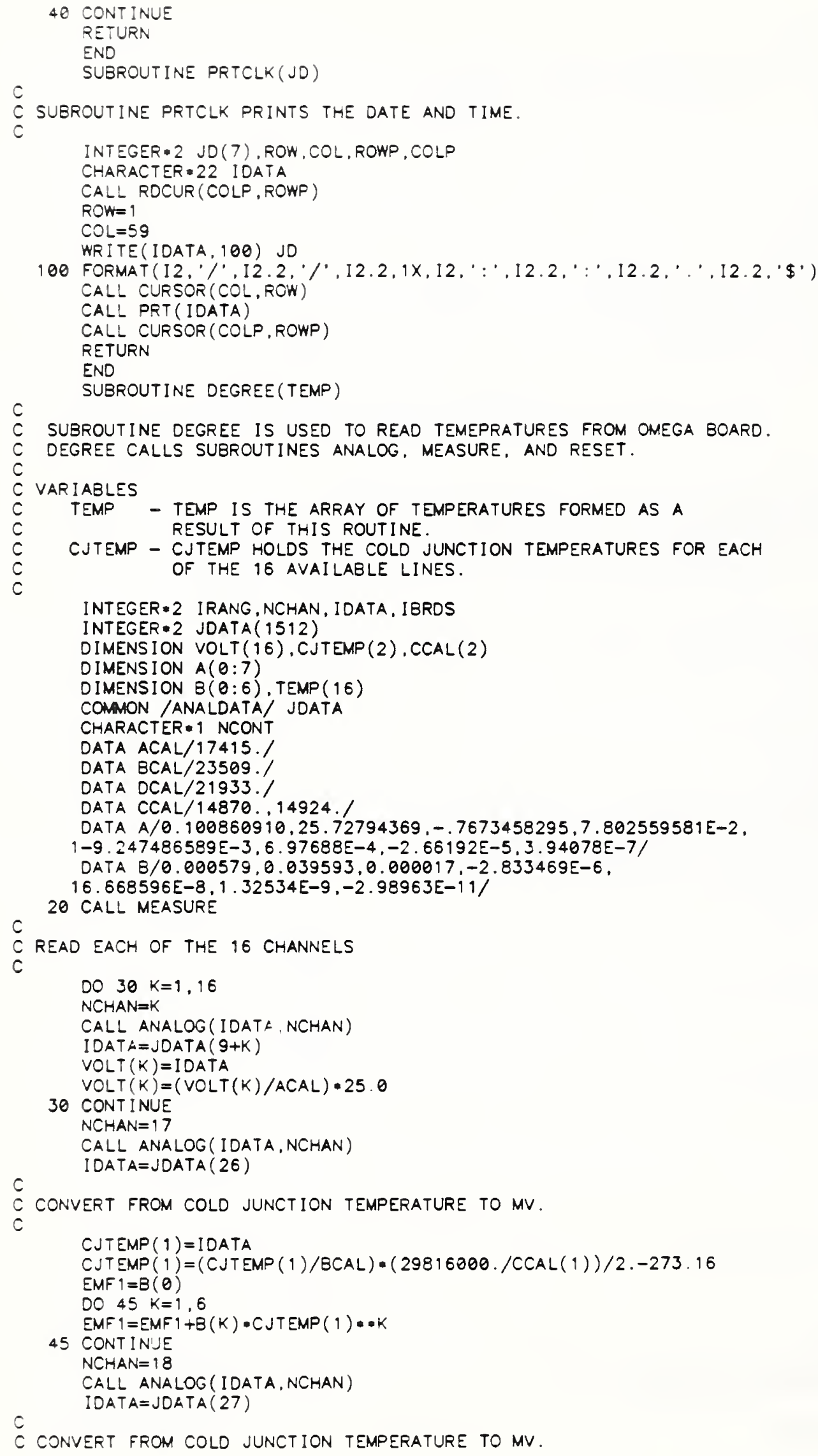


C

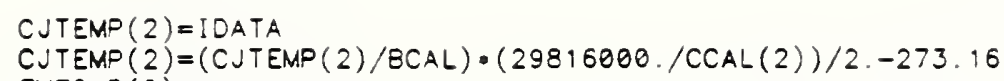




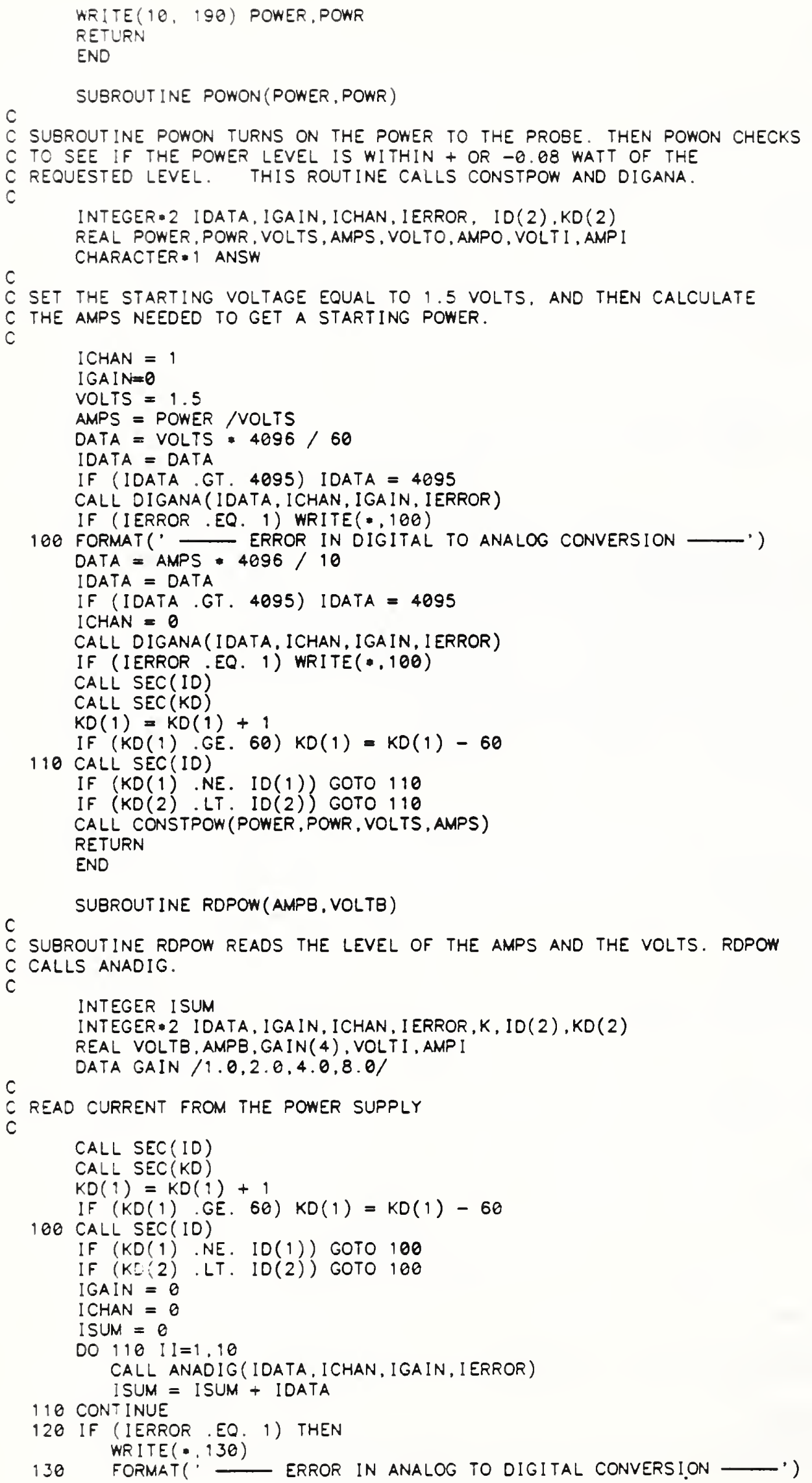




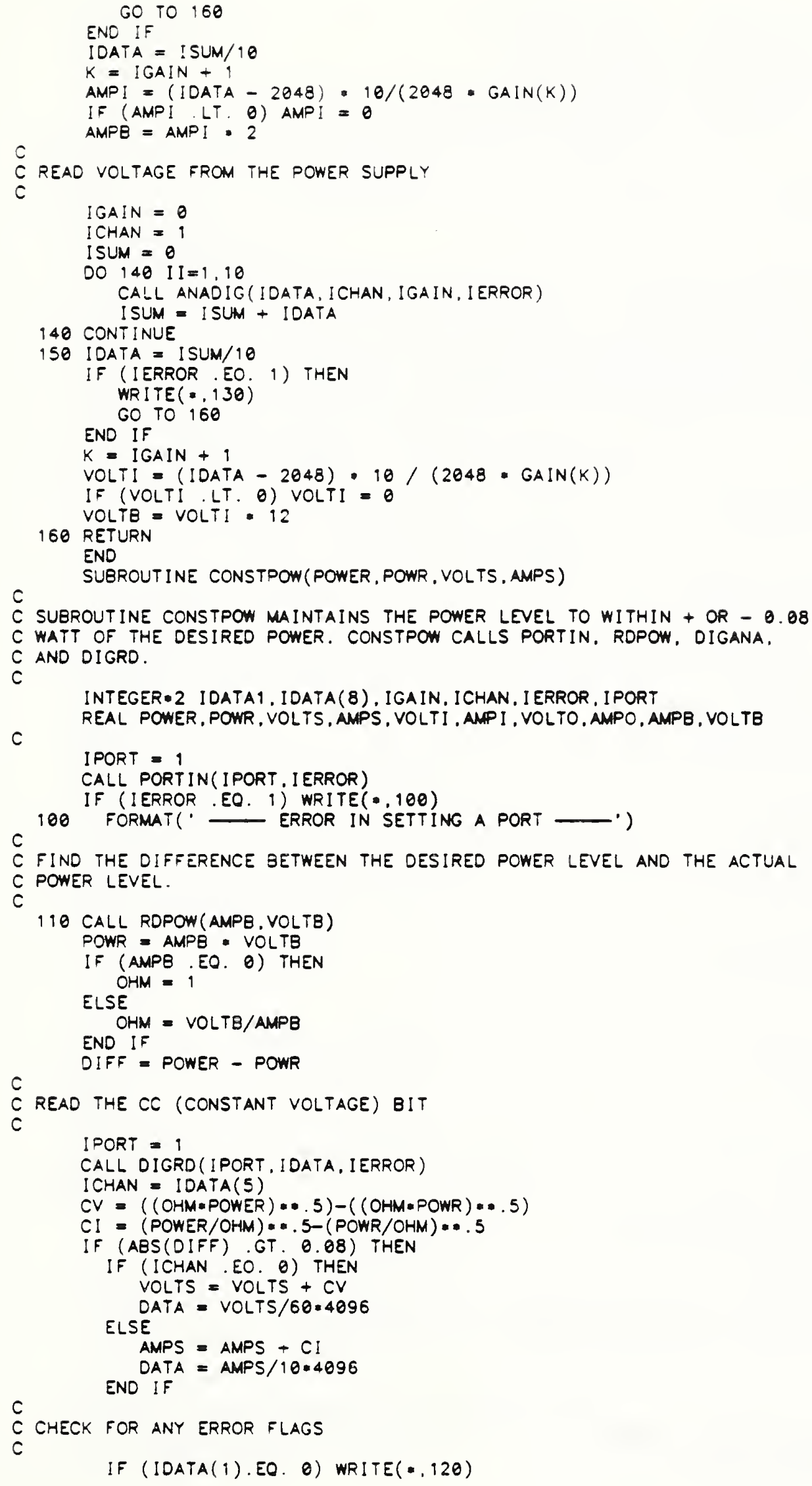




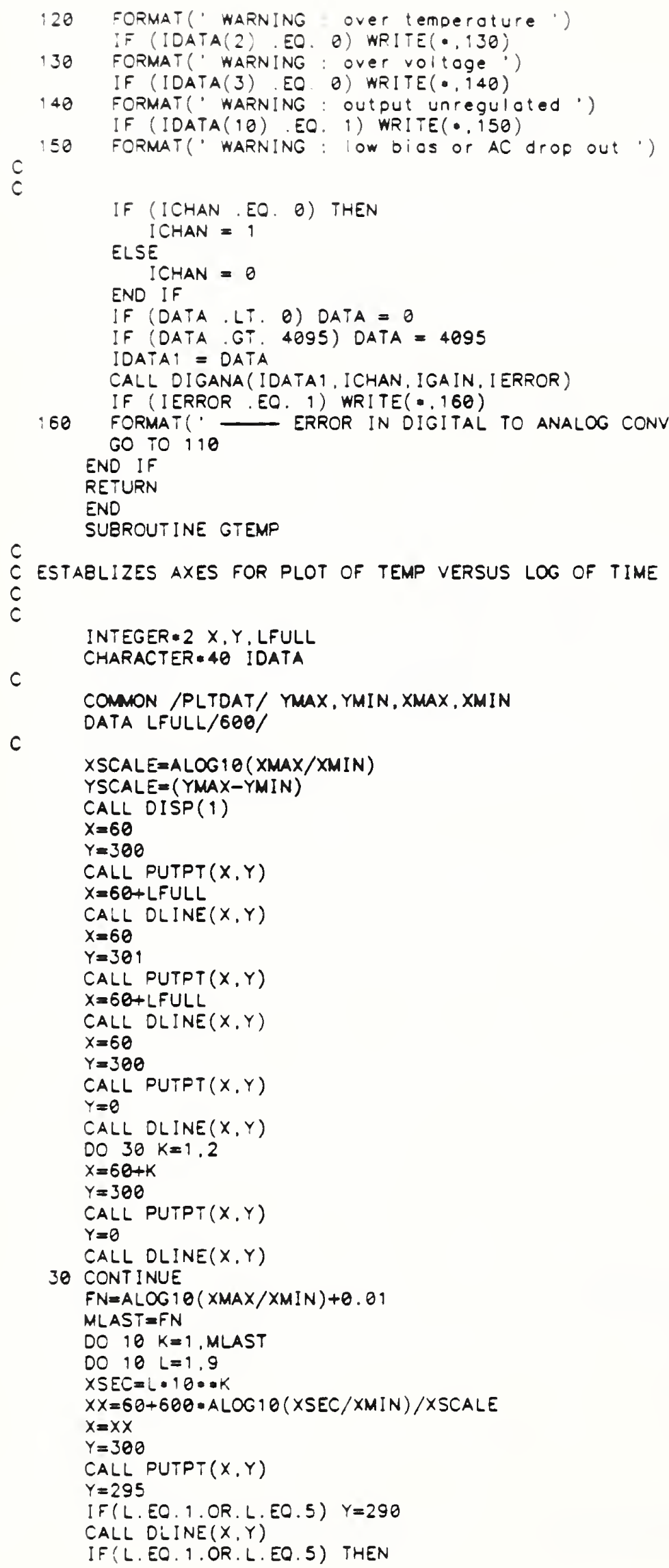




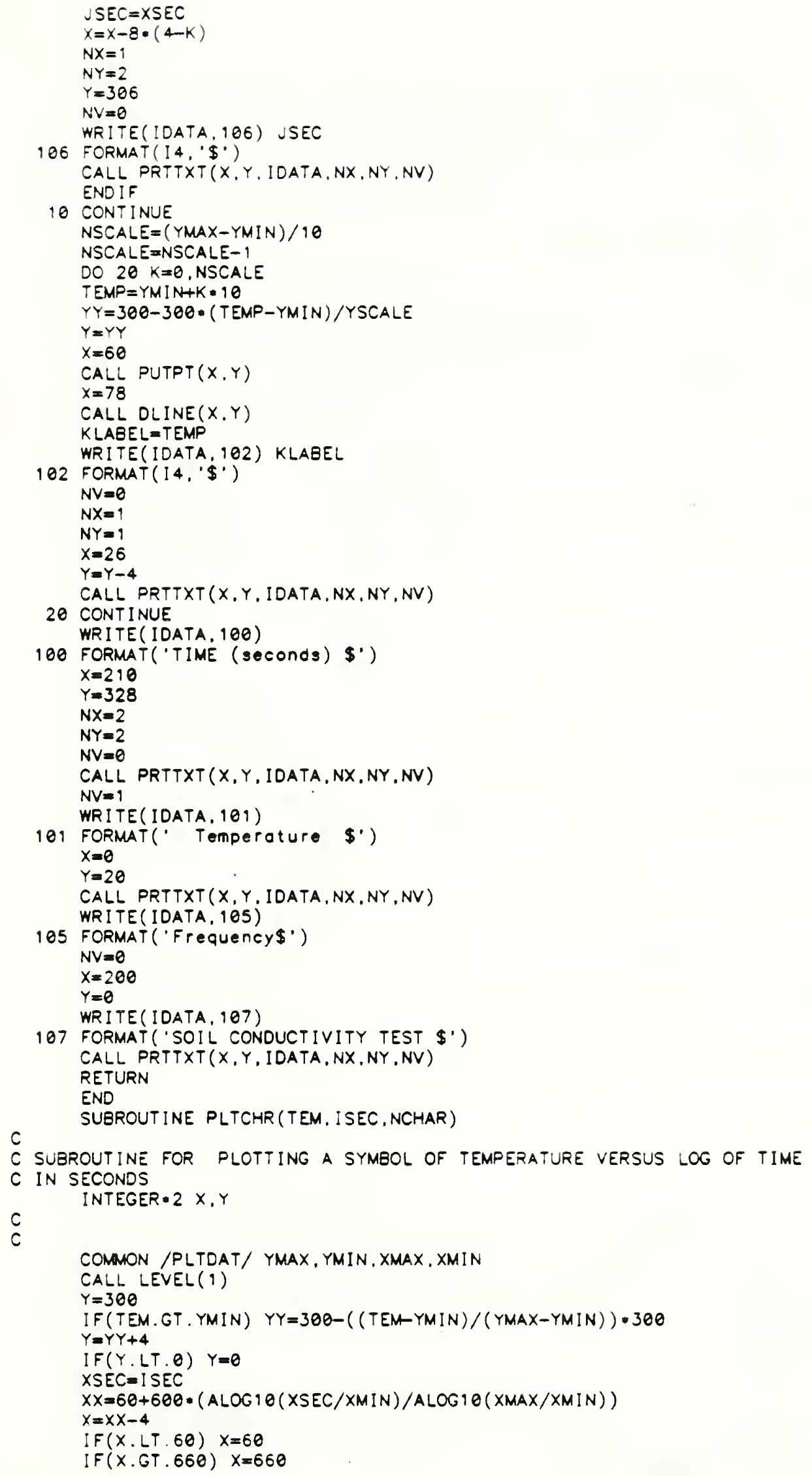




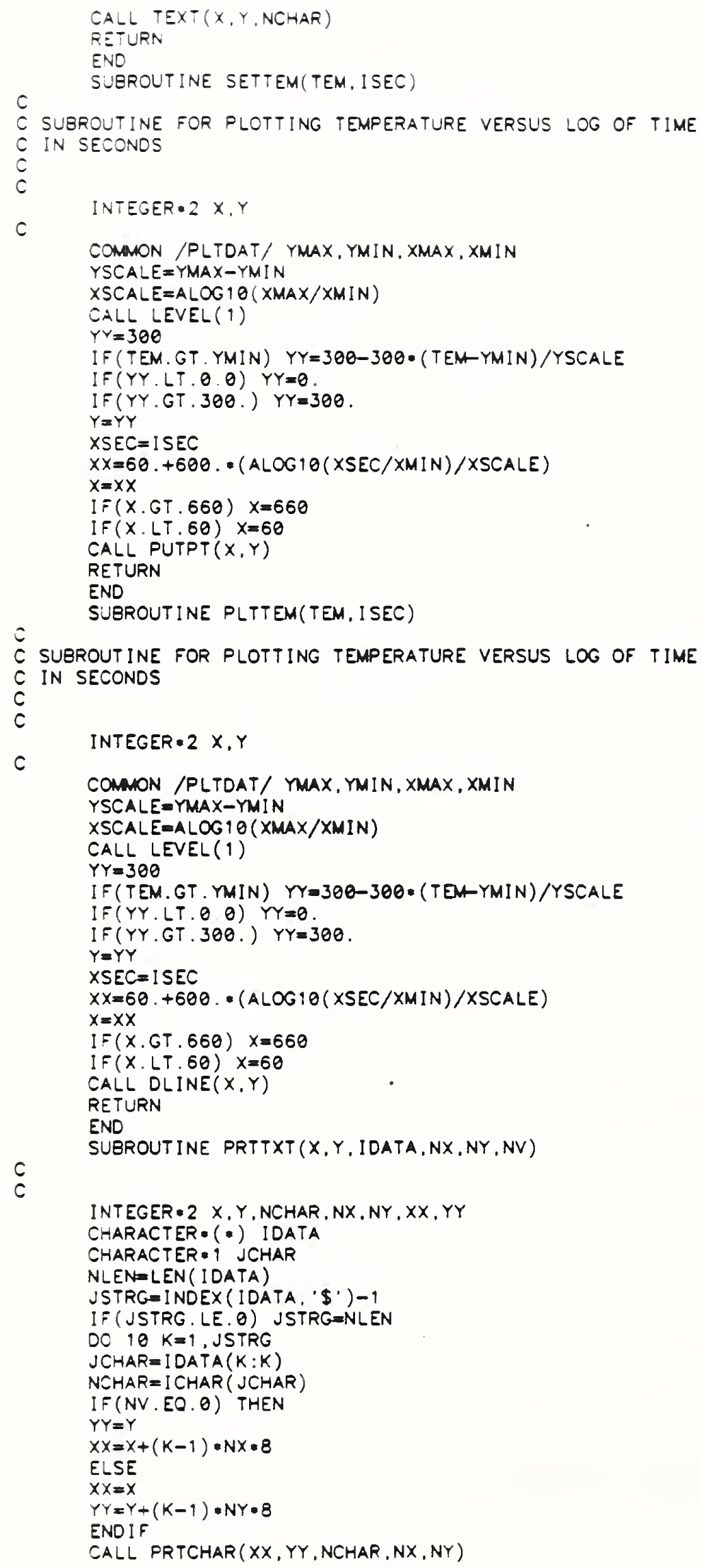


10 CALL LEVEL(1)

CONTINUE

RETURN

END

SUBROUTINE TEMPER

C THIS SUEPROGRAM READS THE TEMPERATURES OF SOIL AT OIFFERENT

C LOCATIONS ANO VARIOUS OEPTHS. UP TO SIXTEEN TEMPERATURE INPUT

C CHANNELS CAN EE HANDLED BY THIS SUBPROGRAM THE OUTPUT DATA AND

C SUMMARY RESULTS OF TEMPERATURE MEASUREMENTS ARE STORED IN TWO FILES

C NAMED BY THE USER. THE SUBROUTINES CALLED GY THIS SUGPROGRAM ARE

C MAKEINX, GETINX, OATAFL, RESET, INITAL, DEGREE, SCRLUP, KEYBO,

C CLOIK AND PRTCLK

C

C VARIABIES

TEMP - CONTAINS DATA OF THE MEASUREO TEMPERATURES

NTC - TOTAL NUMEER OF THERMOCOUPIES USED.

ILABEL - THE IOENTIFICATION TITLE OF THE MEASURING LOCATION

$X H(I, J)$ - THE HOR!ZONTAL DISTANCE MEASURED FROM A REFERENCE POINT TO THE I-TH THERMOCOUPLE OF THE J-TH PROBE, (INCH)

YV(I.J) - THE VERTICAL DEPTH FROM THE GROUND SURFACE FOR THE I-TH THERMOCOUPLE OF THE J-TH PROBE, (INCH)

COL - THE COLUMN NUMBER WHERE INFORMATION IS TO BE WRITTEN TO THE SCREEN.

ROW - THE ROW NUMBER WHERE INFORMATION IS TO BE WRITTEN TO THE SCREEN

NPROB - THE THERMOCOUPLE PROBE NUMBER.

TDATA - AN ARRAY OF THE TEMPERATURE DATA.

TUERTH - AN ARRAY OF THE UNDISTURBEO EARTH TEMPERATURE.

CHARACTER 40 ILABEL

CHARACTER 80 IDATA

CHARACTER 1 ANSW, ANSWR

CHARACTER 12 DTAFL

REAL KSAV

INTEGER 2 ROW, COL, JD(7), RULWI, CULWI, RLRWI , CLRWI

DIMENSION XH(16,15), YV(16,15), TDATA $(16,15), \operatorname{TEMP}(16), \operatorname{LDTA}(16,15)$,

- TUERTH $(16,15)$

COMMON / TCLOC/ NTC, NPROB, XH, N

COMMON / NDKS/ NDPT.KSAV

COMMON / LOGA/ LDTA

LOGICAL LDTA

DATA RULWI/7/, CULWI/1/,RLRWI/23/,CLRWI/80/

NPMAX $=1$

$X H M A X=1.0$

DO $8 \quad I=1.16$

DO $5 \mathrm{~J}=1,15$

$\operatorname{TDATA}(I, J)=0$.

$X H(I, J)=0$.

$Y V(I, J)=0$.

TUERTH $(I, j)=0$

LOTA $(I . J)=$. FALSE.

C

5 CONTINUE

8 CONTINUE

C CLEAR SCREEN

$\mathrm{COL}=0$

ROW $=0$

CALL CURSOR(COL.ROW)

ROW $=5$

COL $=1$

CALL CURSOR (COL.ROW)

WRITE $(* 10)$

10 FORMAT( $15 X$. 'SOIL TEMPERATURE DATA ACOUISITION PROGRAM•)

$c$

C DETERMINE IF AN EXISTING INDEX FILE IS TO BE USED OR A NEW INDEX

C FILE SHOULO BE CREATED

20 ROW $=8$

$C O L=1$

CALL CURSOR (COL.ROW)

WR:TE $: .180)$

REAO $(\cdot, 11 \theta)$ ANSW

IF ((ANSW .EQ. 'Y') .OR. (ANSW.EQ. ' $\left.y^{\prime}\right)$ ) THEN 


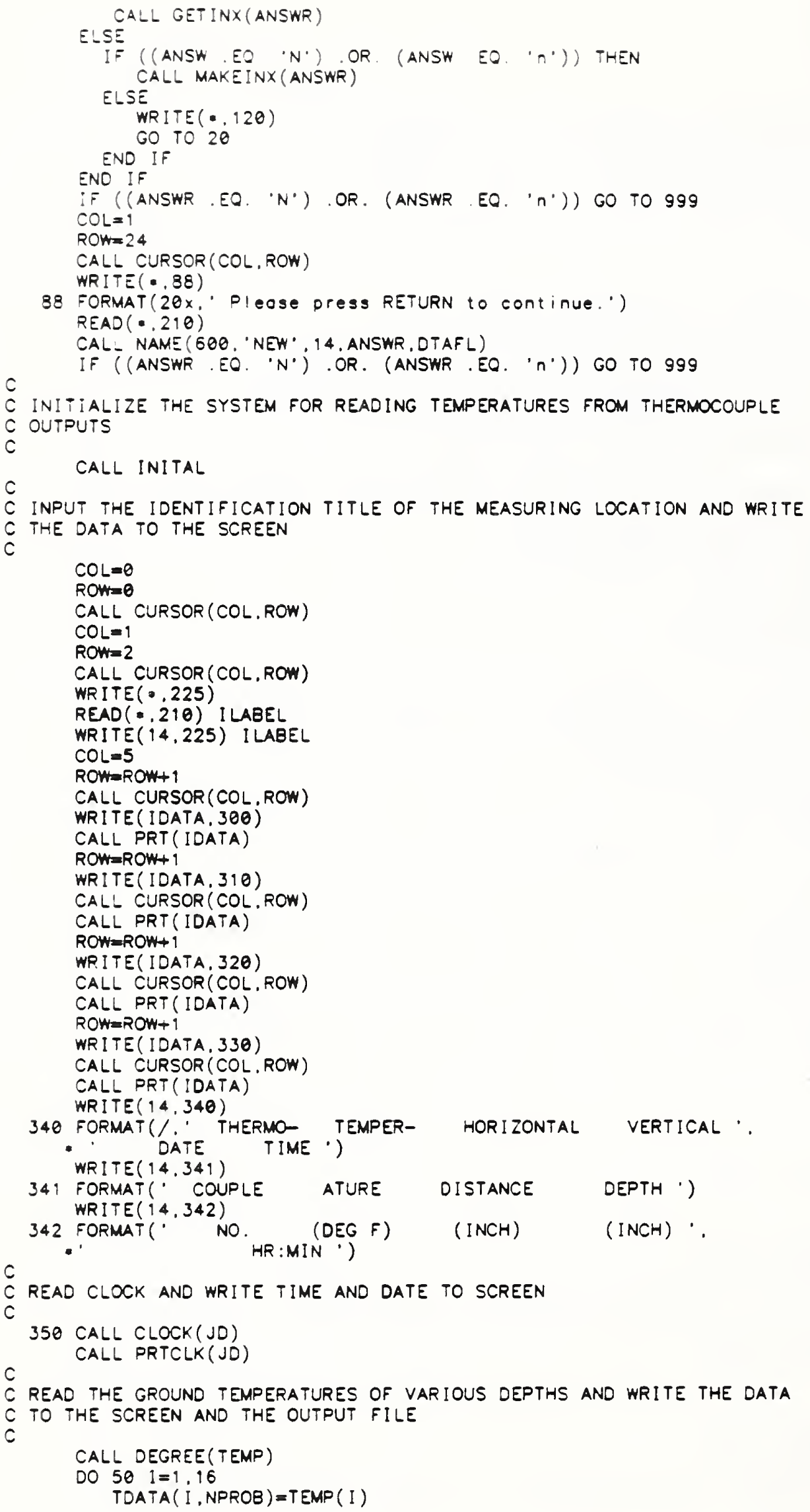




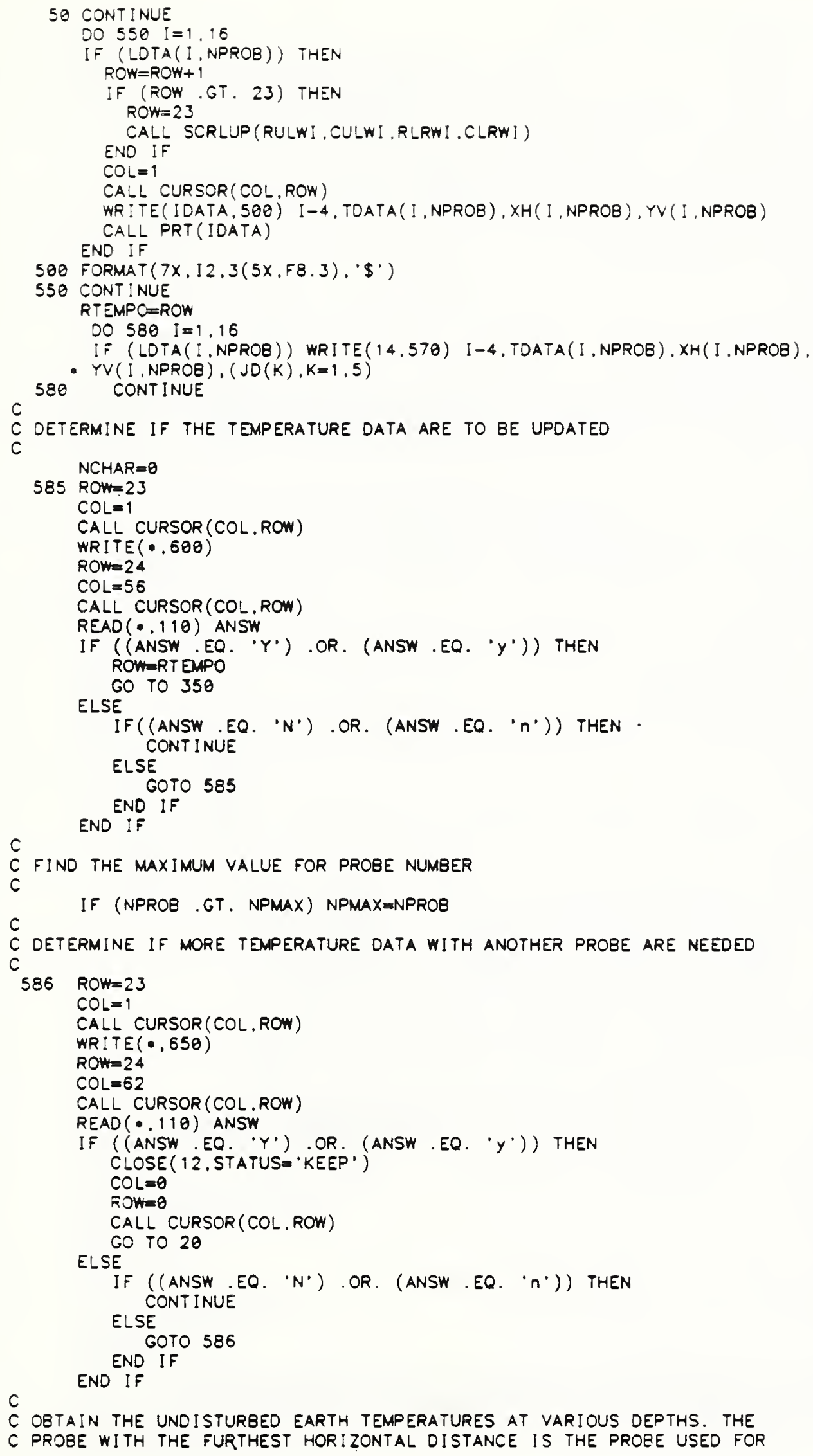




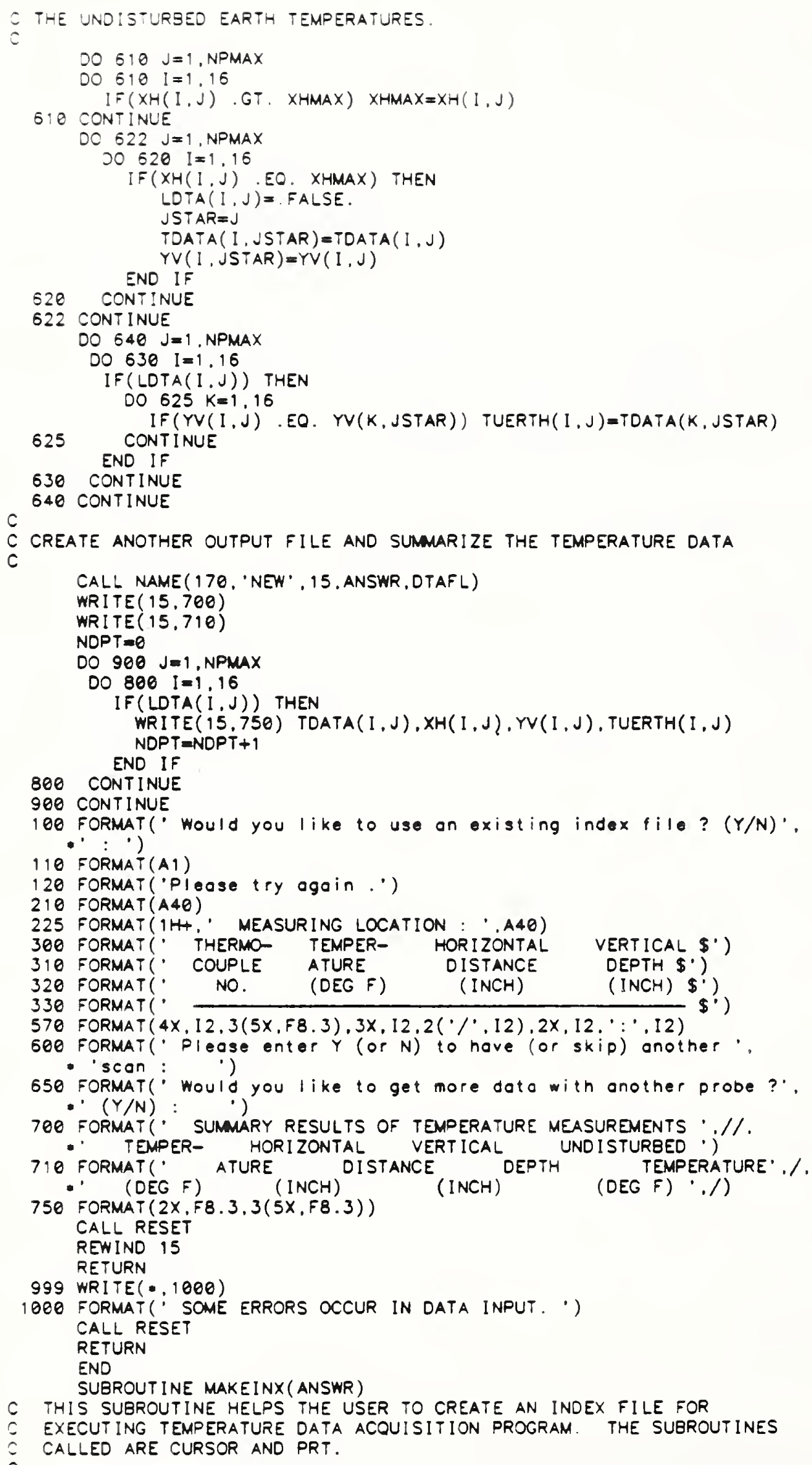




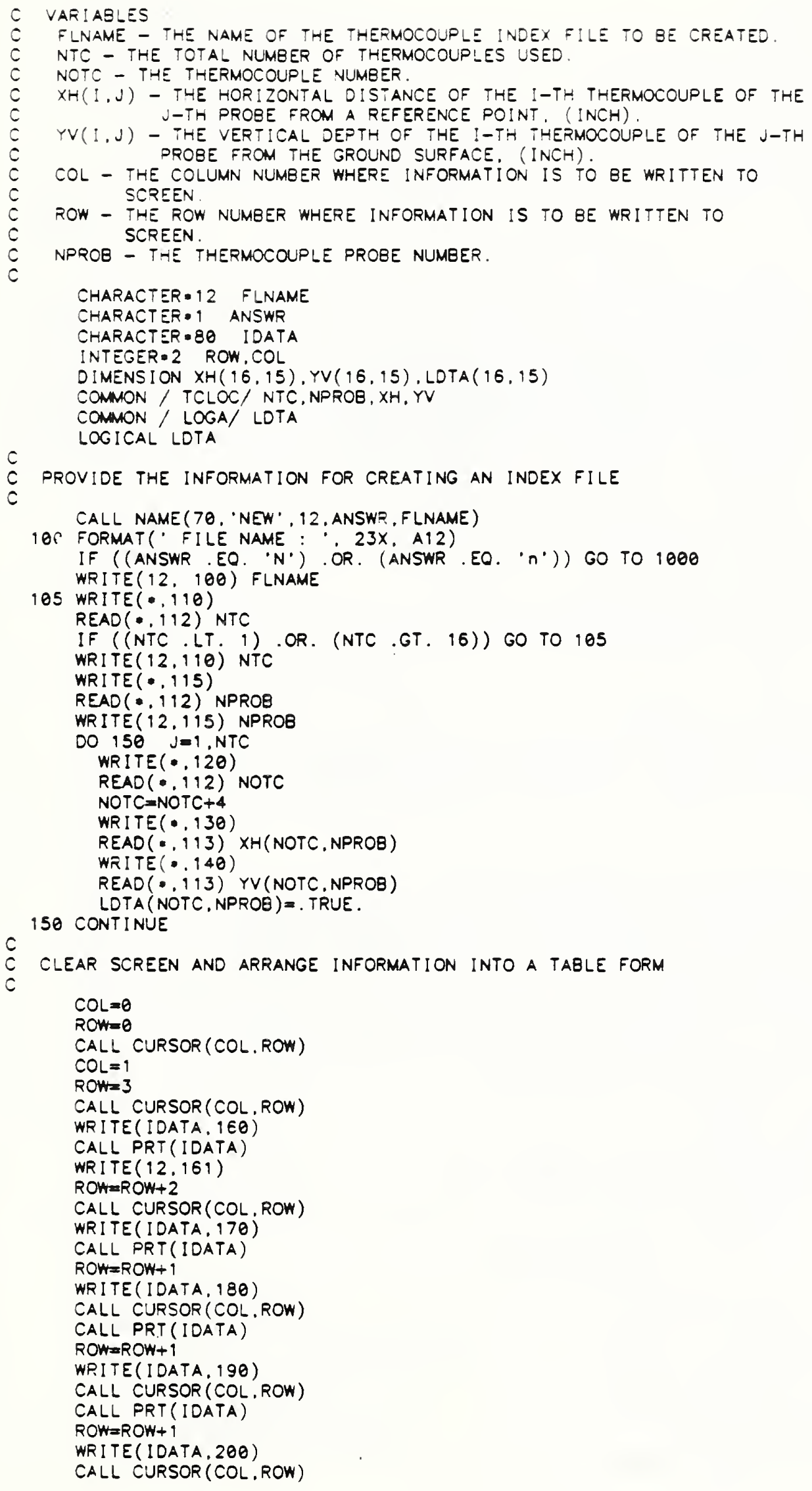




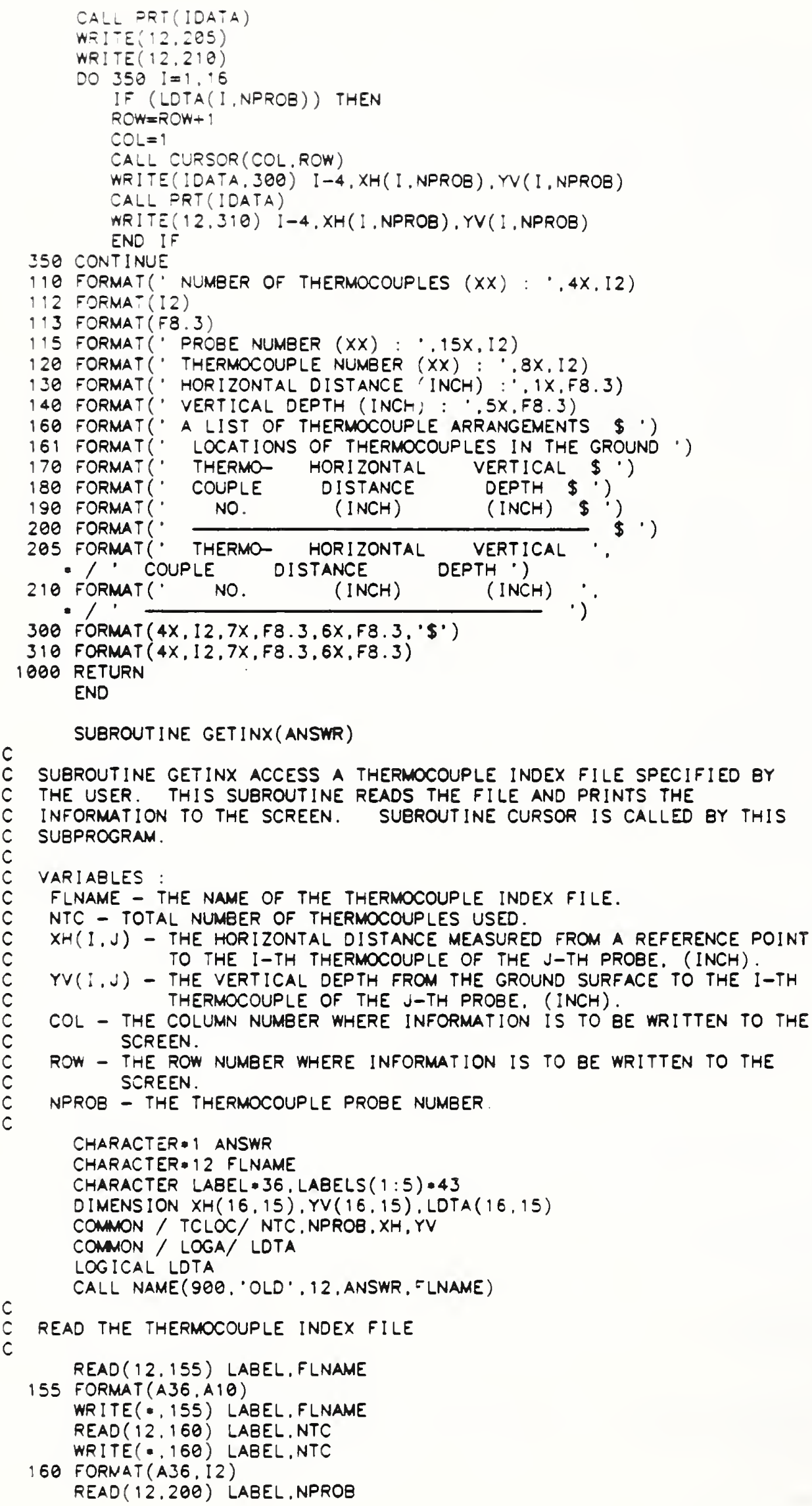




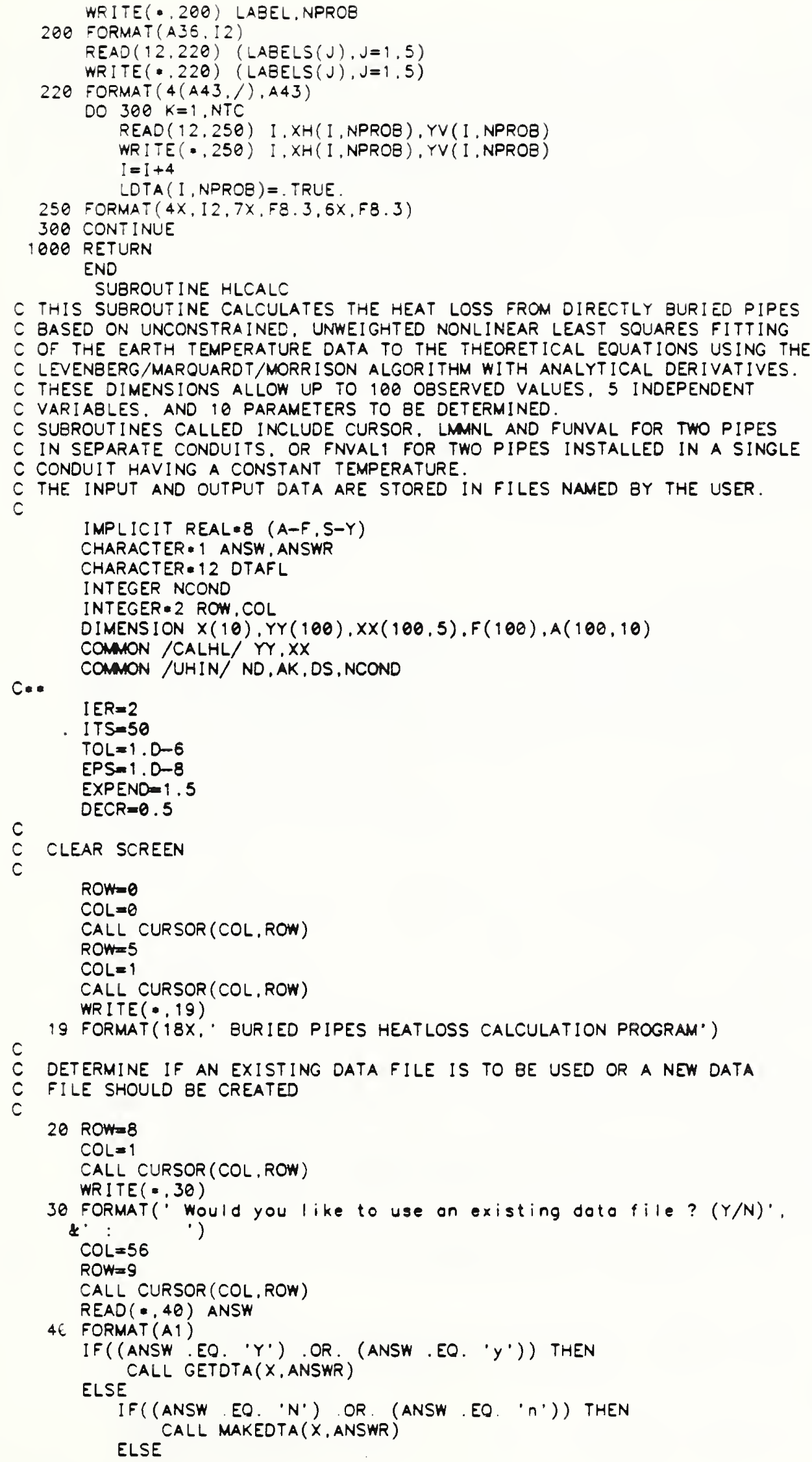




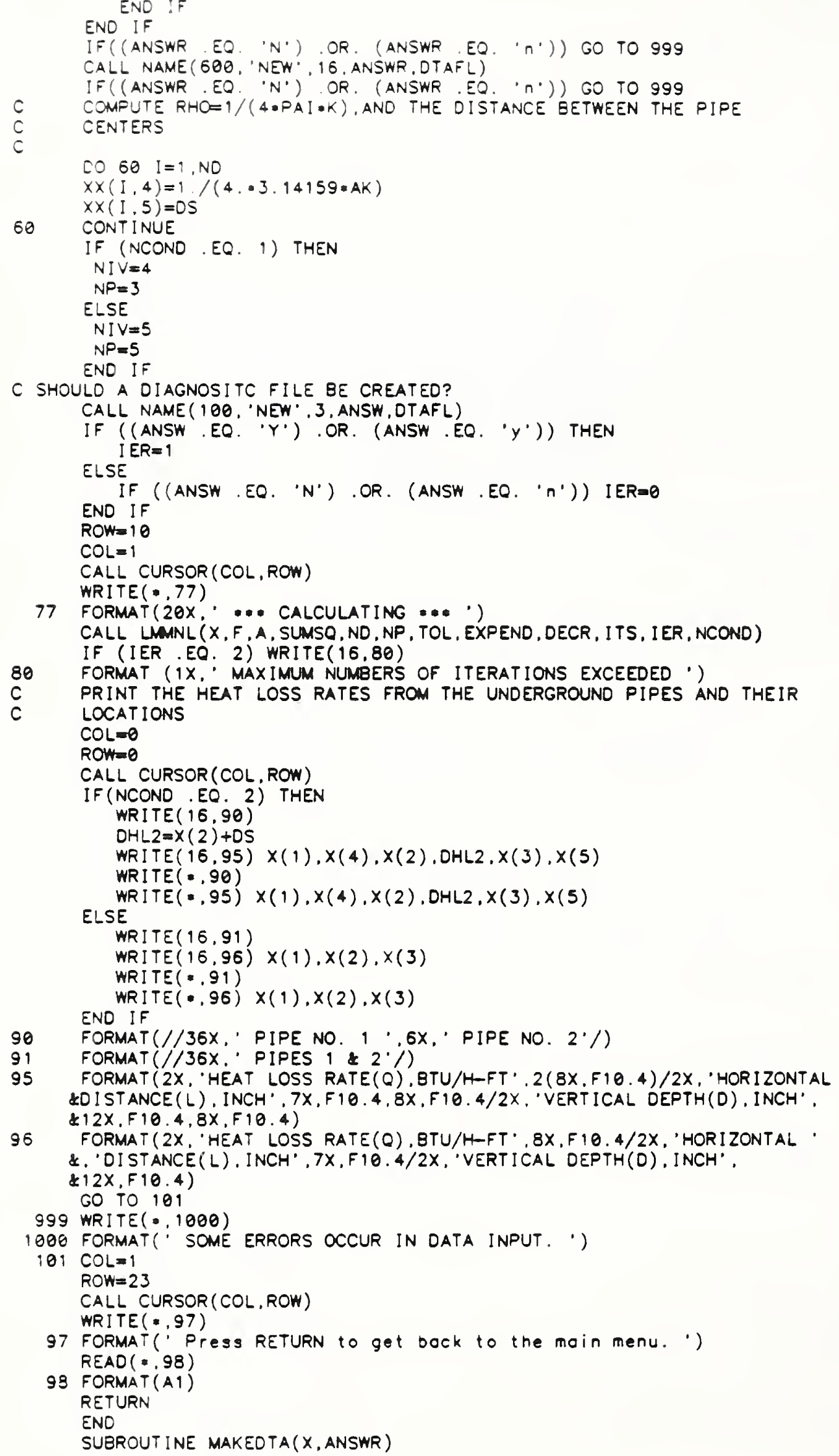




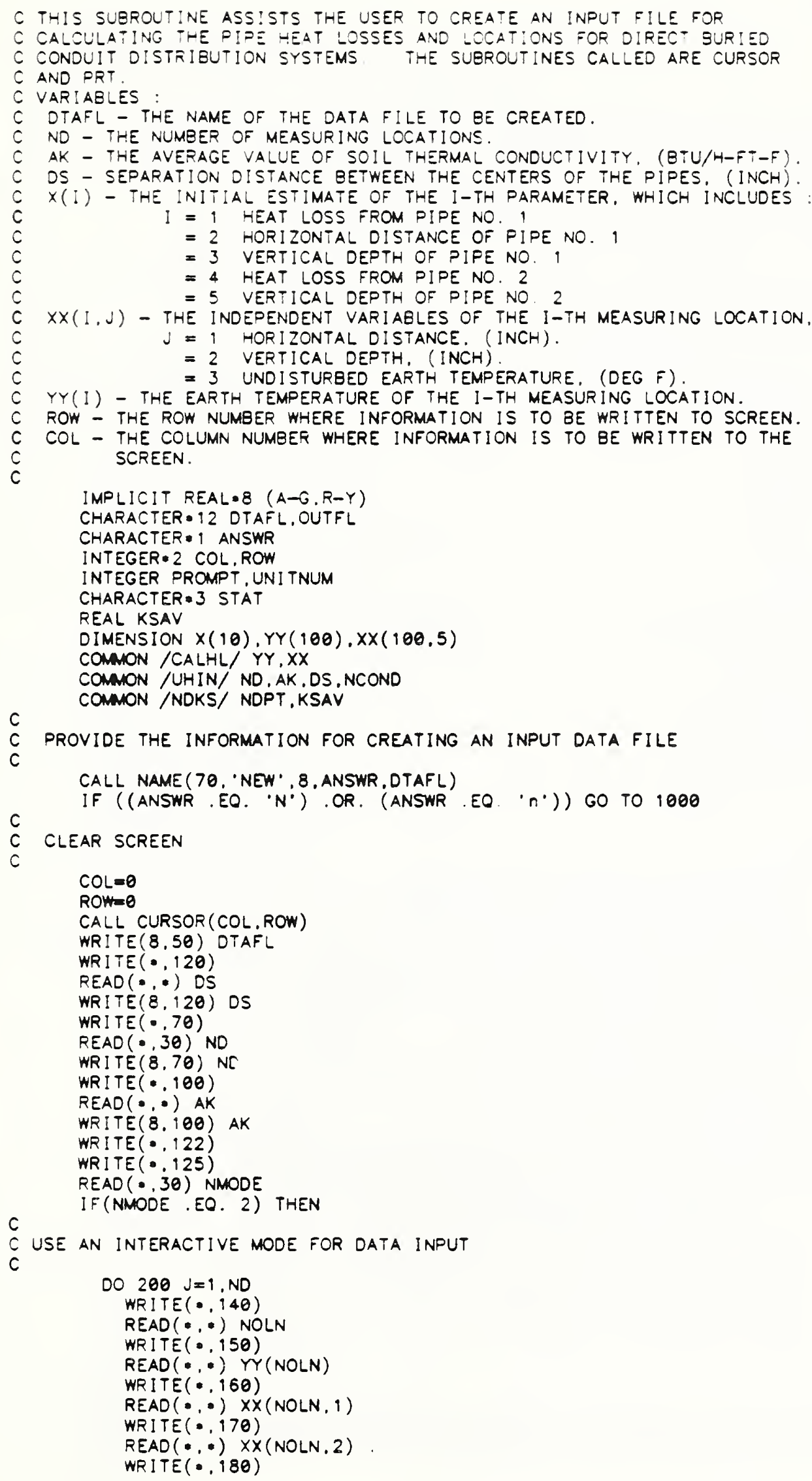




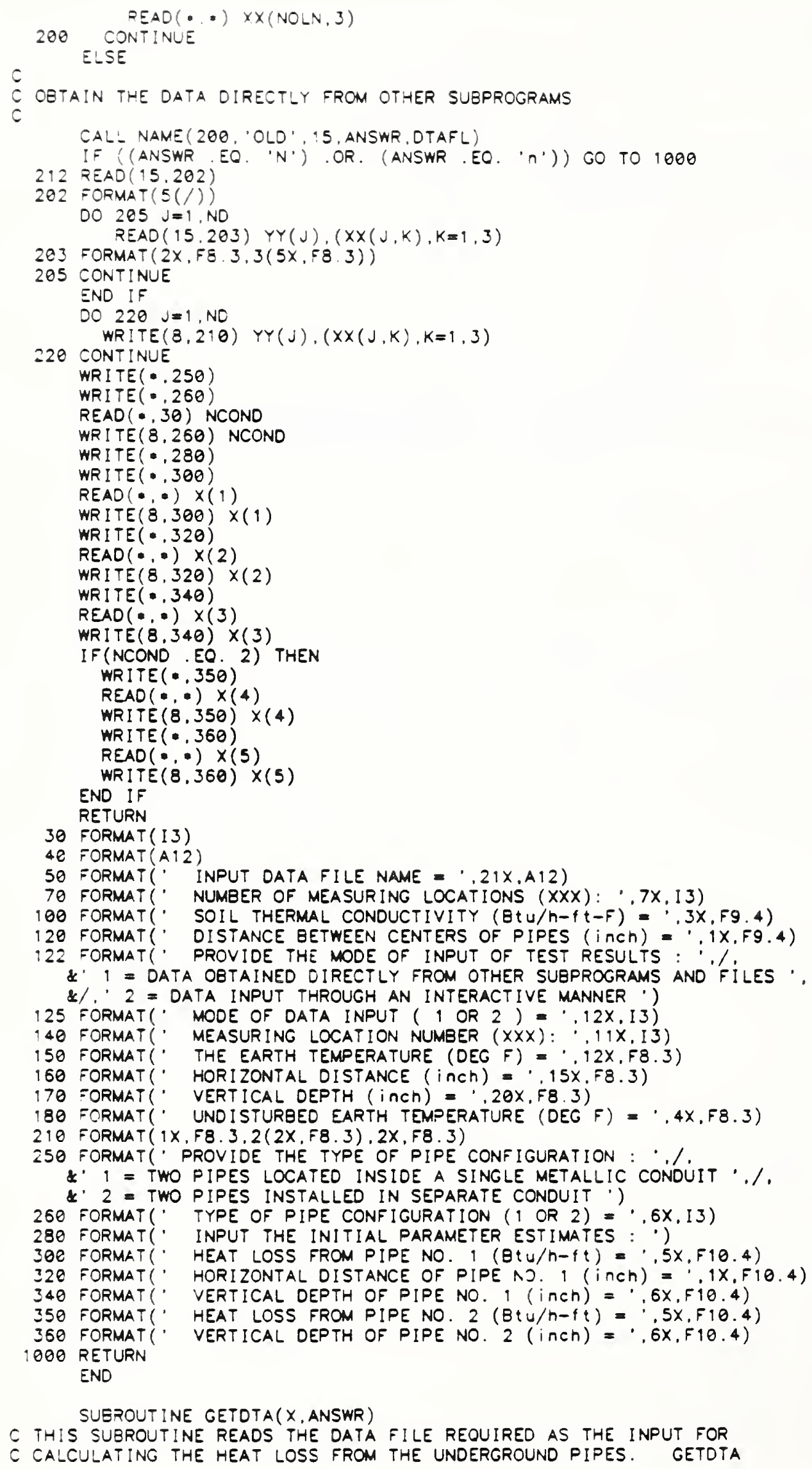




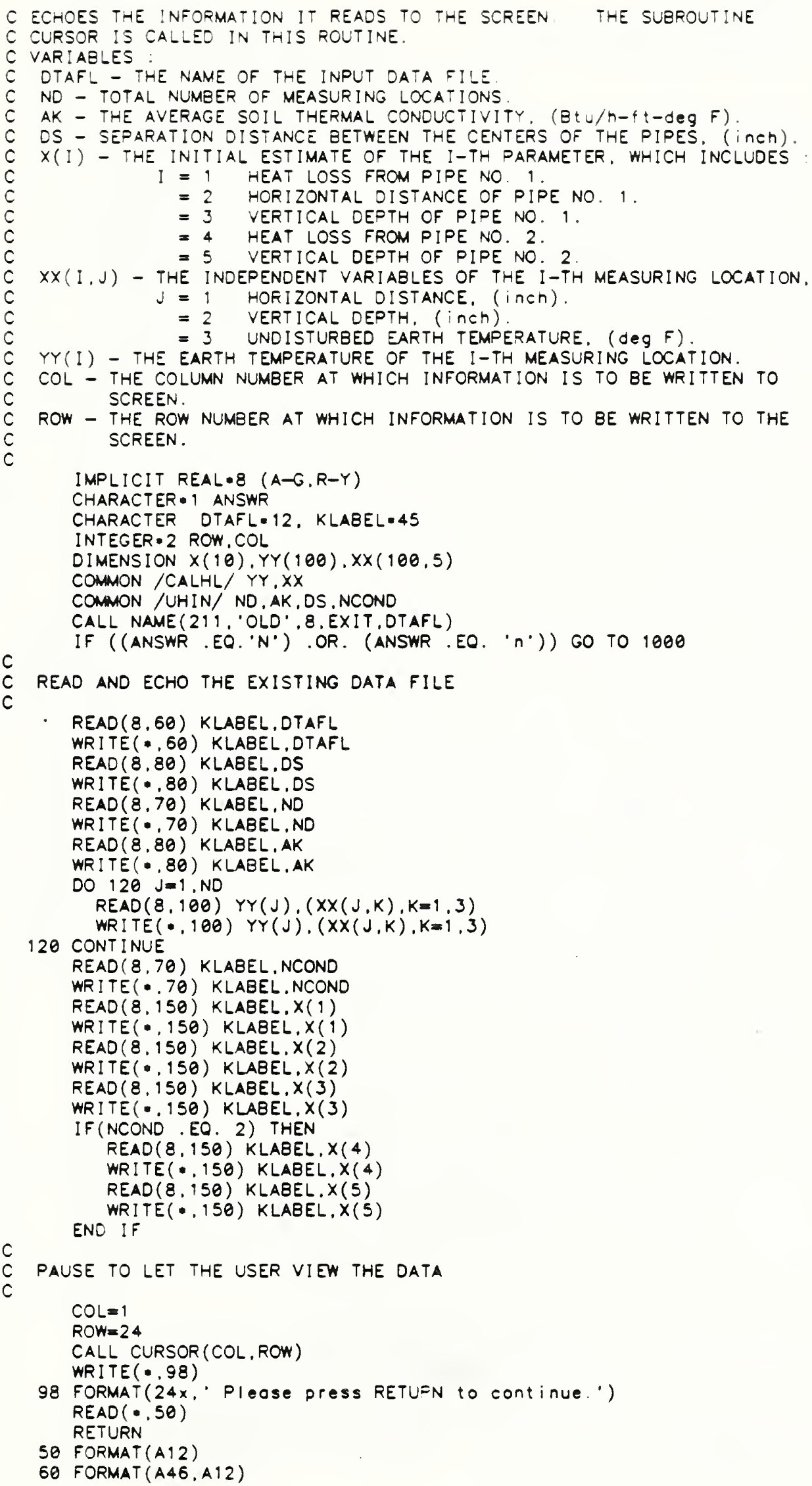




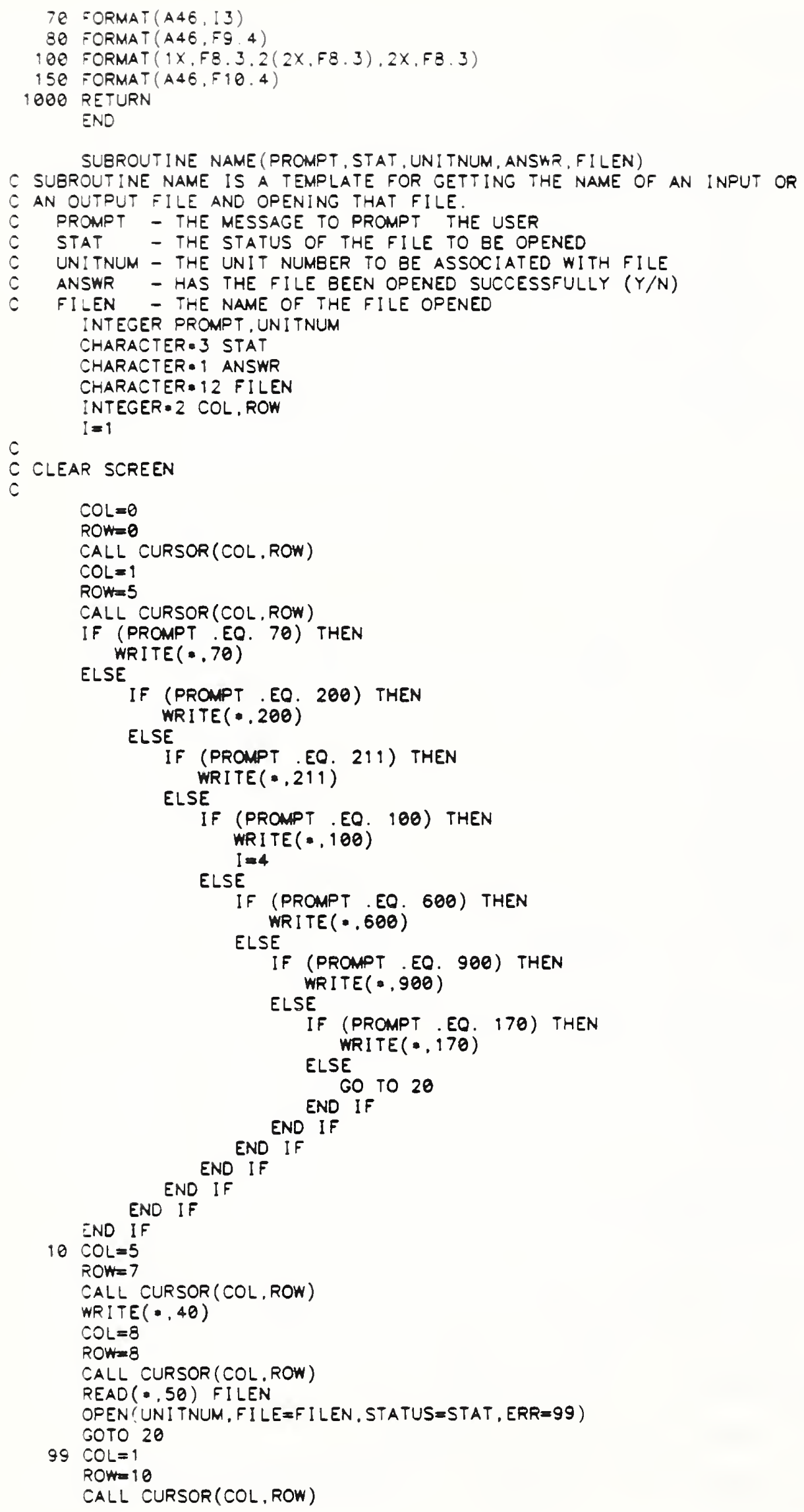




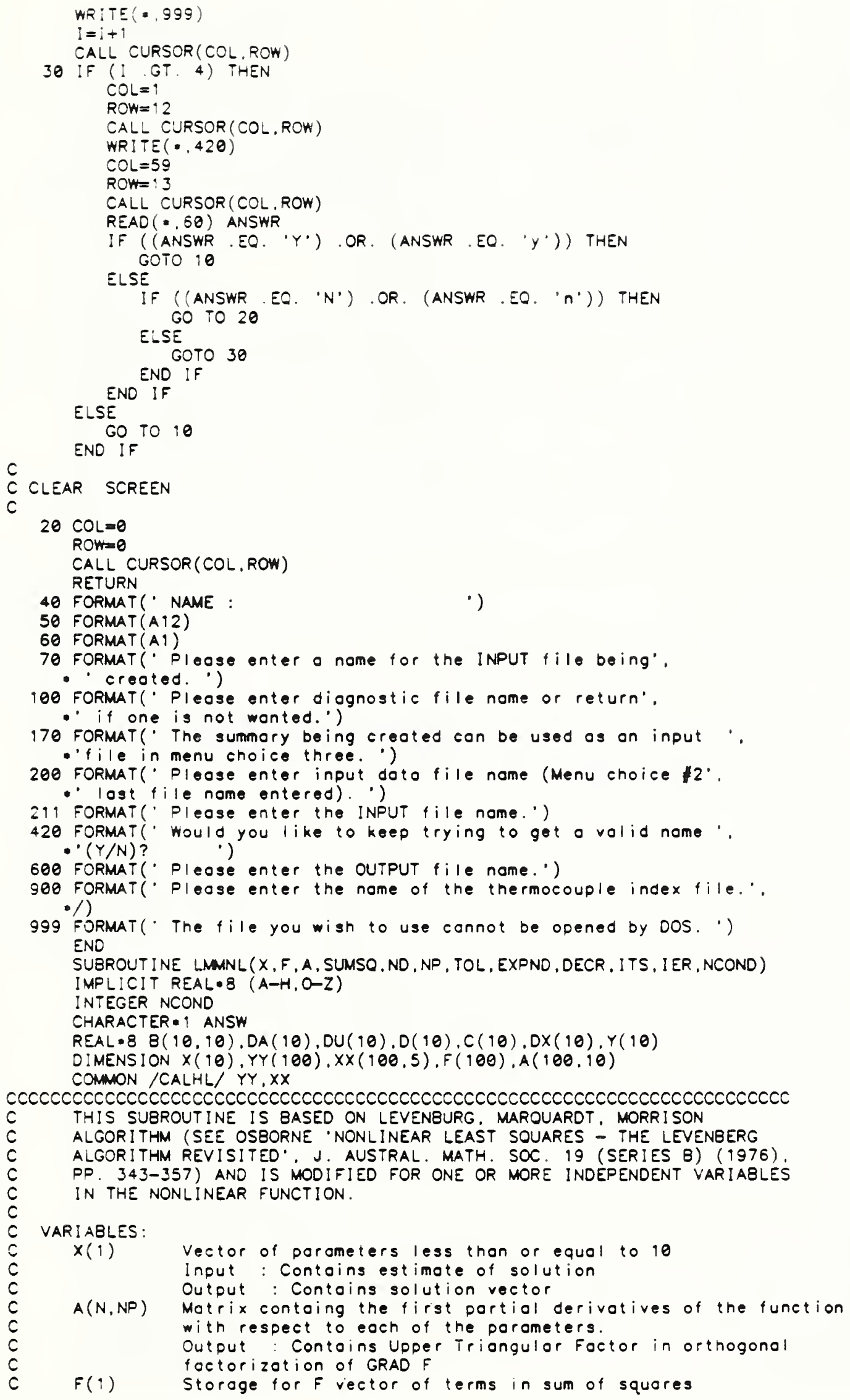




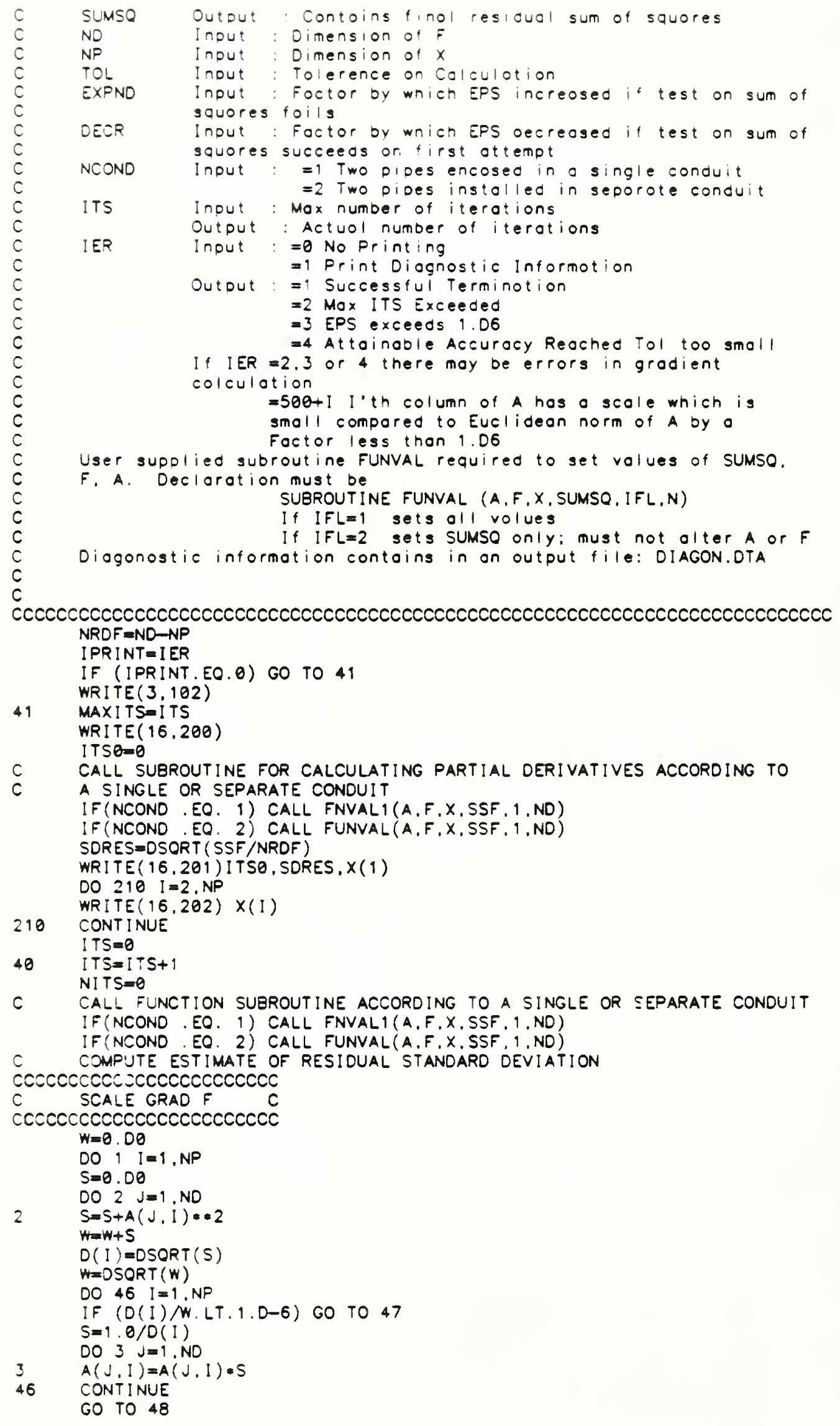




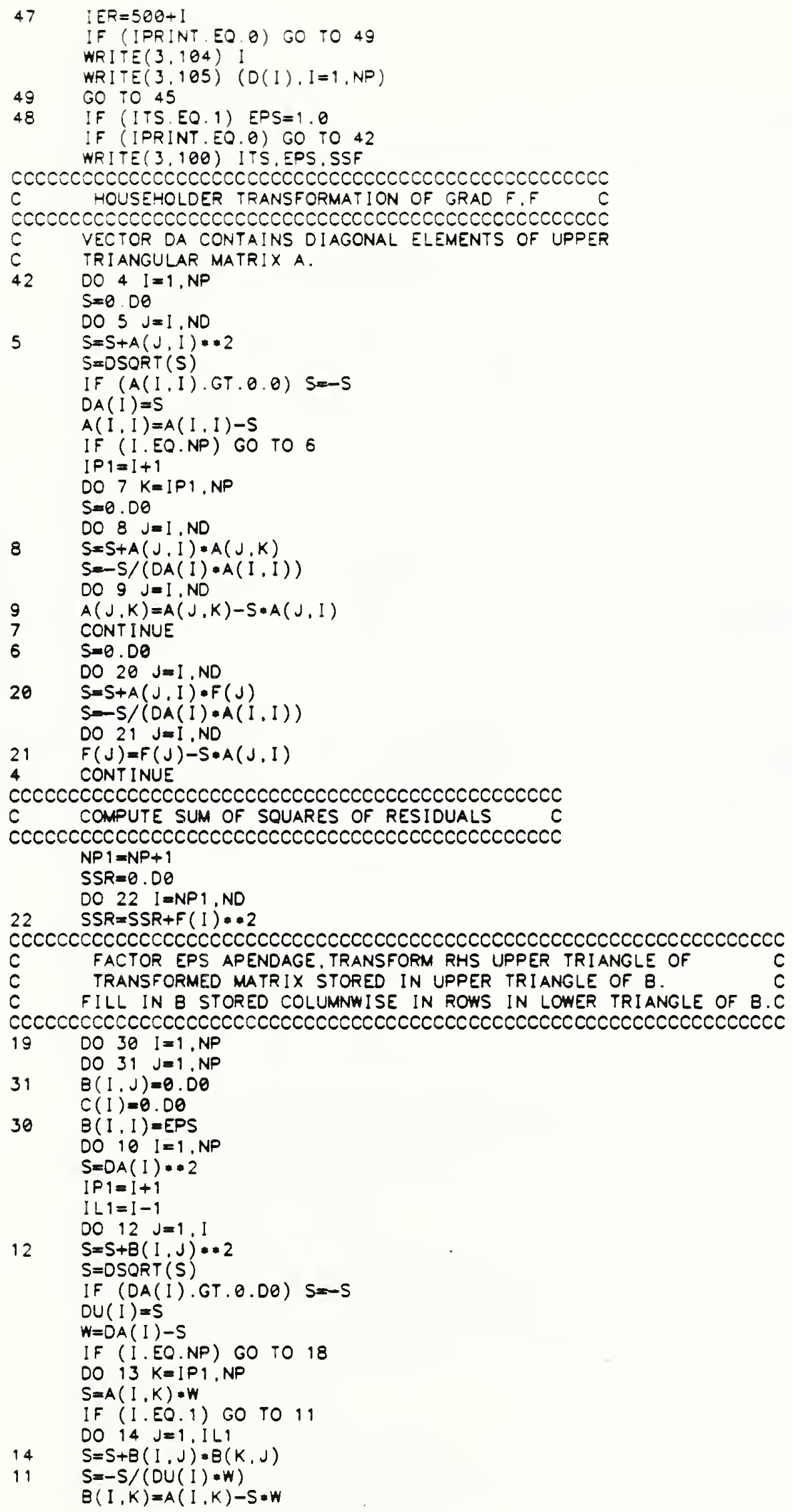




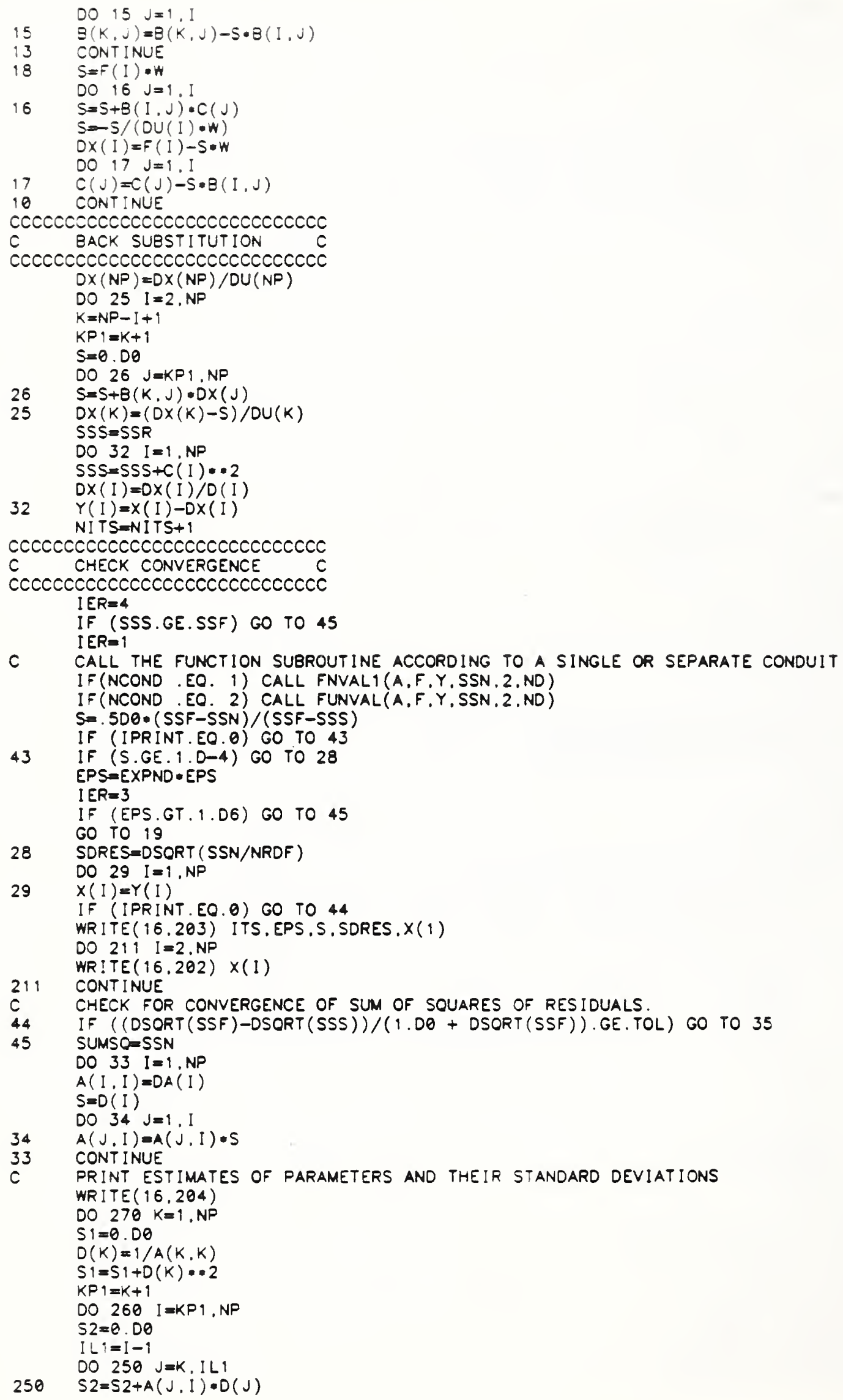




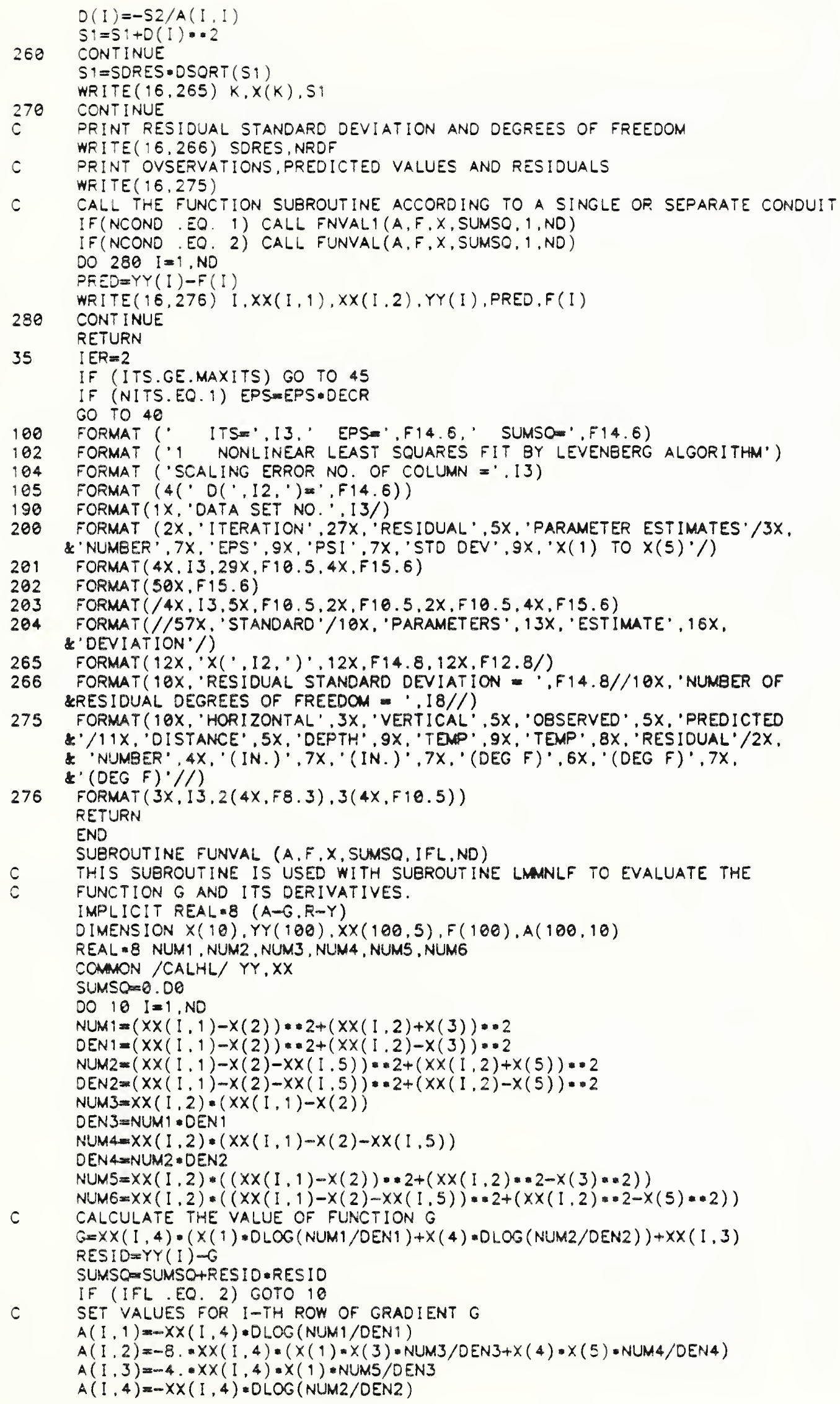




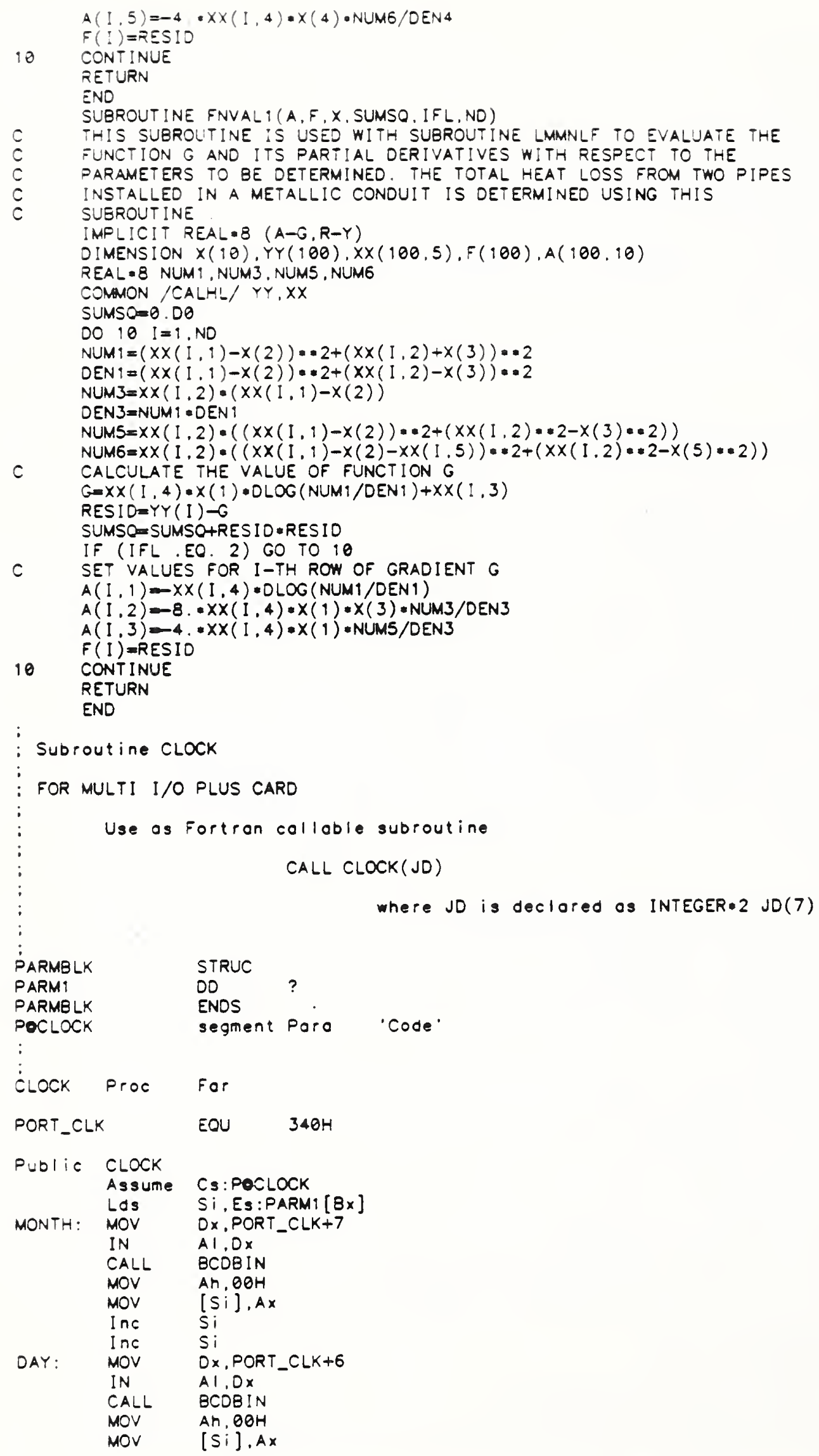




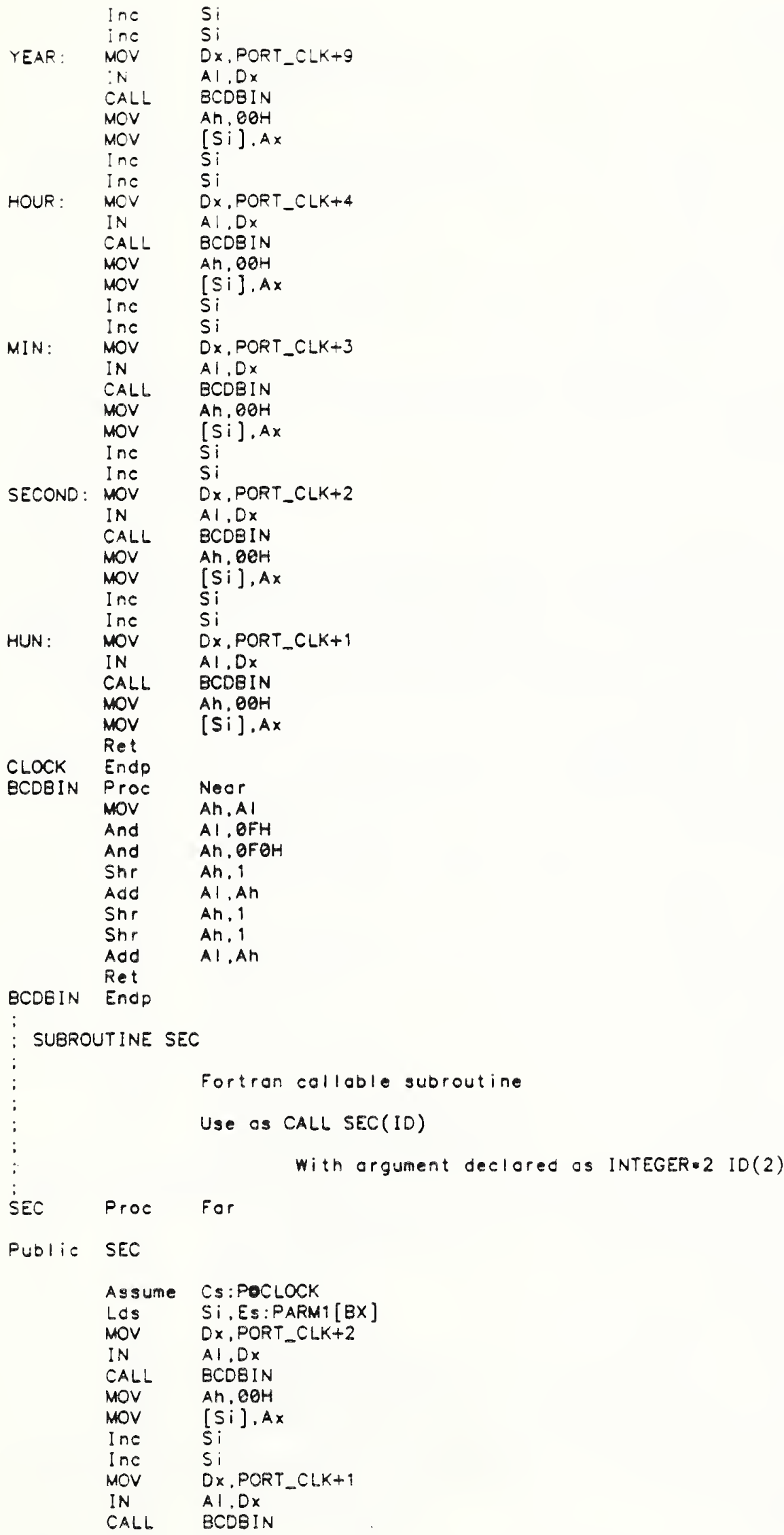




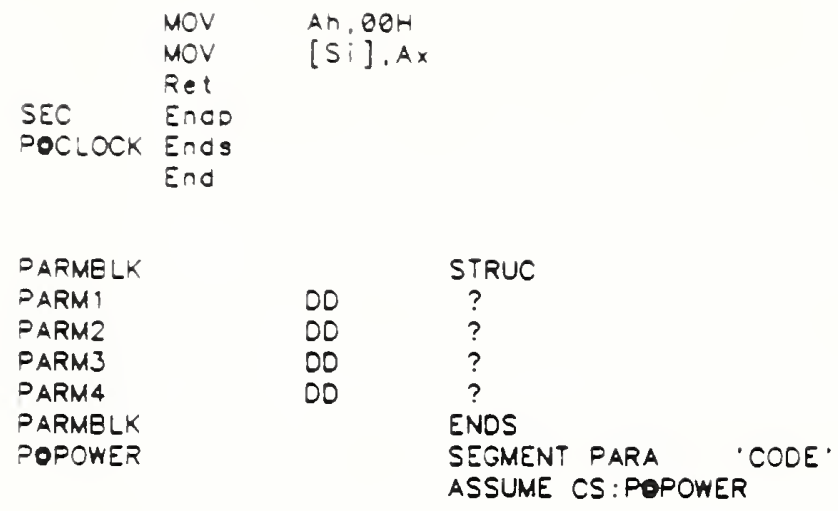

SUBTTL SUBROUTINE RESETP

RESETP PROC FAR

PUELIC RESETP

:THE RESET WILL TAKE PLACE REGAROLESS OF WHAT OPERATING SEOUENCE THE OT2801 :SERIES BOARO MAY BE EXECUTING PRIOR TO RUNNING THIS PROGRAM.

TO CALL FROM FORTRAN USE : CALL RESETP

COMMAND_REGISTER EQU
STATUS_REGISTER EQU

DATA_REGISTER EOU

COMMAND_WAIT EQU

WRITE_WAIT EOU

CRESET EOU OH

CSTOP EOU OFH

CCLEAR EOU $1 \mathrm{H}$

CAOIN EOU $\quad O C H$

COAOUT EQU $8 \mathrm{H}$

CSIN EOU 4 H

CSOUT EOU $5 \mathrm{H}$

CDIOIN EOU $6 H$

COIOOUT EOU $7 H$

:

ERR EOU $1 \mathrm{H} \quad ; \quad 1=$ COOE FOR ERROR

NOERR EQU OH $\quad$ OH $\theta=$ COOE FOR NO ERROR

$\begin{array}{lll}\text { ERRCK } & \text { EOU } 80 \mathrm{H}\end{array}$

STOP THE OT2801 SERIES BOARO AND EMPTY THE DATA OUT REGISTER.

$$
\begin{array}{ll}
\text { MOV } & \text { OX.COMMAND_REGISTER } \\
\text { MOV } & \text { AL.CSTOP } \\
\text { OUT } & \text { OX.AL } \\
\text { MOV } & \text { DX.OATA_REGISTER } \\
\text { IN } & \text { AL.OX }
\end{array}
$$

WAIT UNTIL THE DT280 9 SERIES BOARD DATA IN FLAG IS CLEAR AND READY FLAG iIS SET. THEN WRITE THE RESET COMMANO BYTE TO THE COMMANO REGISTER.

$\begin{array}{lll} & \text { MOV } & \text { OX.STATUS_REGISTER } \\ \text { WRWAIT: } & \text { IN } & \text { AL.OX } \\ & \text { ANO } & \text { AL.WRITE_WAIT } \\ & \text { JNZ } & \text { WRWAIT } \\ \text { OKAY: IN } & \text { AL.OX }\end{array}$




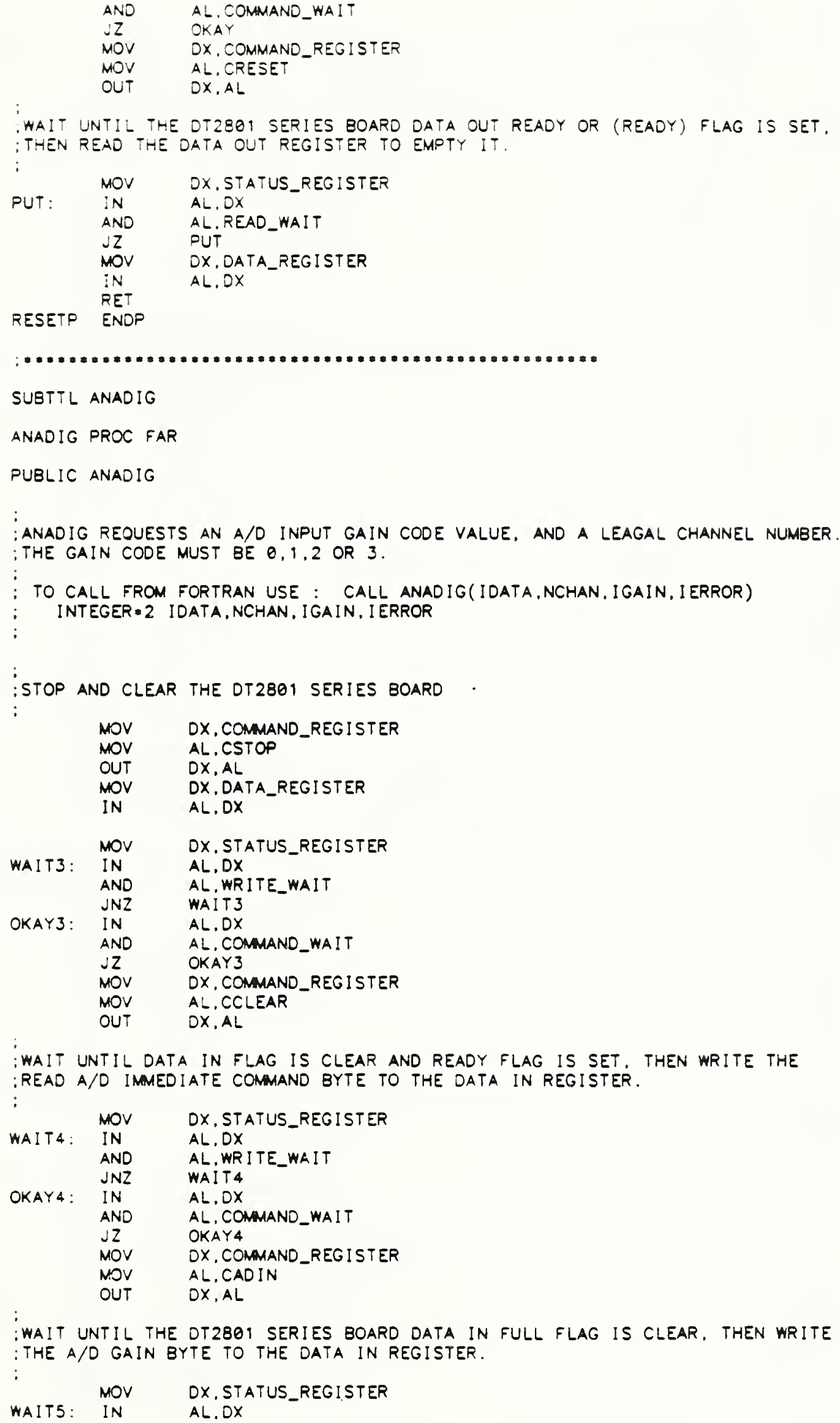




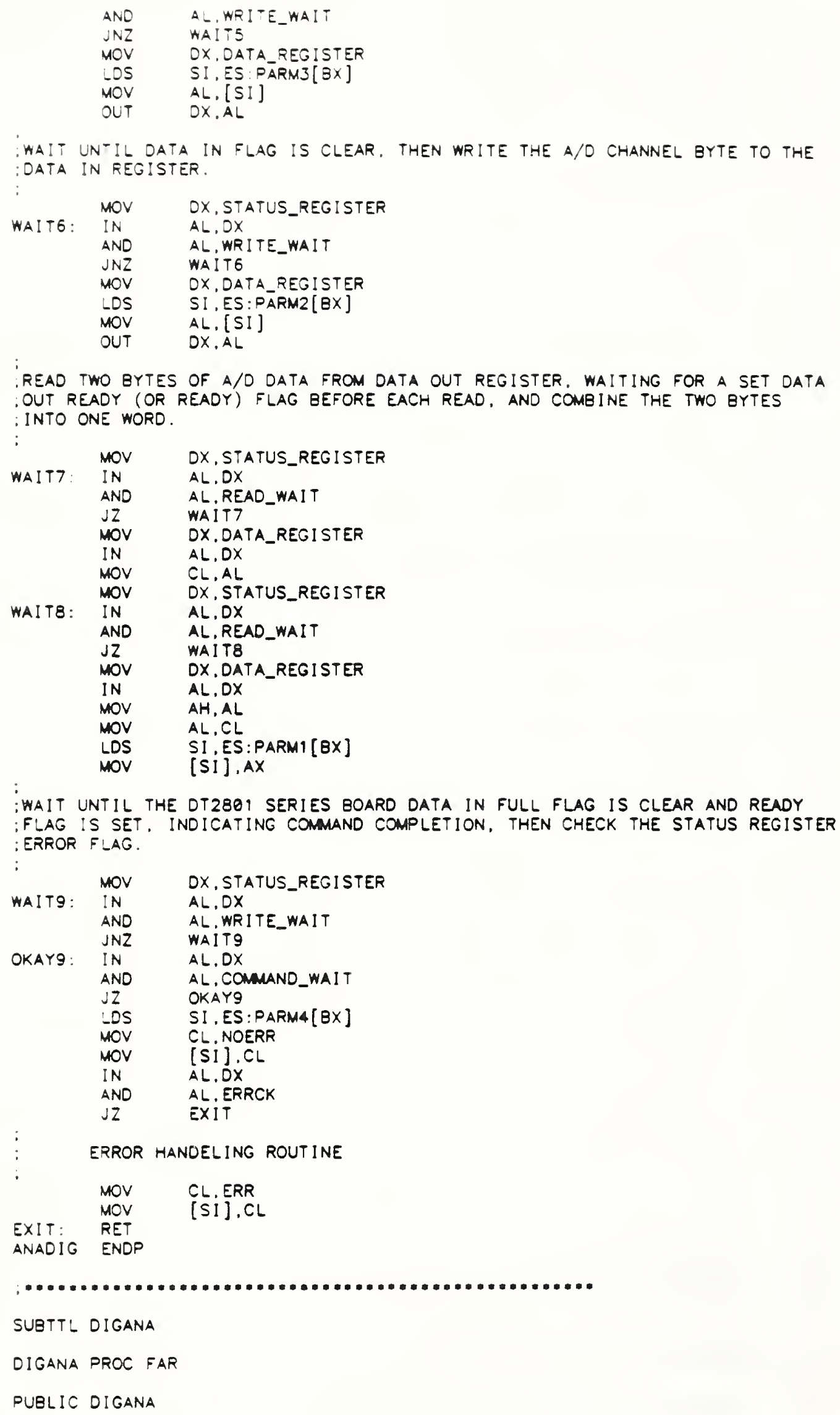




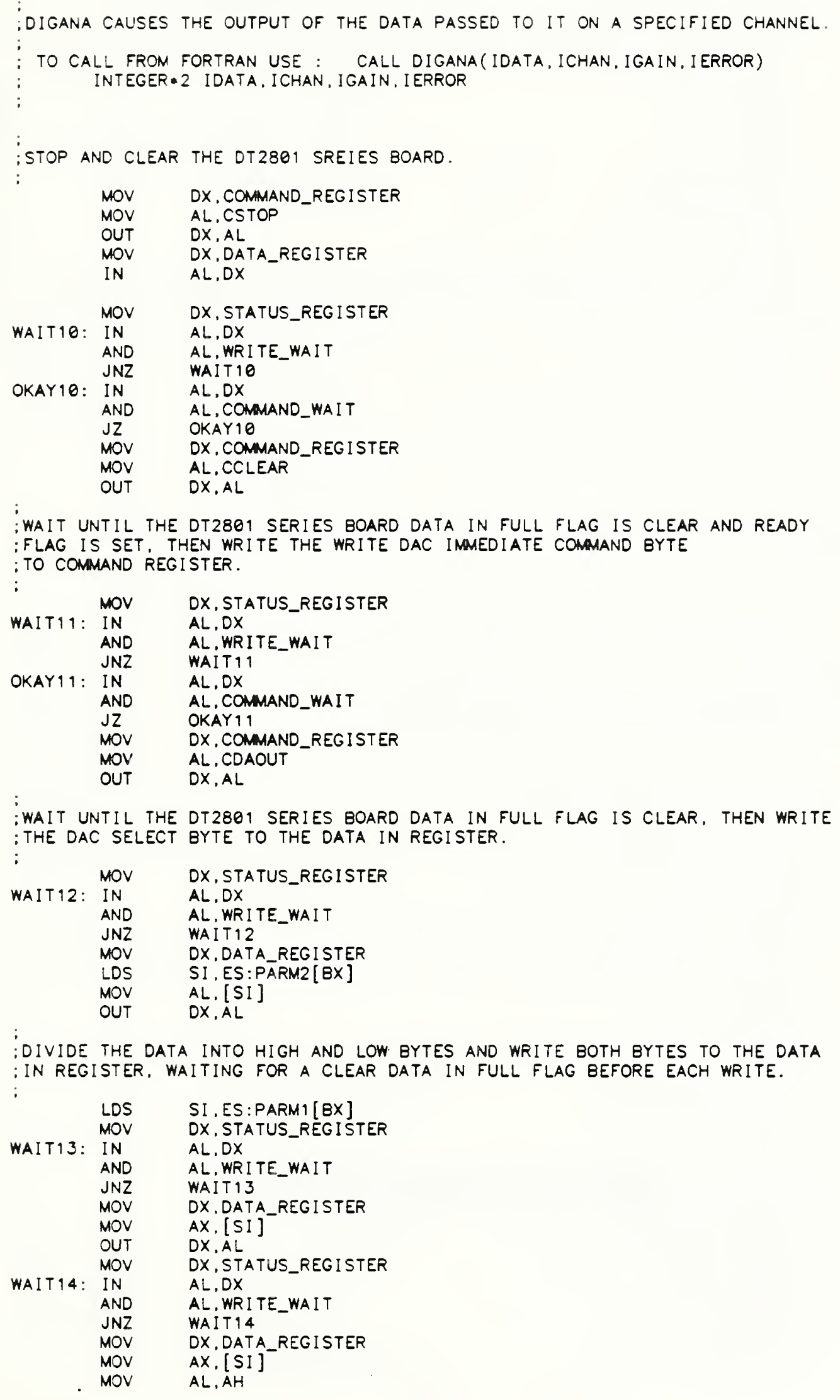


OUT DX,AL

WWAT UNTIL THE DT2801 SERIES 8OARD DATA IN FULL FLAG IS CLEAR AND READY

;FLAG IS SET. INDICATING COMMAND COMPLETION. THEN CHECK THE STATUS REgISTER :ERROR FLAG

\begin{tabular}{|c|c|c|}
\hline \multirow{3}{*}{ WAIT15: } & MOV & DX,STATUS_REGISTER \\
\hline & IN & $A L, D X$ \\
\hline & AND & AL,WRITE_WAIT \\
\hline & JNZ & WAIT15 \\
\hline \multirow{9}{*}{ OKAY 15: } & IN & $A L, D X$ \\
\hline & AND & AL, COMMAND_WAIT \\
\hline & $j z$ & OKAY 15 \\
\hline & LDS & SI, ES : PARM4 $[B X]$ \\
\hline & MOV & CL, NOERR \\
\hline & MOV & {$[S I], C L$} \\
\hline & IN & $A L, D X$ \\
\hline & AND & AL, ERRCK \\
\hline & $J z$ & BYE \\
\hline
\end{tabular}

ERROR HANDELING ROUTINE

MOV CL,ERR

MOV [SI],CL

BYE: RET

DIGANA ENDP

SUBTTL PORTIN

PORTIN PROC FAR

PUBLIC PORTIN

:PORTIN SETS THE DIGITAL PORT FOR INPUT. DIGRD SHOULD BE USED TO READ THE iVALUE OF THE PORT.

:TO CALL FROM FORTRAN USE : CALL PORTIN(IPORT, IERROR) INTEGER 2 IPORT, IERROR

;STOP AND CLEAR THE DT2801 SERIES BOARD

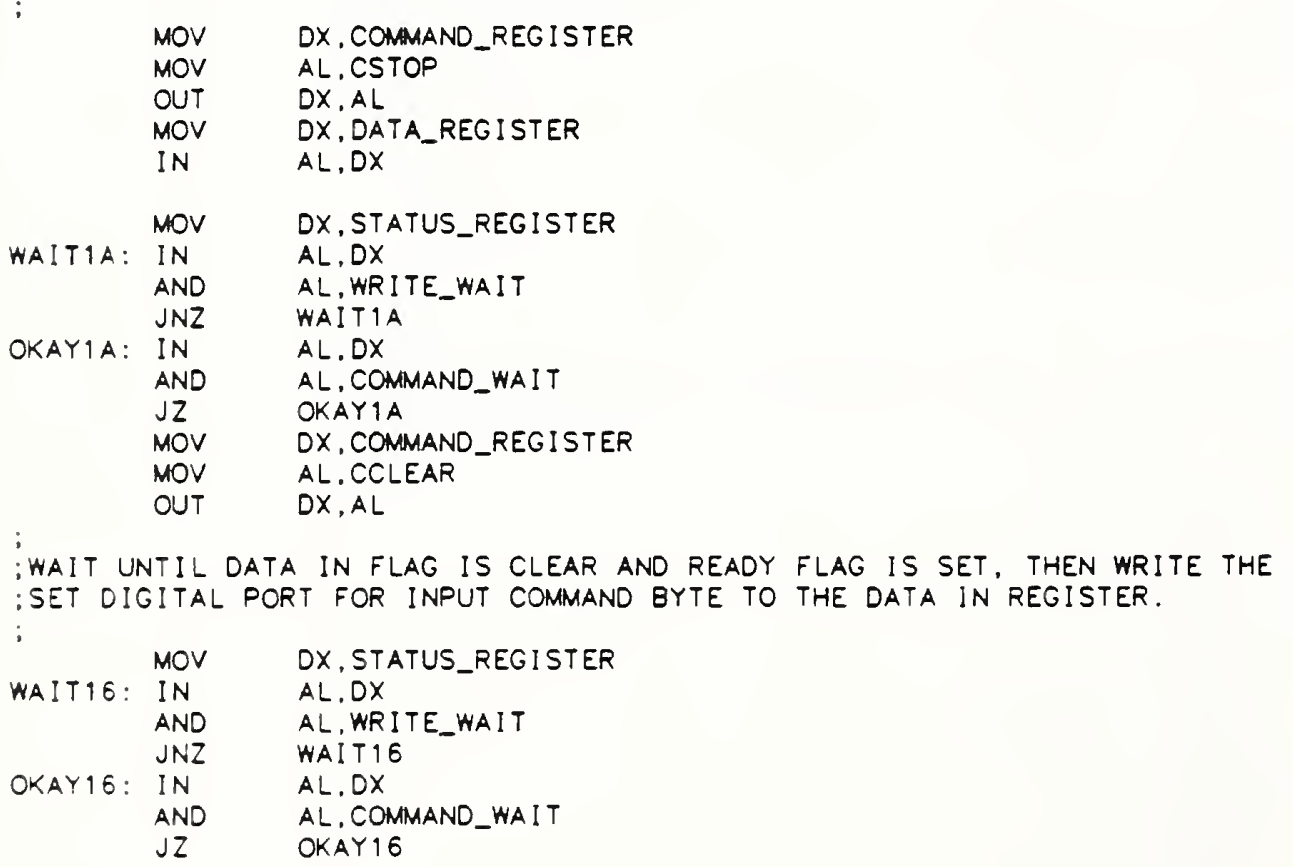




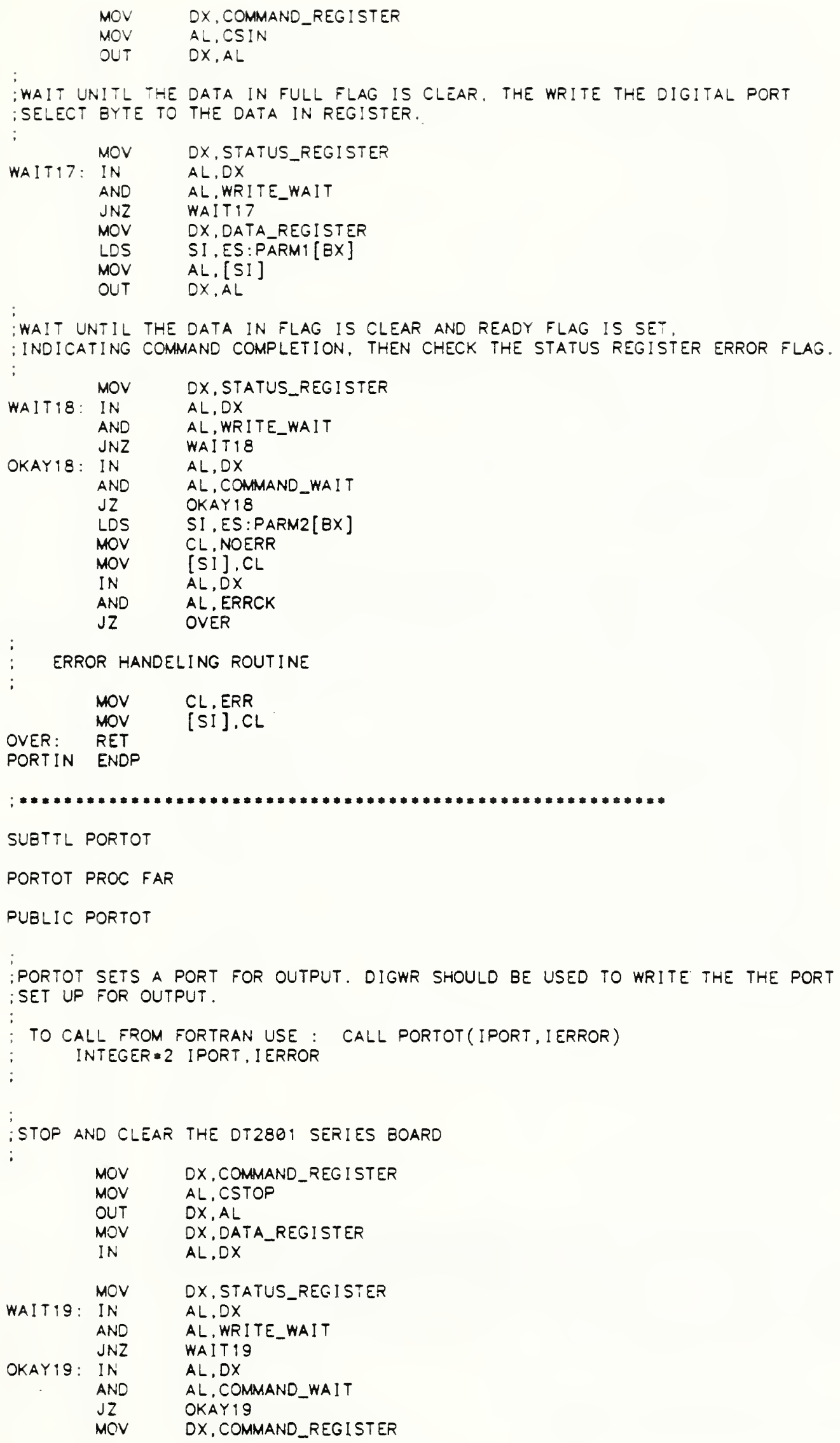




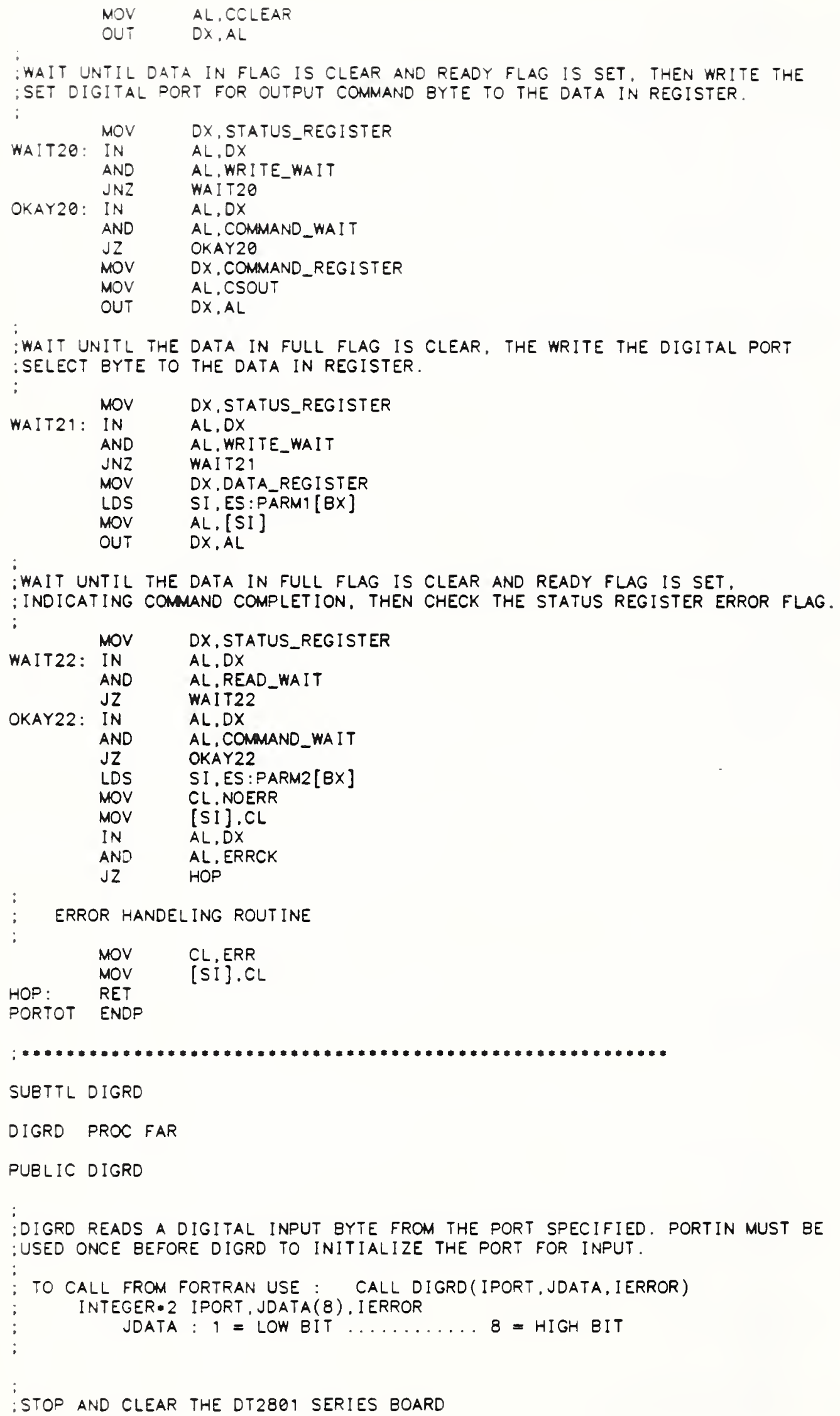




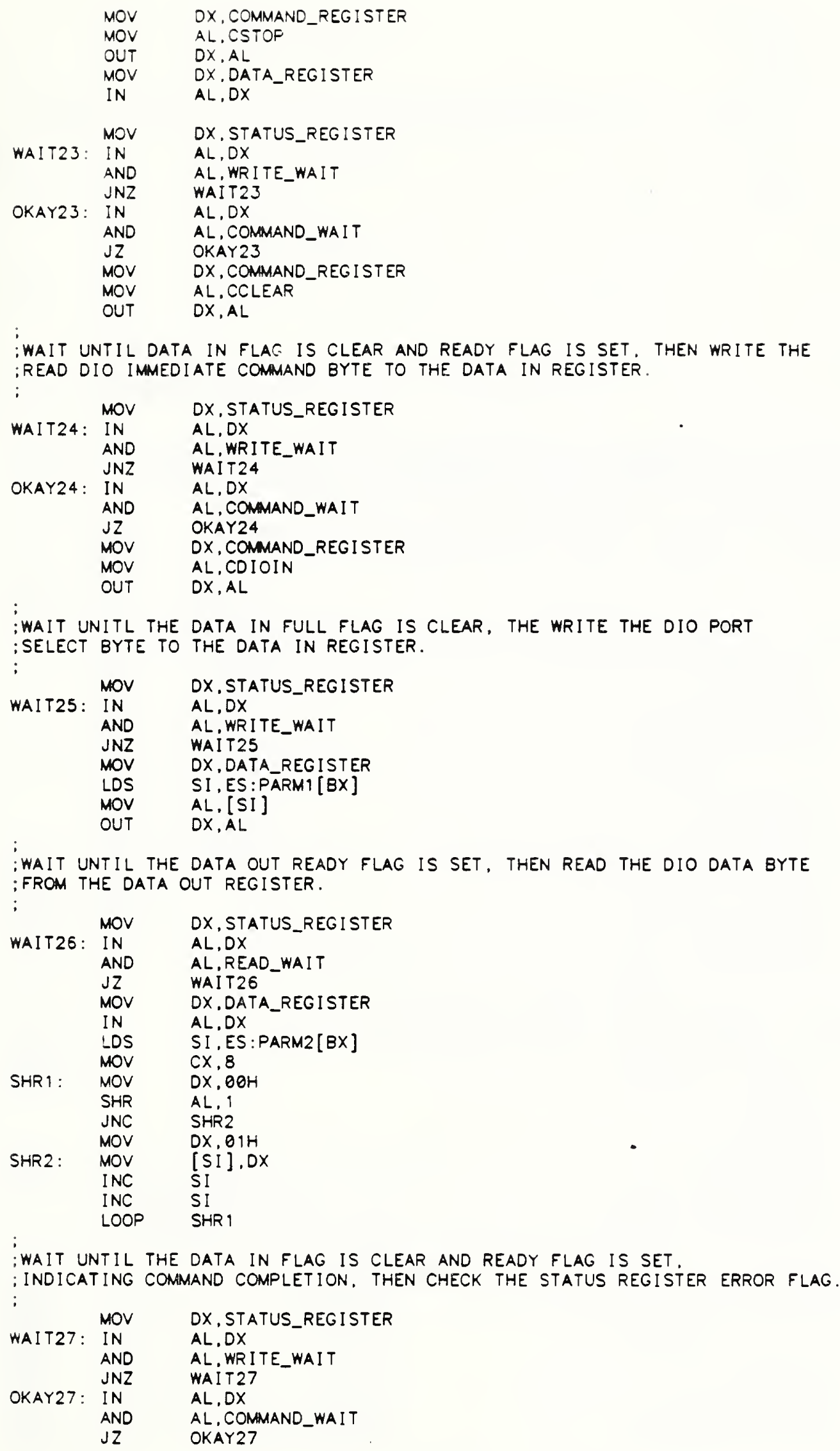




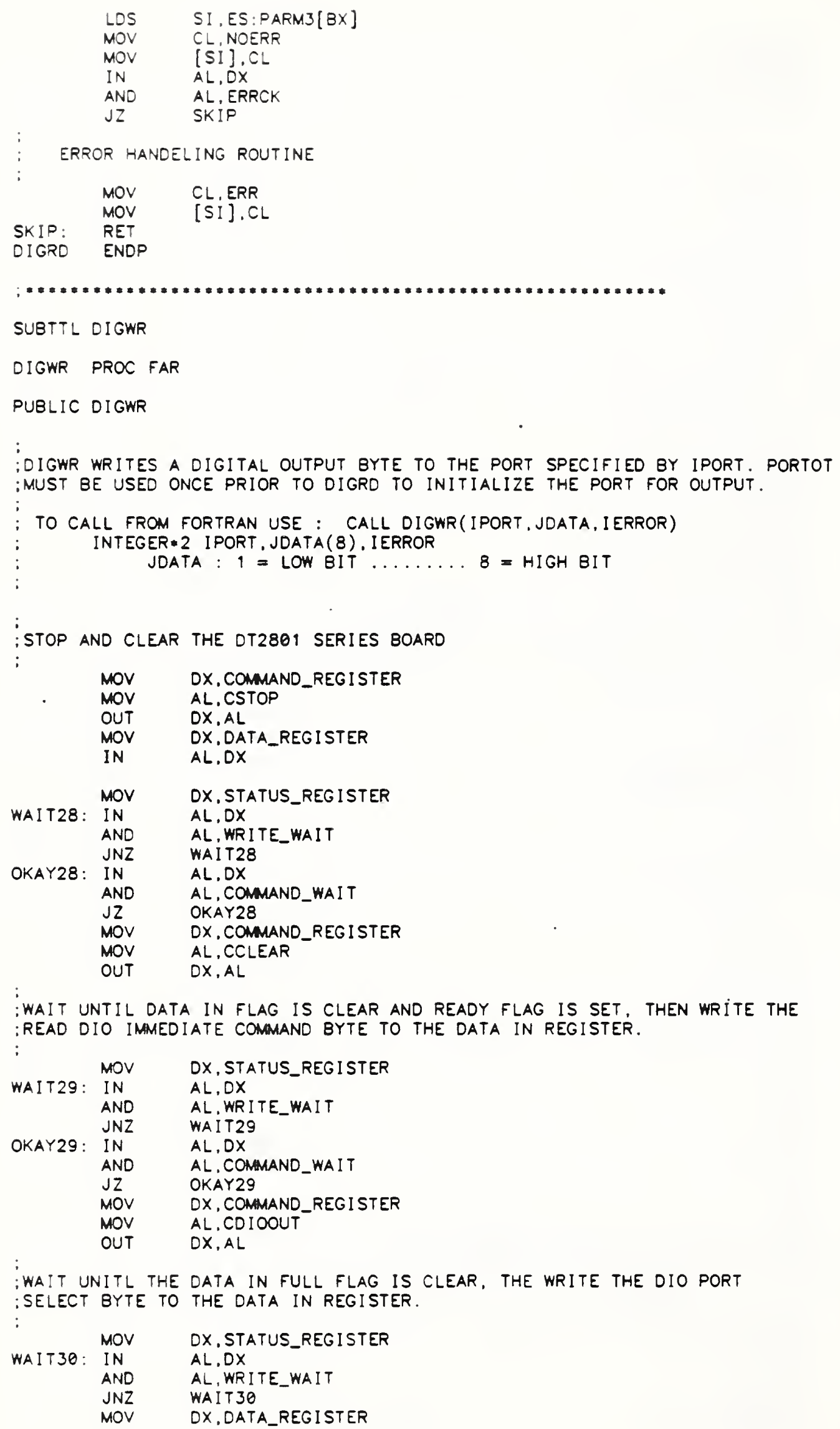




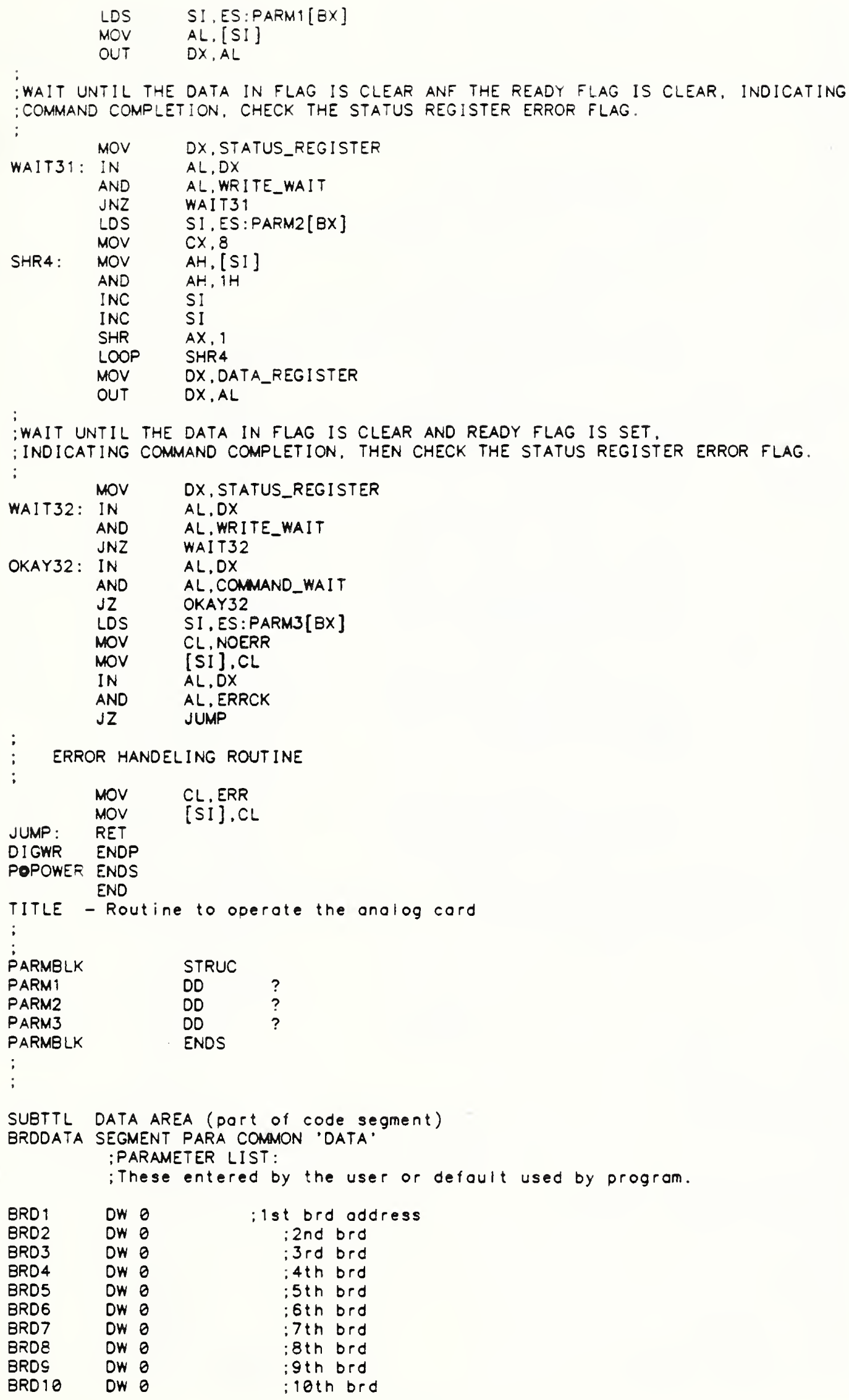




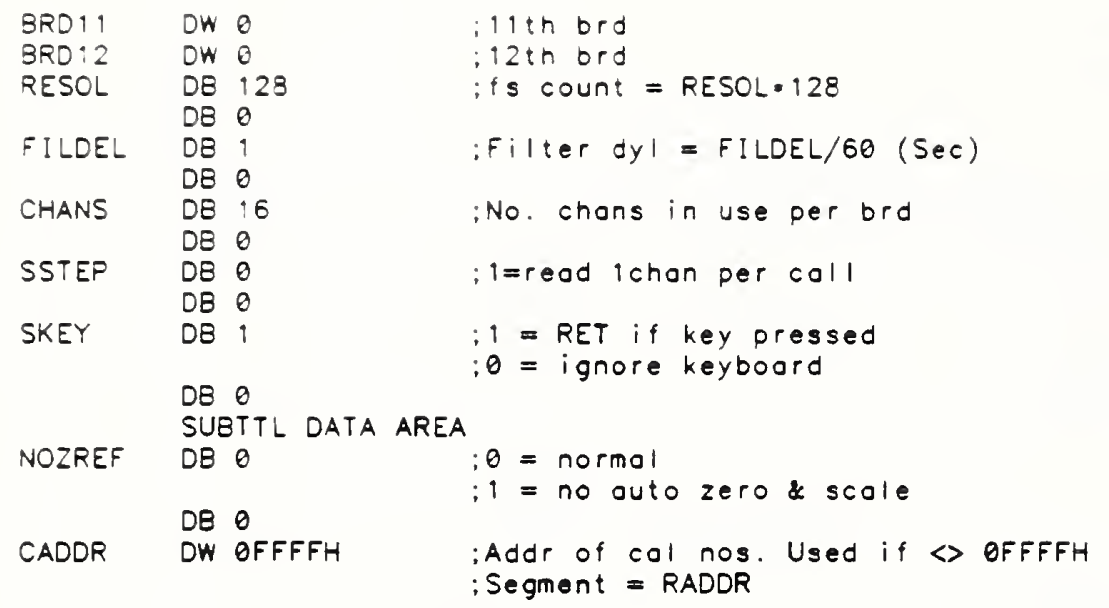




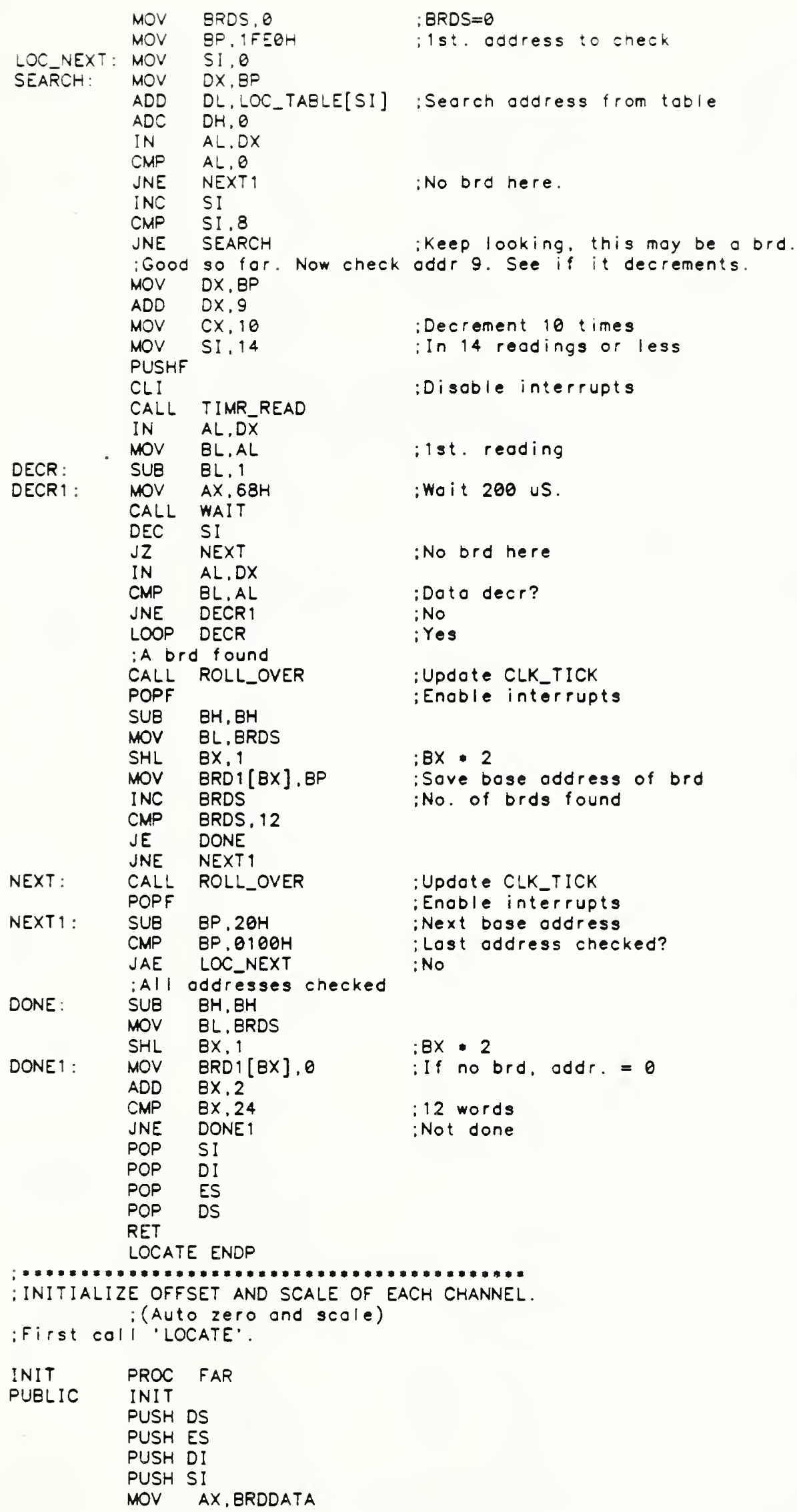




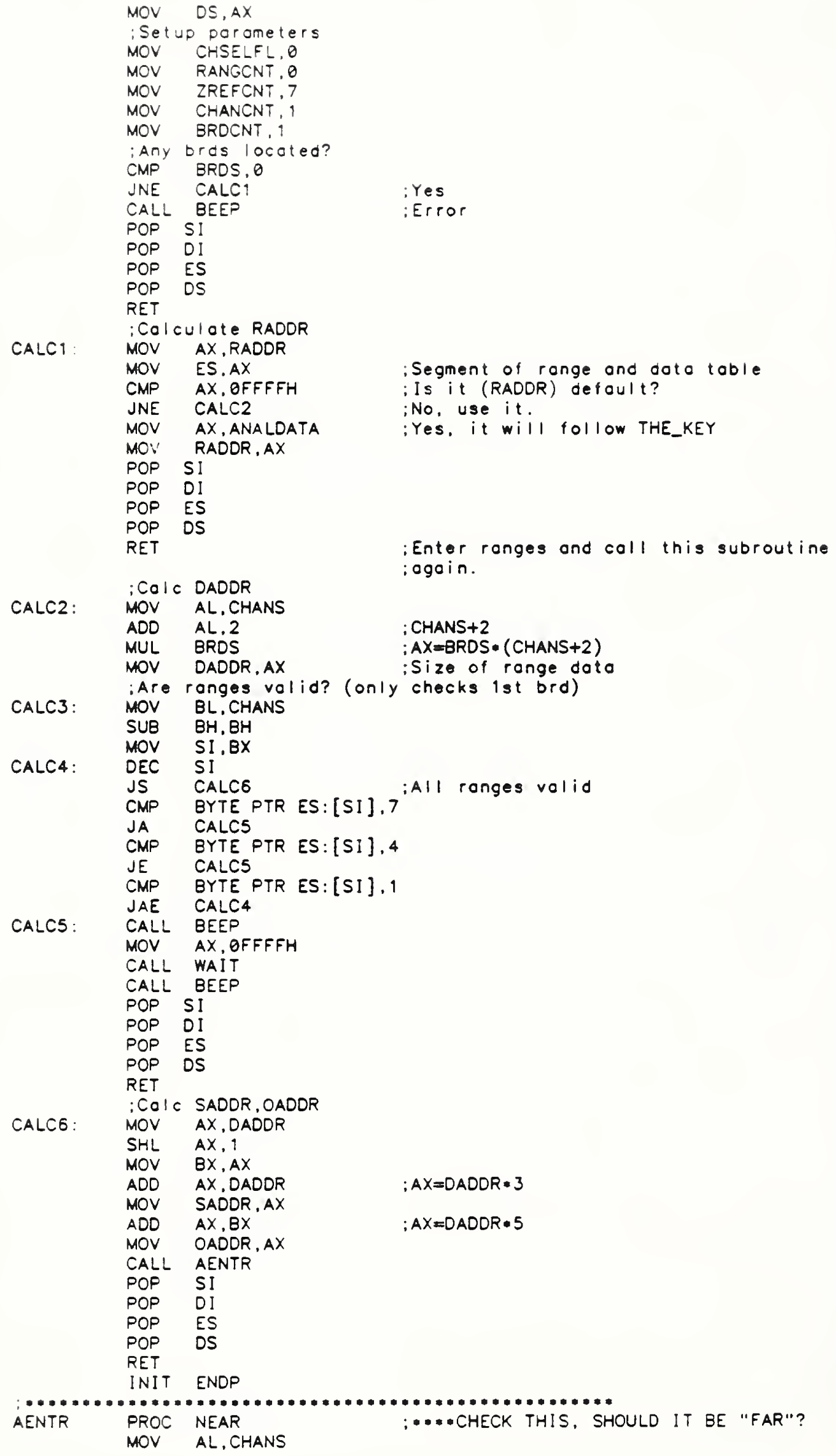




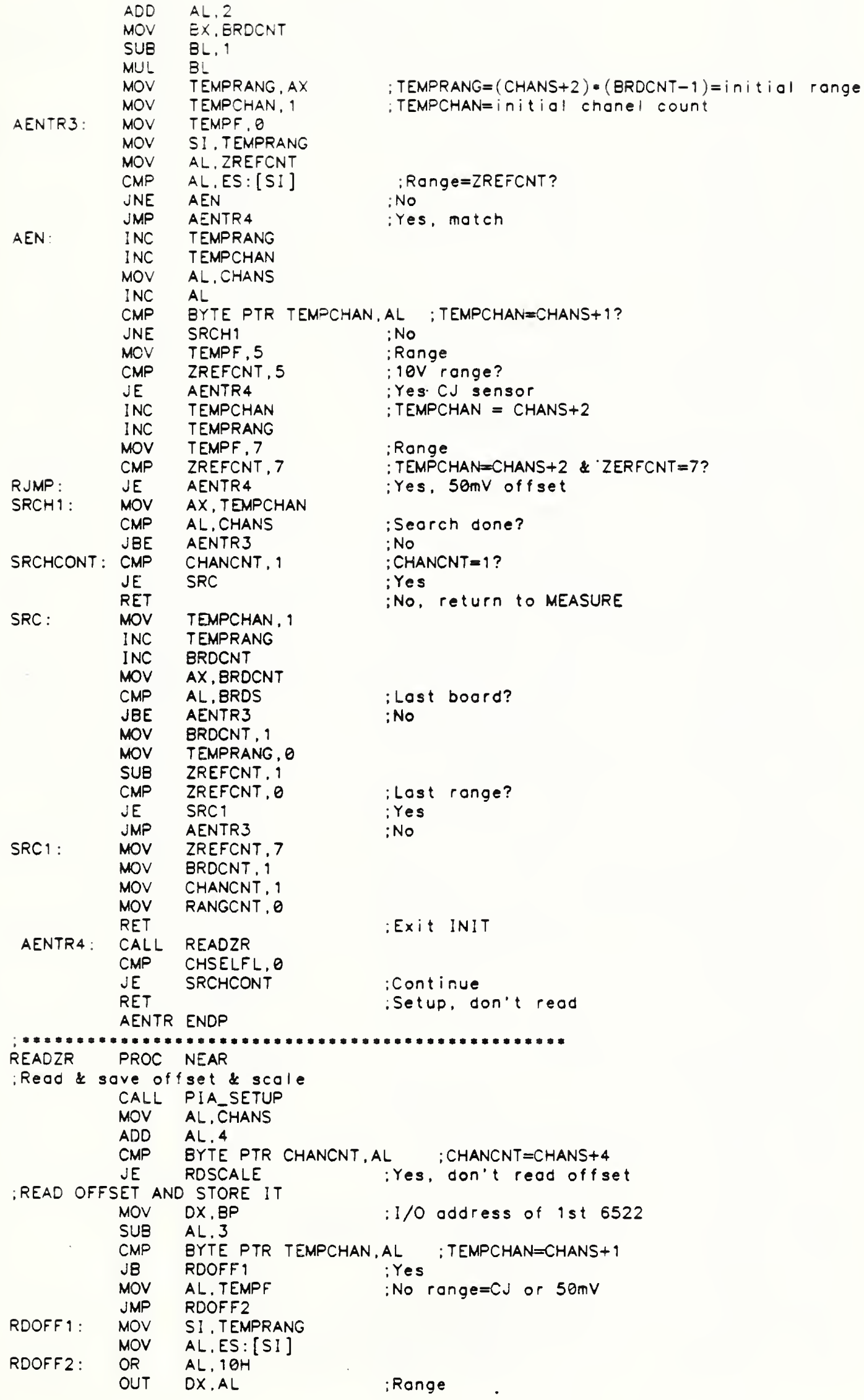




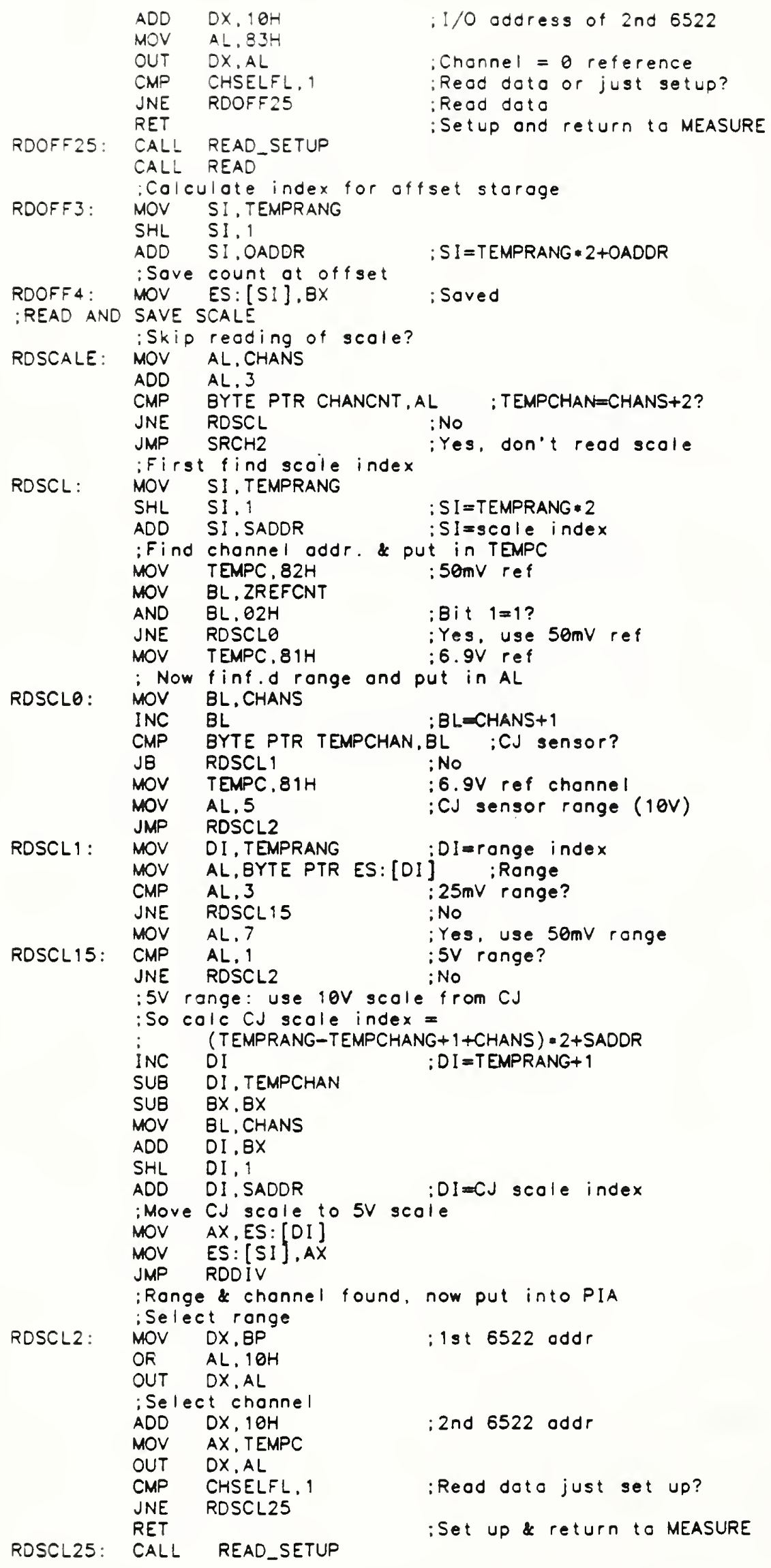




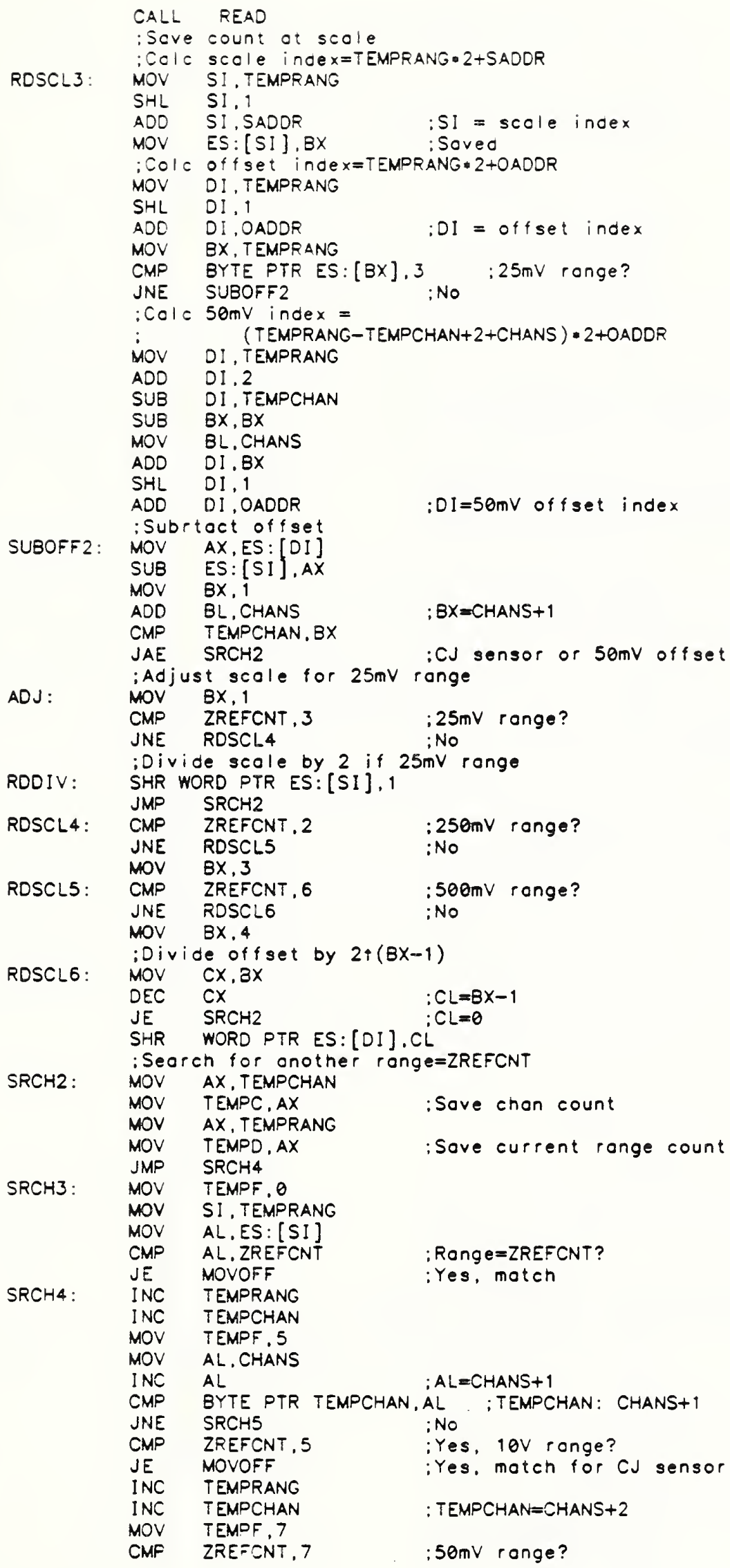




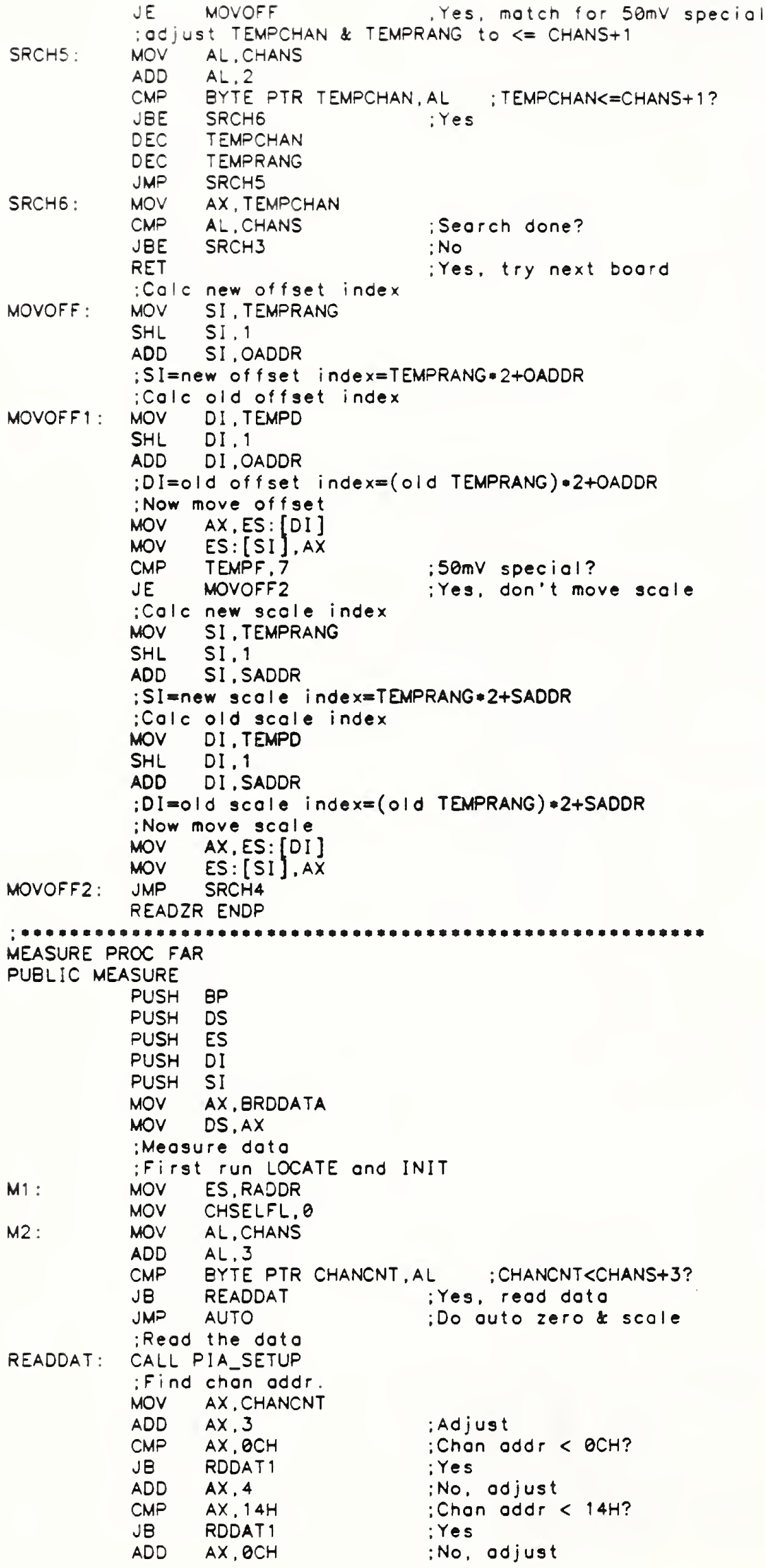




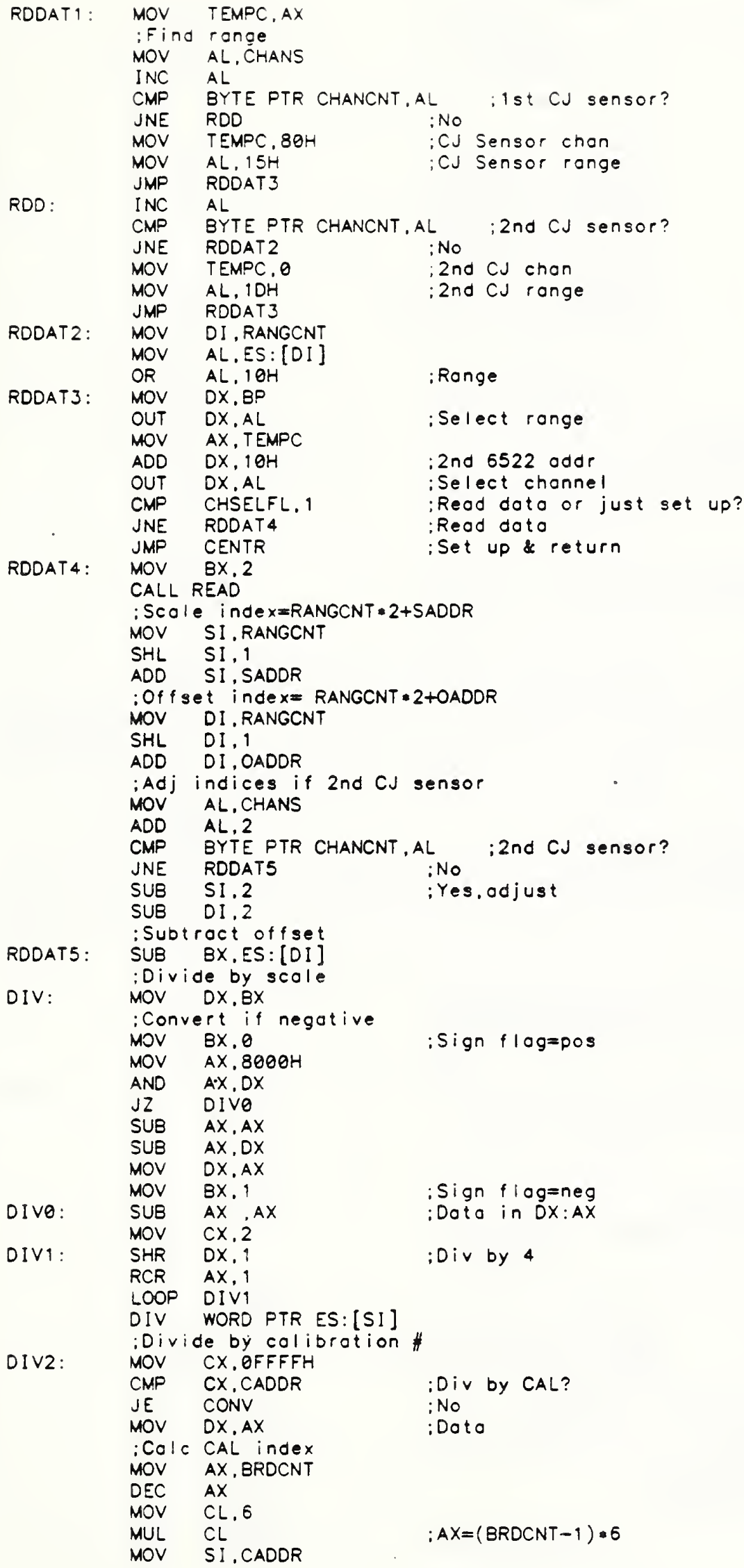




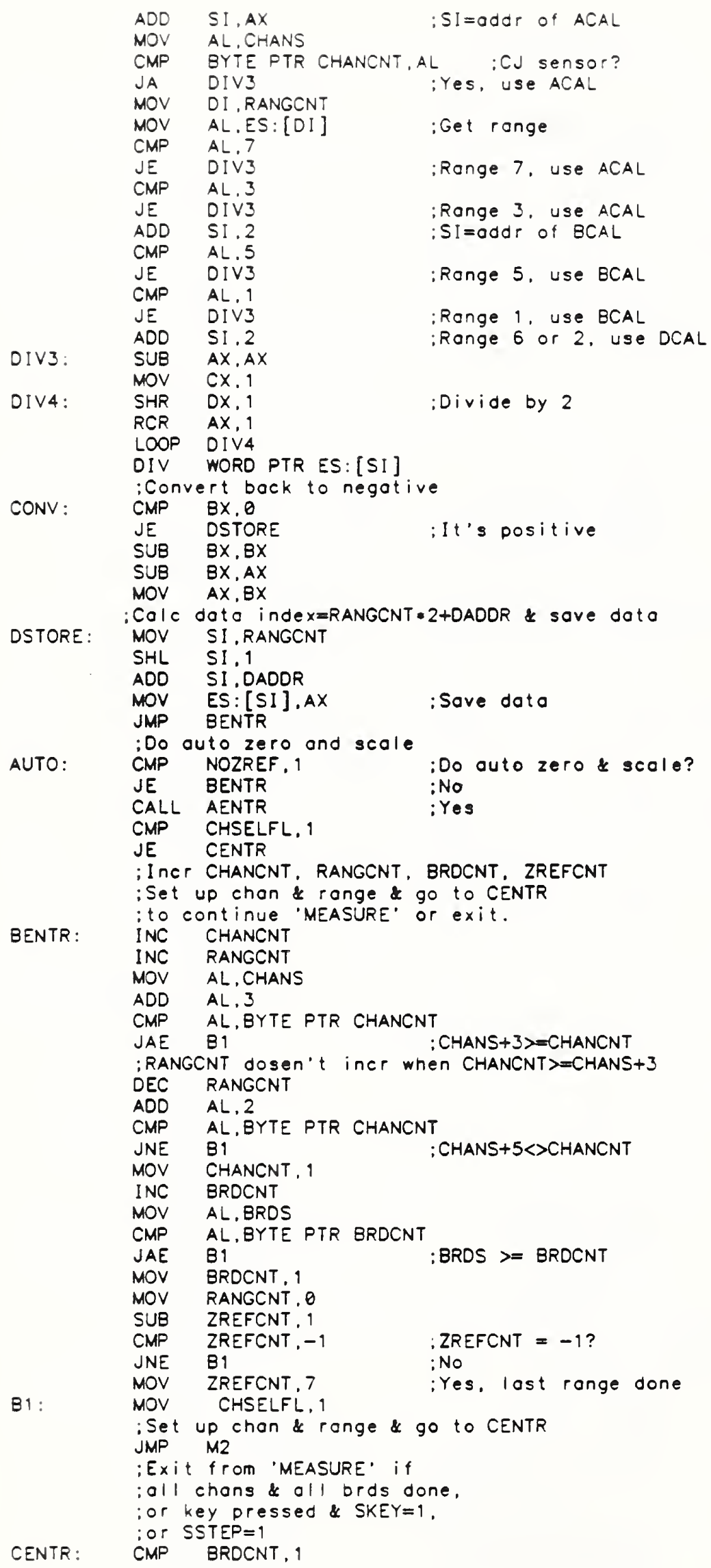




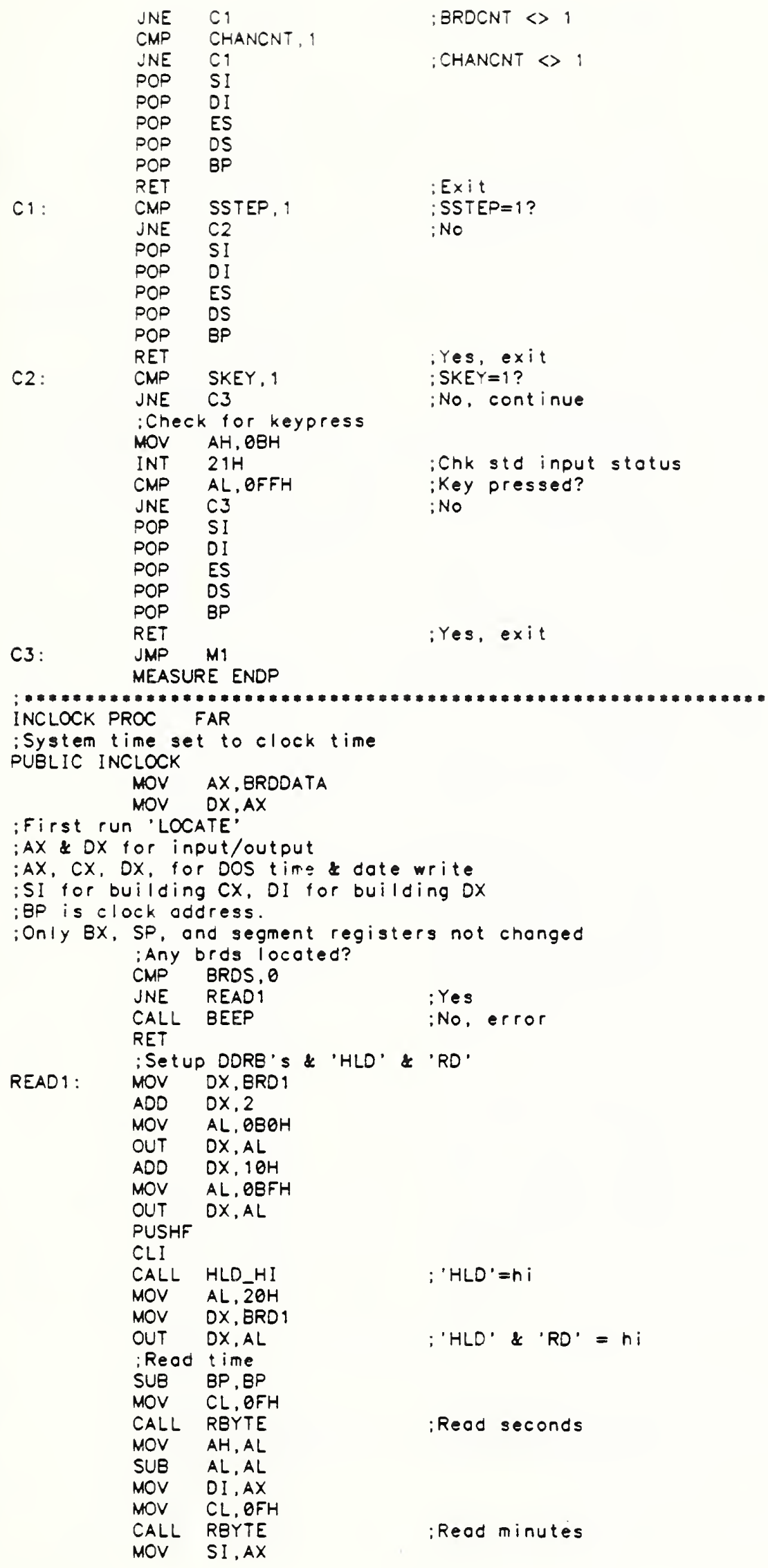




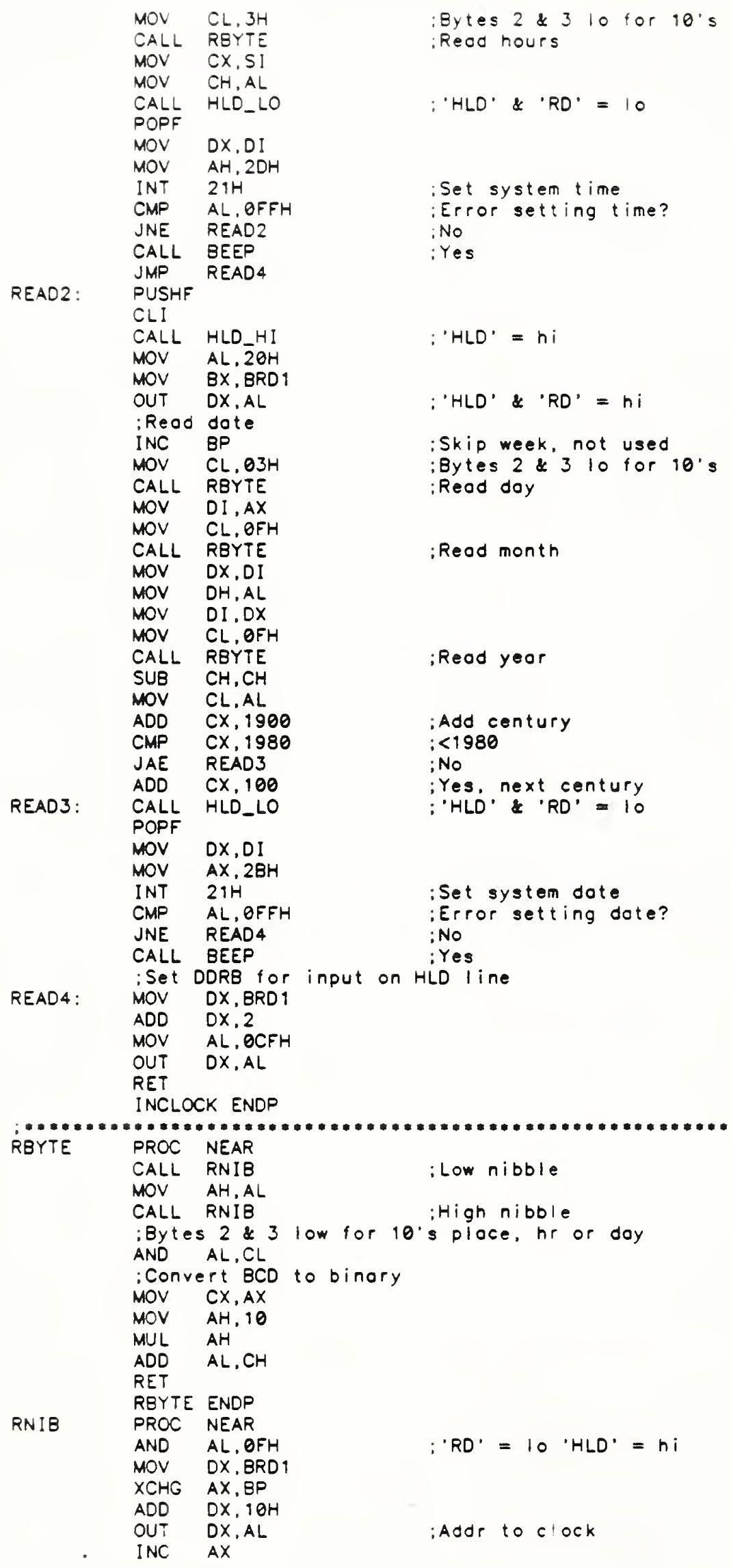




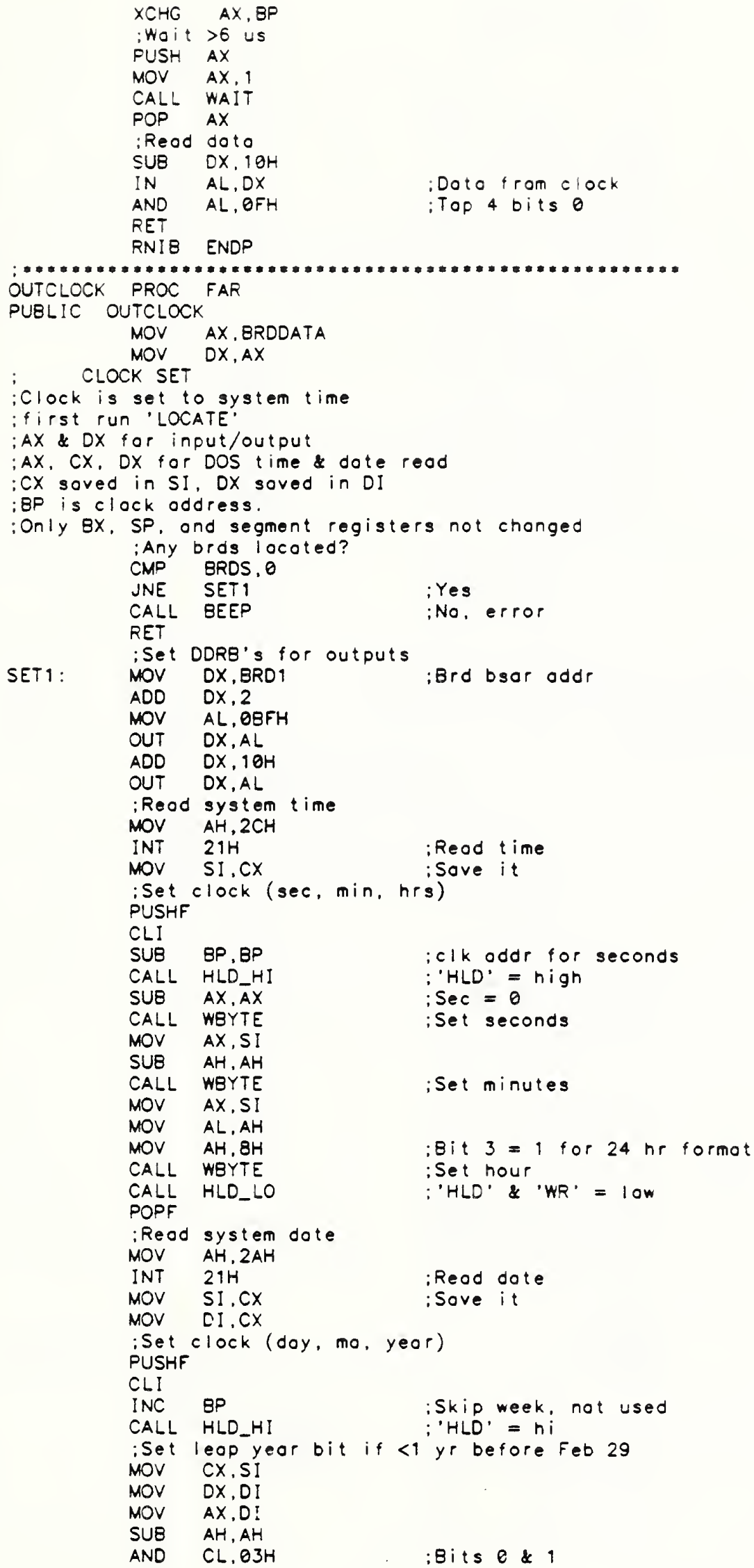




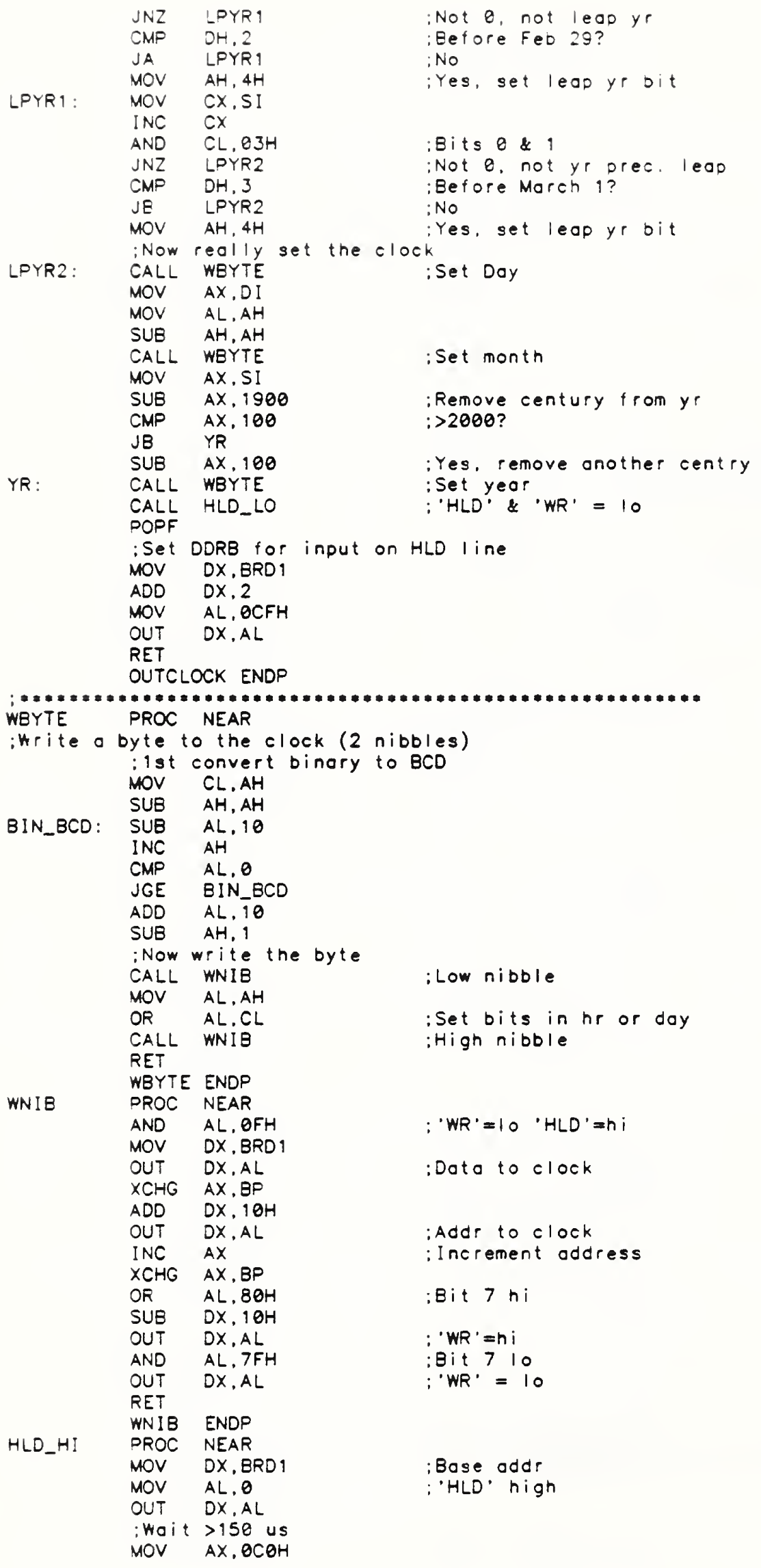




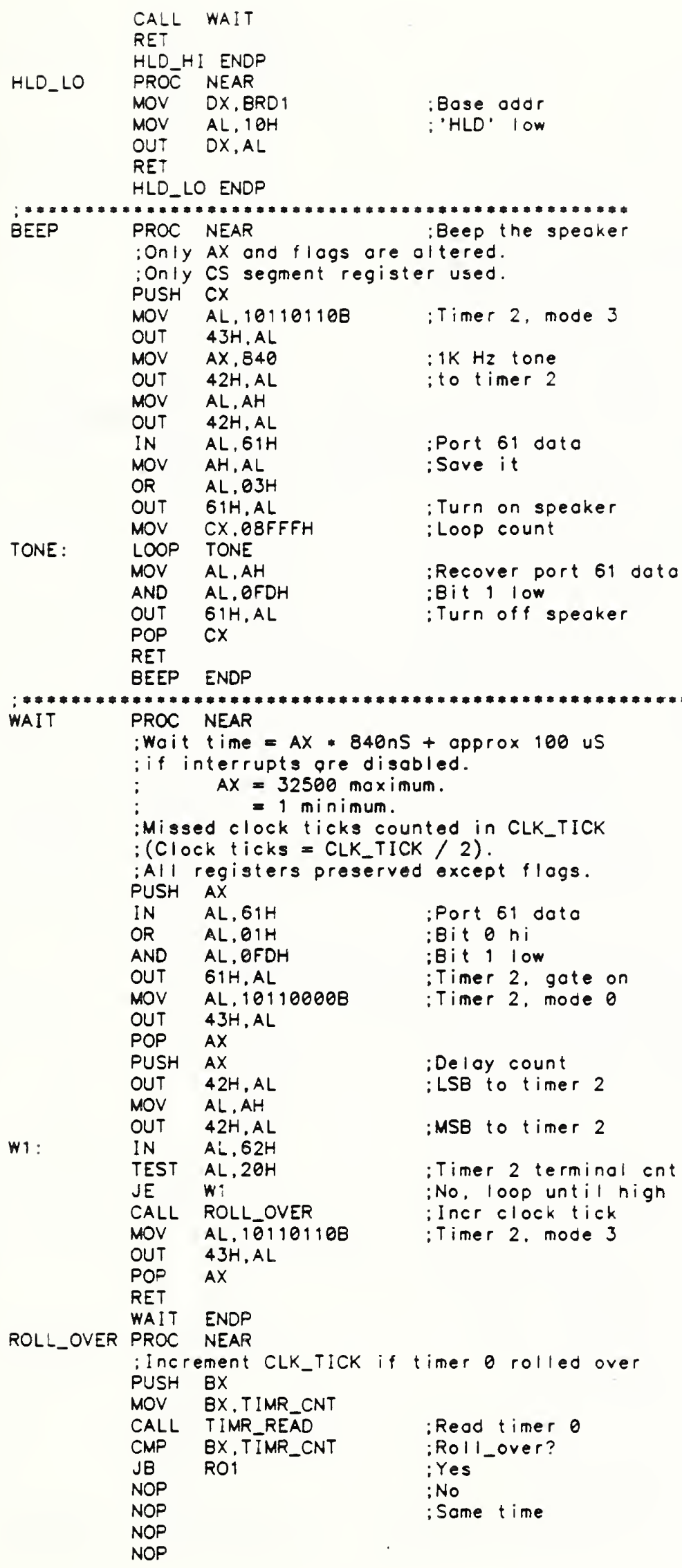




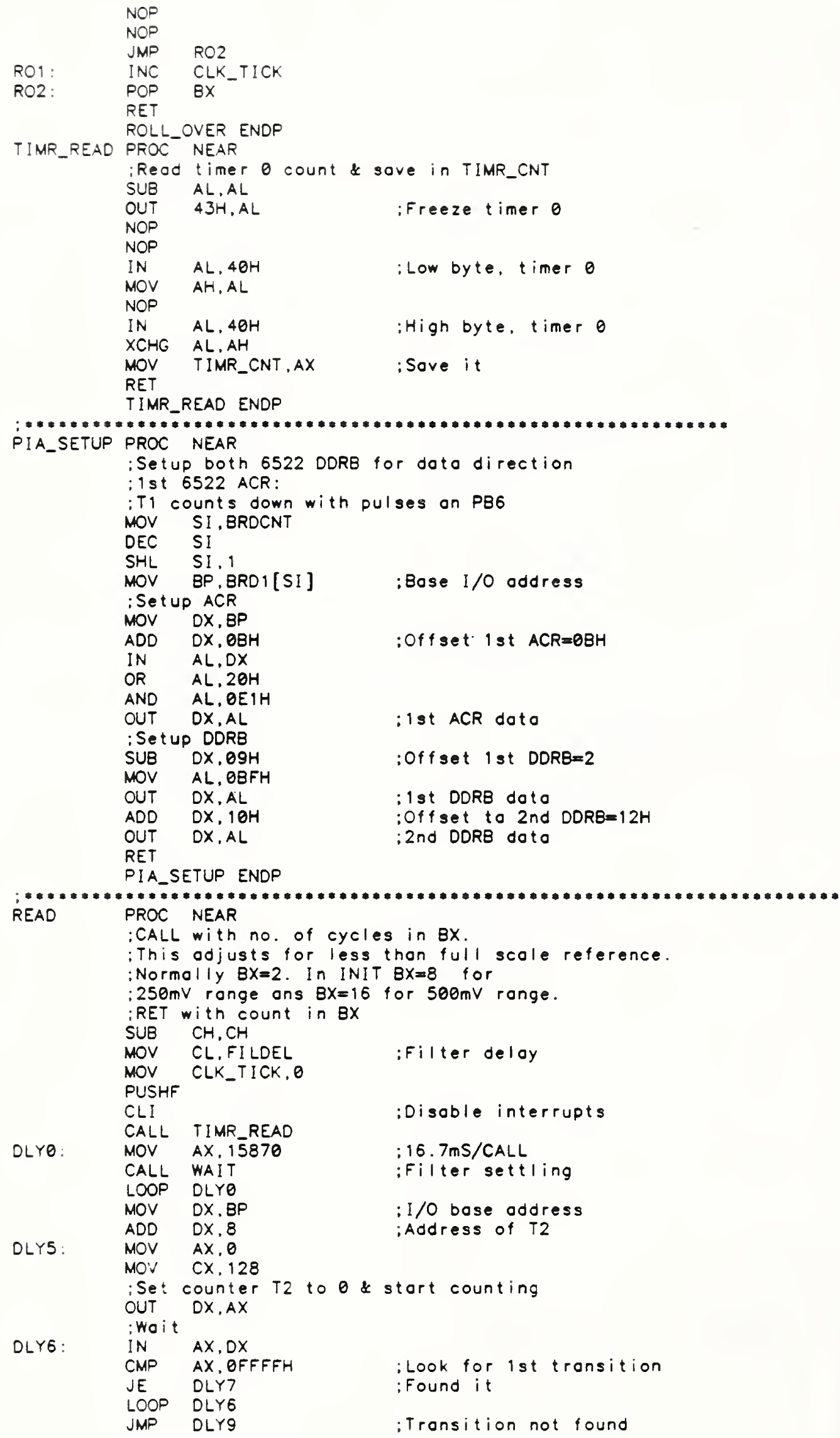




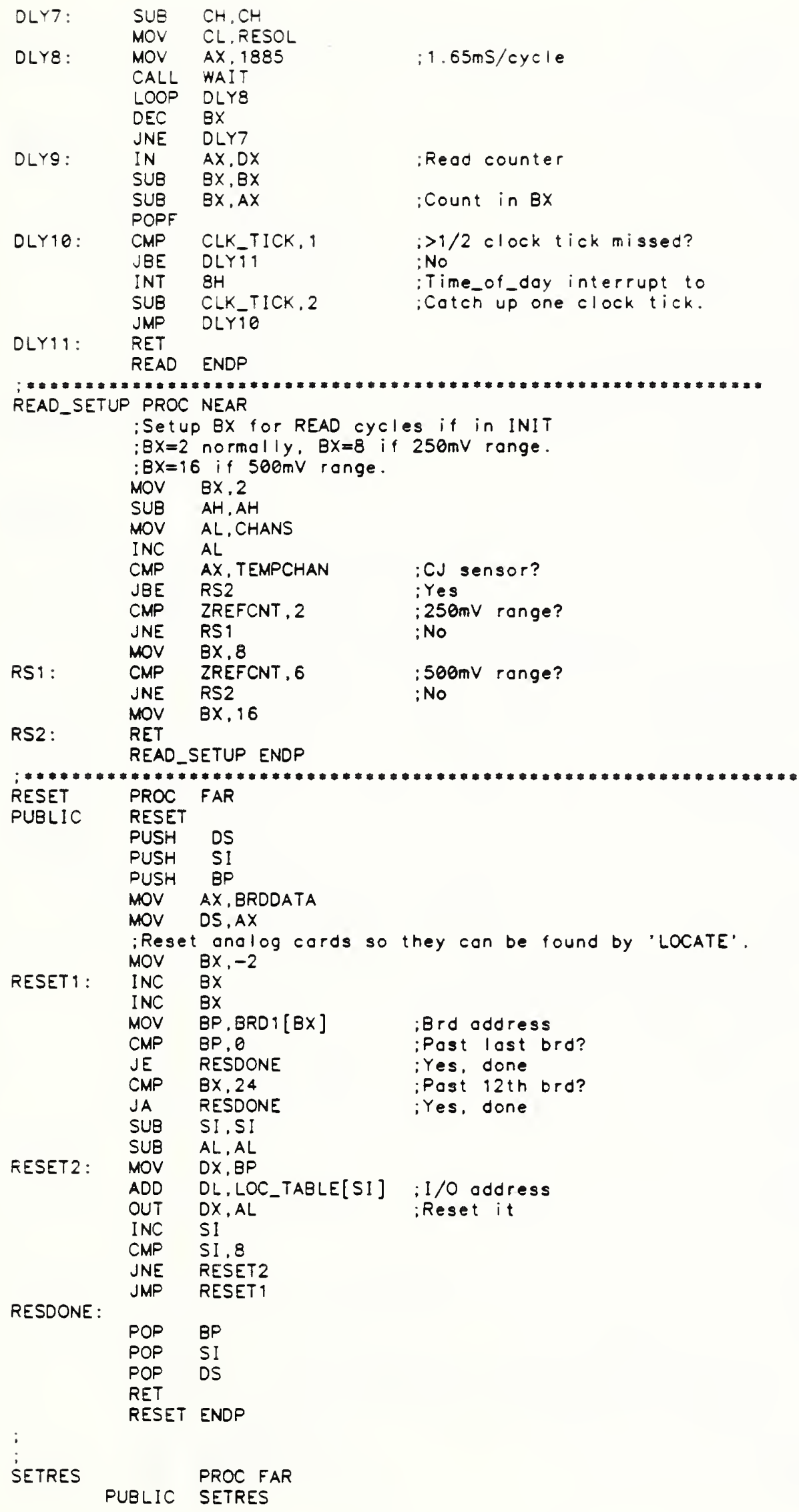

RESDONE :

$\begin{array}{ll}\text { POP } & \text { BP } \\ \text { POP } & \text { SI } \\ \text { POP } & \text { DS } \\ \text { RET } & \end{array}$

RESET ENDP 


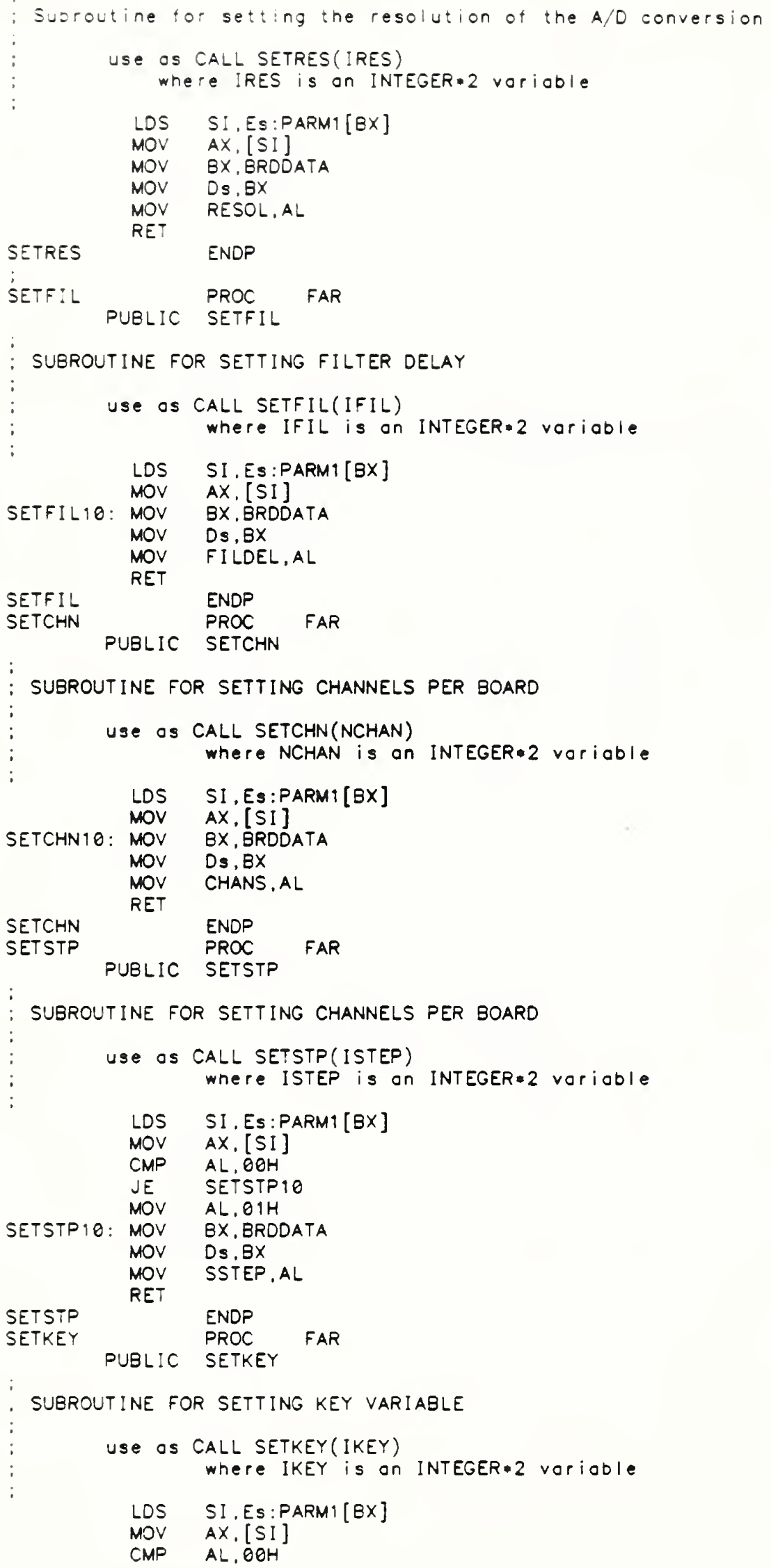




$\begin{array}{lll} & \text { JE } & \text { SETKEY1O } \\ \text { MOV } & \text { AL,OIH } \\ \text { SETKEYIO: } & \text { MOV } & \text { BX,BRDDATA } \\ & \text { MOV } & \text { DS,BX } \\ & \text { MOV } & \text { SKEY,AL } \\ & \text { RET } & \\ \text { SETKEY } & & \text { ENDP } \\ \text { SETNOZ } & & \text { PROC } \\ & \text { PUBLIC } & \text { SETNOZ }\end{array}$

SUBROUTINE FOR SETTING NOZREF

use OS CALL SETNOZ (INOZ)

where INOZ is on INTEGER 2 voriable

LDS SI,ES:PARMI[BX]

MOV AX.[SI]

CMP AL,OOH

JE SETNOZ10

MOV AL.O1H

SETNOZ10: MOV BX,BRDDATA

MOV DS, BX

MOV NOZREF, AL

SETNOZ

RET

SETBRD

ENDP

PROC

PUBLIC SETBRD FAR

SUBROUTINE FOR SETTING NUMBER OF BOARDS

use os CALL SETBRD(NBRDS)

where NBRDS is on INTEGER 2 variable

LDS SI,ES:PARM1[BX]

MOV AX, [SI]

SETBRD 10: MOV BX,BRDDATA

MOV DS, BX

MOV BRDS,AL

SETBRD RET ENDP

GETBRD PROC FAR

PUBLIC GETBRD

SUBROUTINE FOR SETTING NUMBER OF BOARDS

use as CALL GETBRD(NBRDS)

where NBRDS is on INTEGER 2 voriable

MOV AX, BRDDATA

MOV DS, AX

MOV AH,OOH

MOV AL,BRDS

LDS SI.ES:PARM1[BX]

MOV [SI], AX

GETBRD ENDP

;

SRDADR PROC FAR

Routine for returning boord oddress

use os CALL BRDADR (IWORD,N)

where IWORD is the board address (INTEGER 2 variable)

$N$ is the boord number ( 1 to 12) (INTEGER 2 varioble)

MOV AX,BRDDATA

LDS SI,ES:PARM2[BX]

PUSH BX

MOV BX.[SI] 


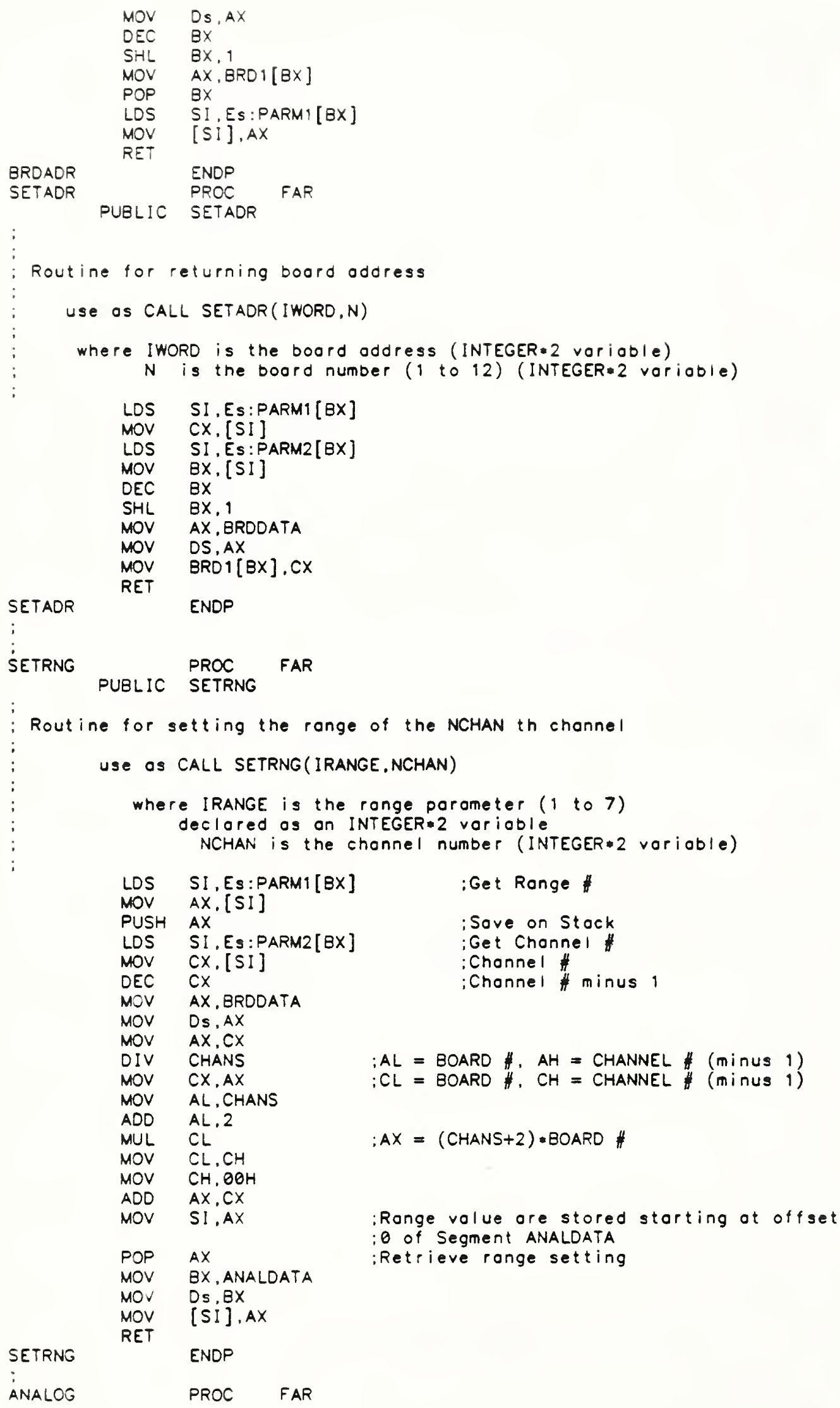




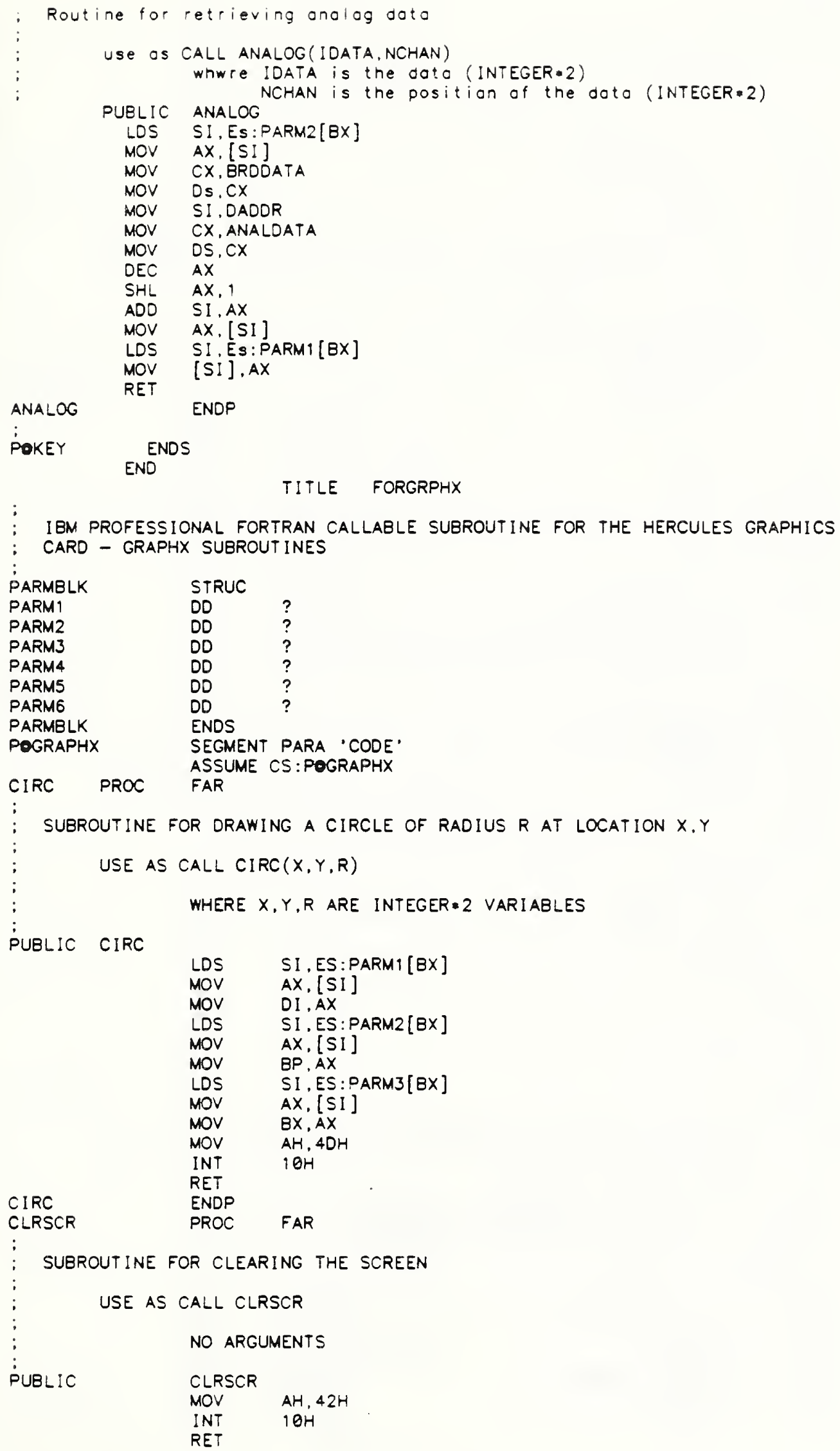




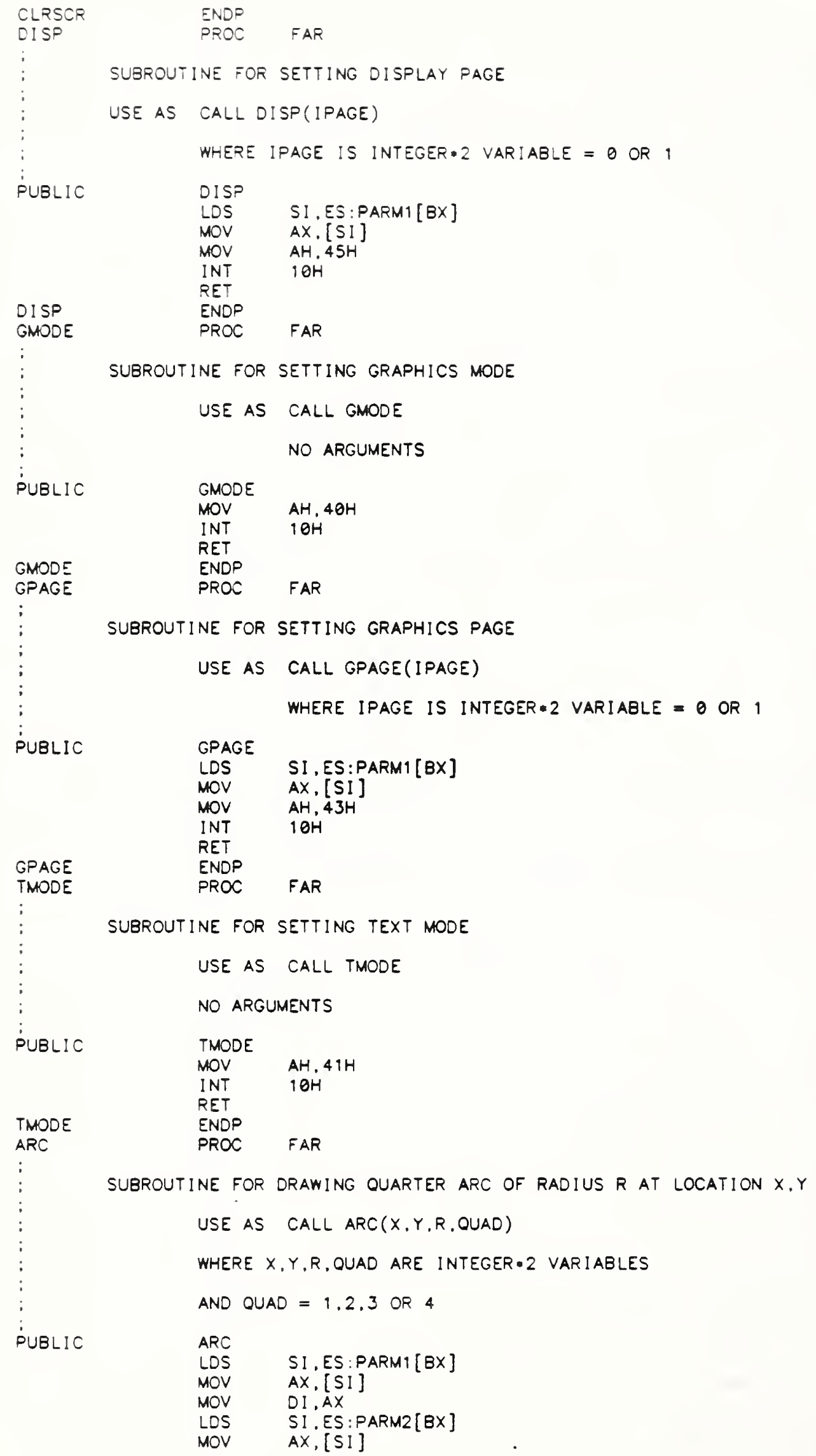




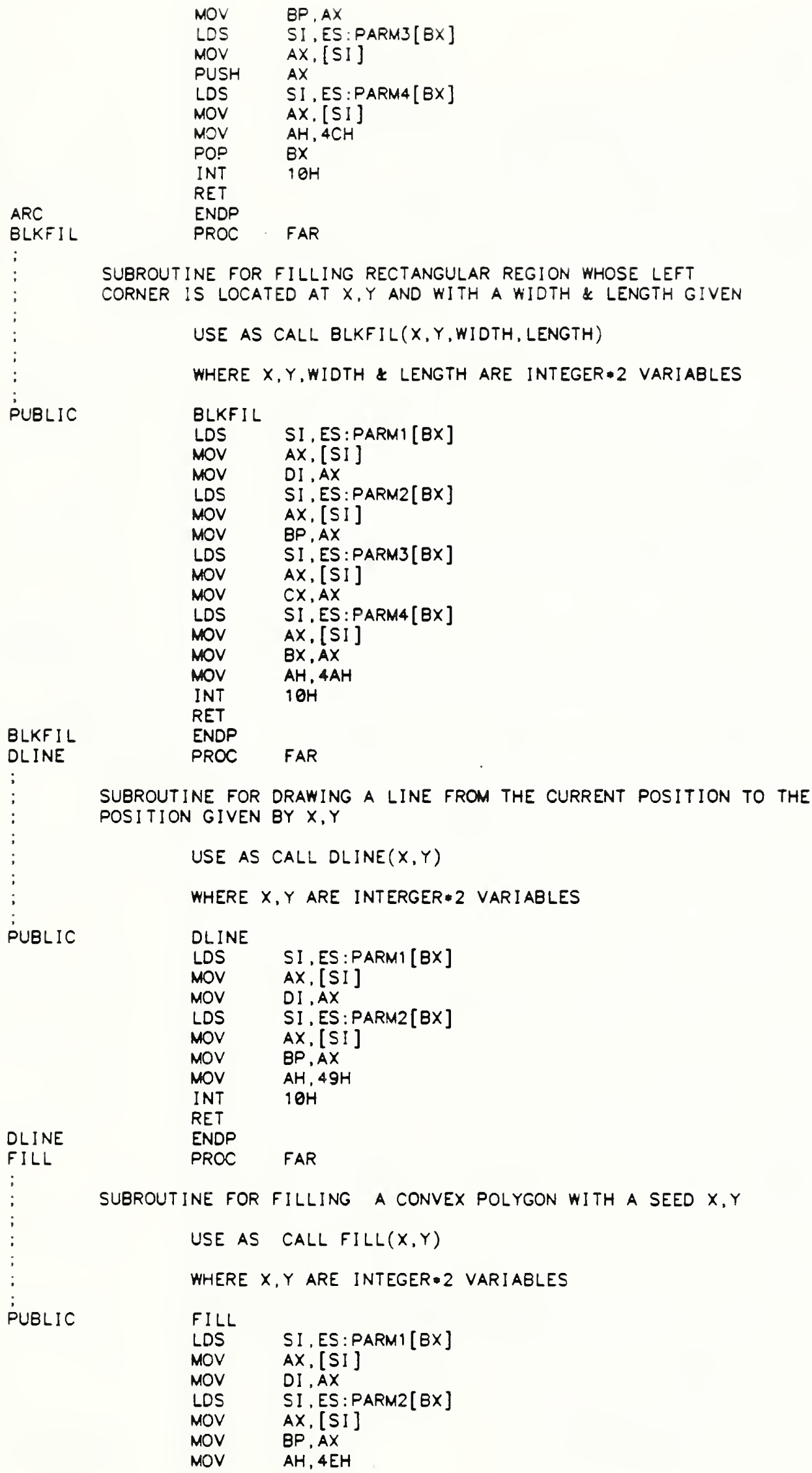




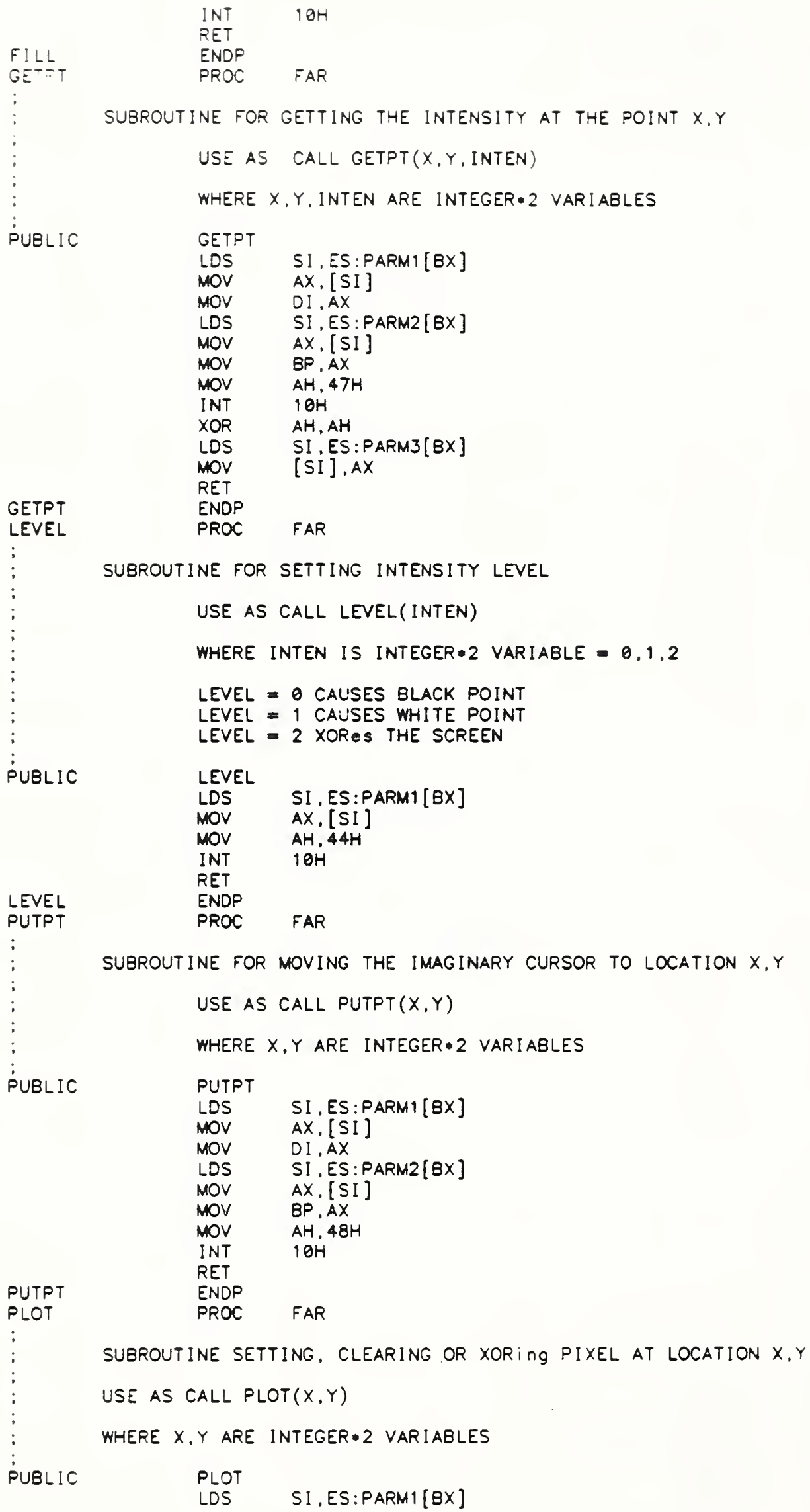




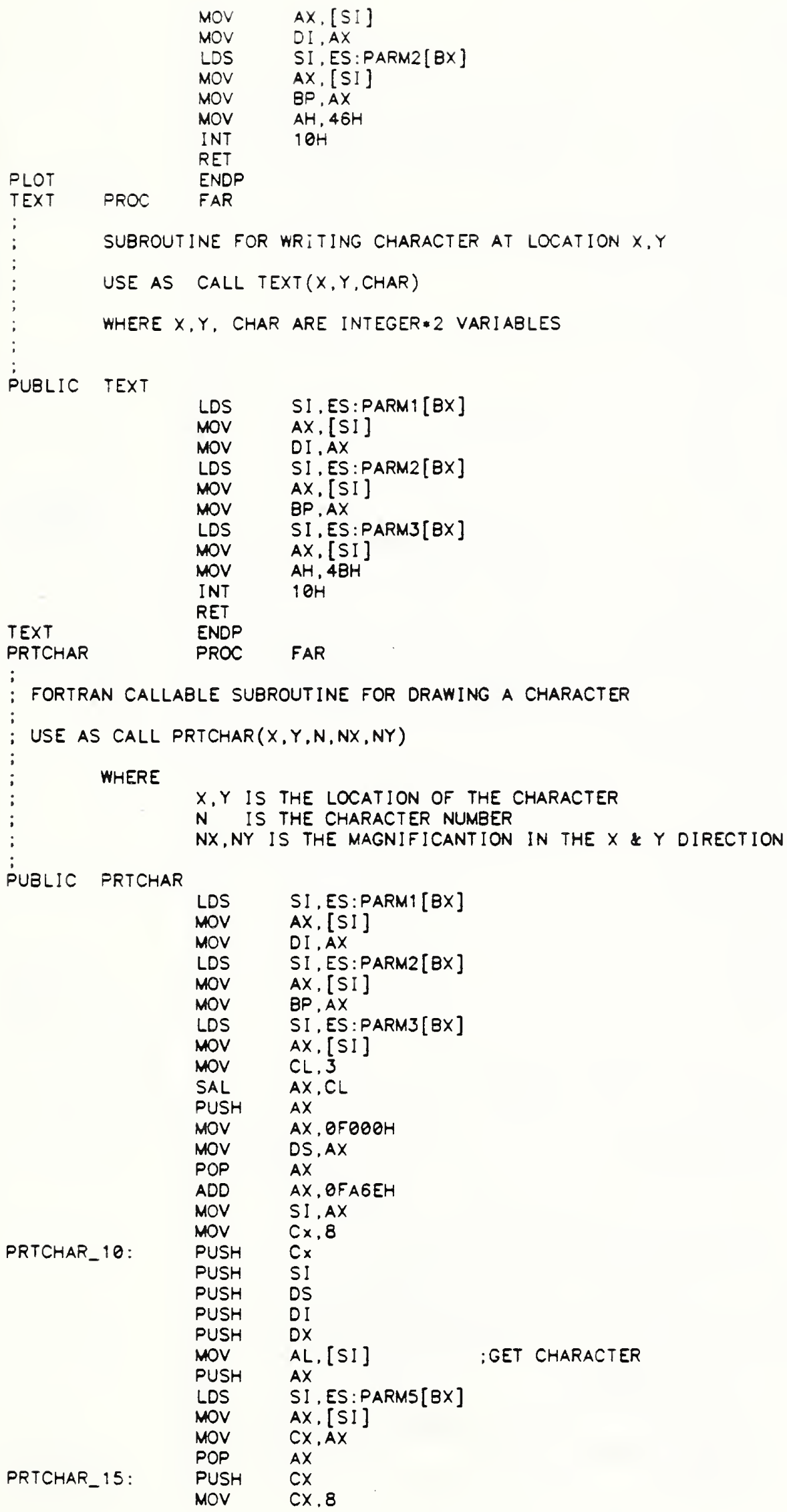




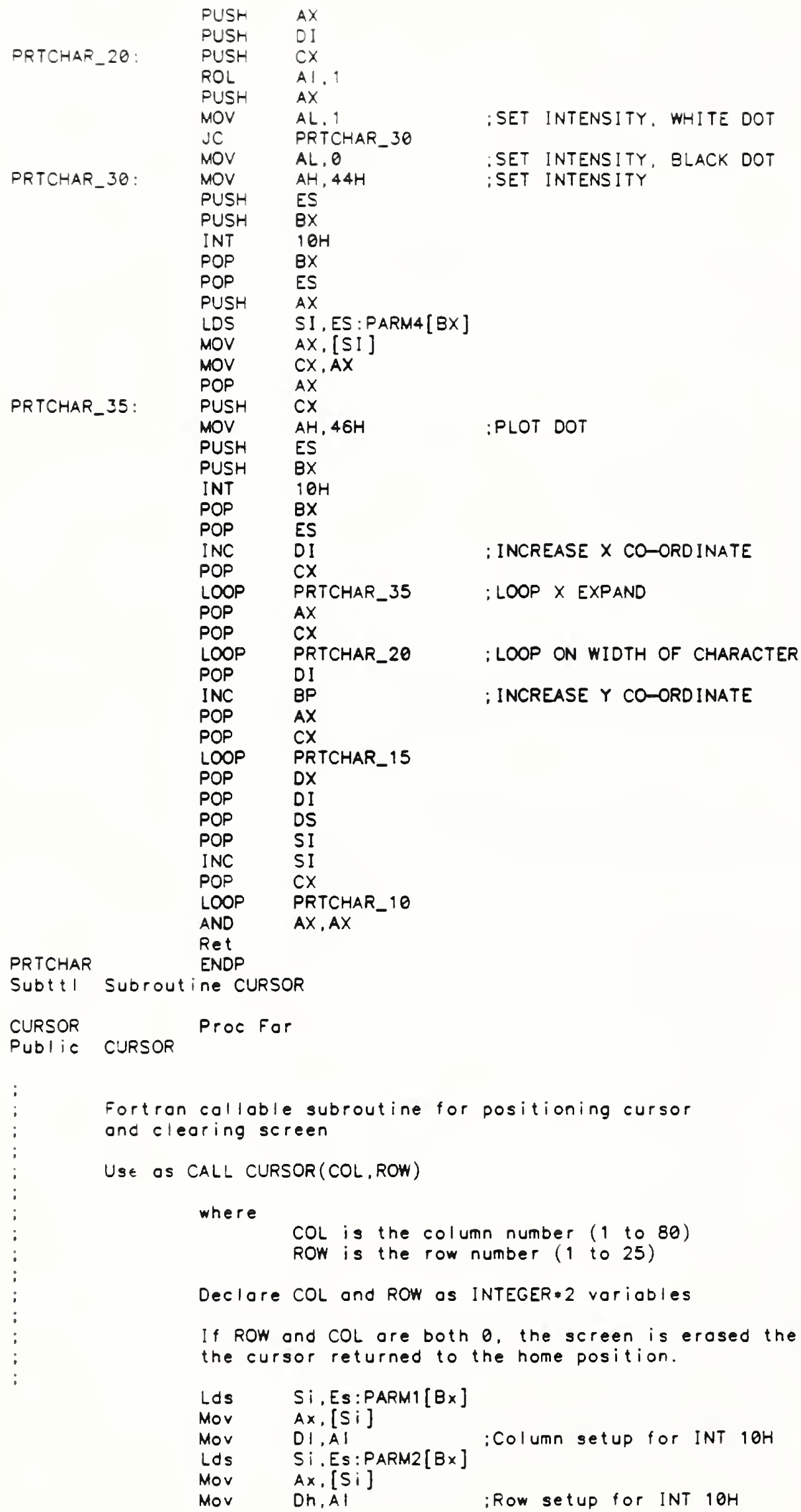




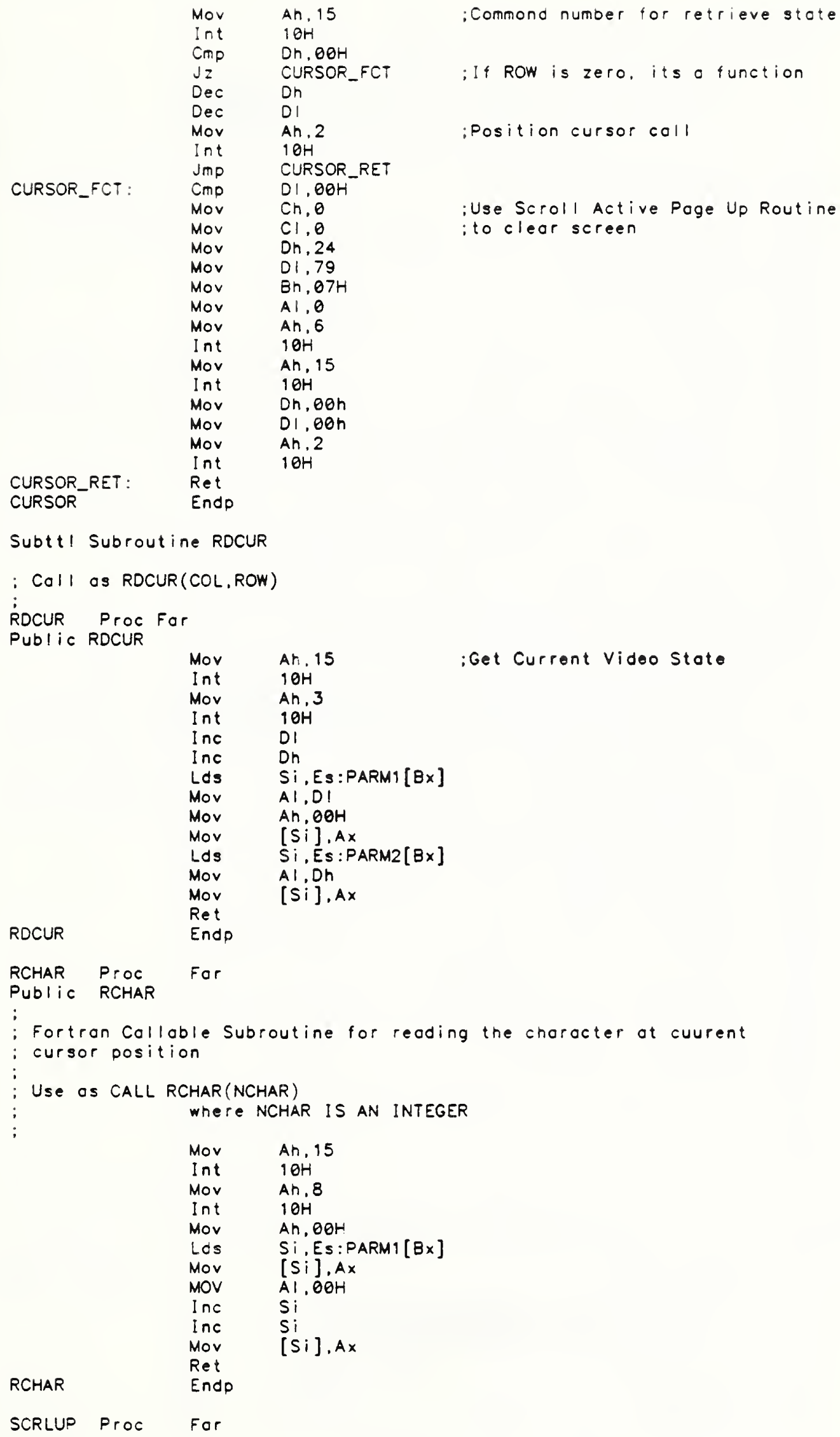




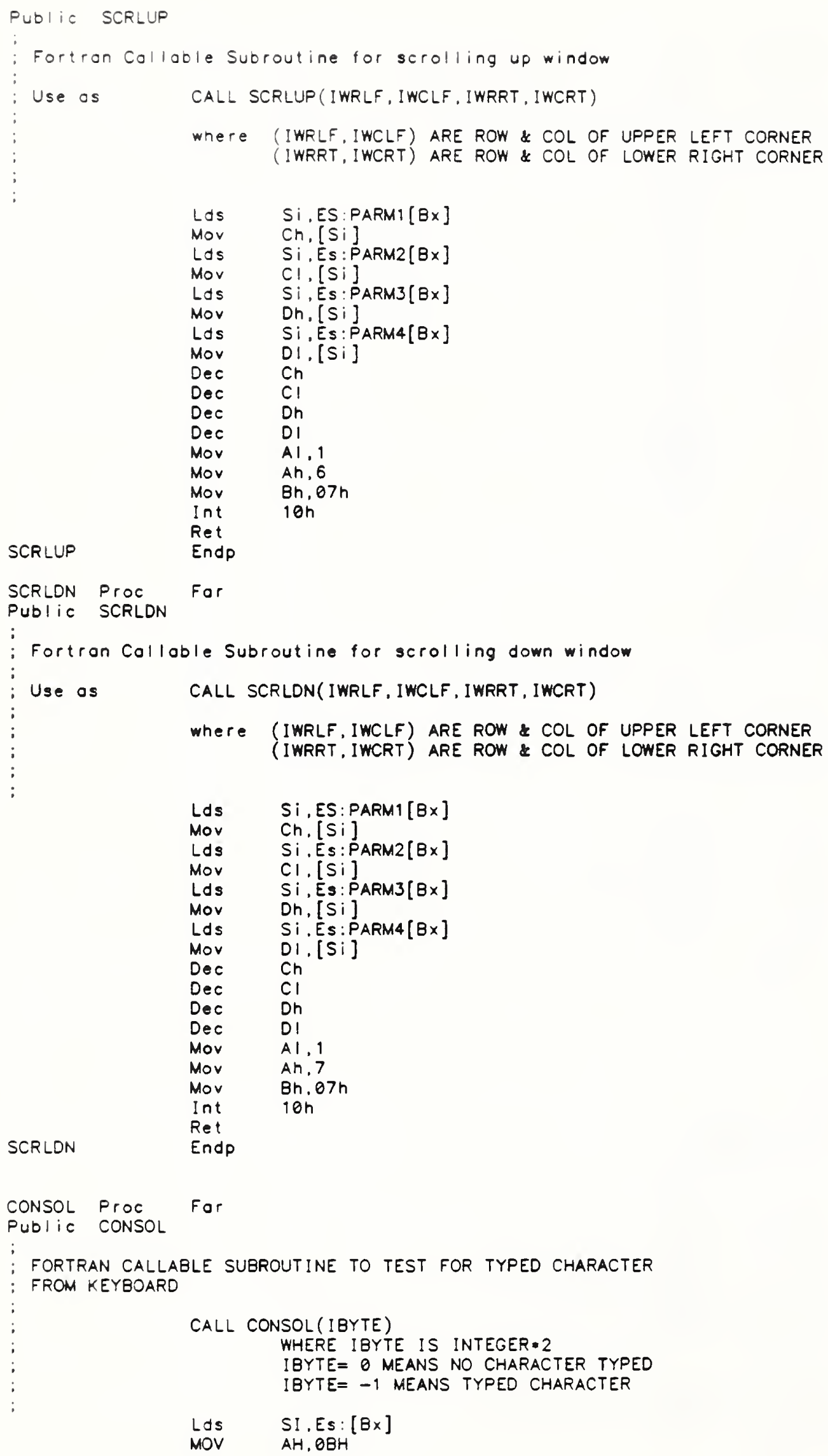




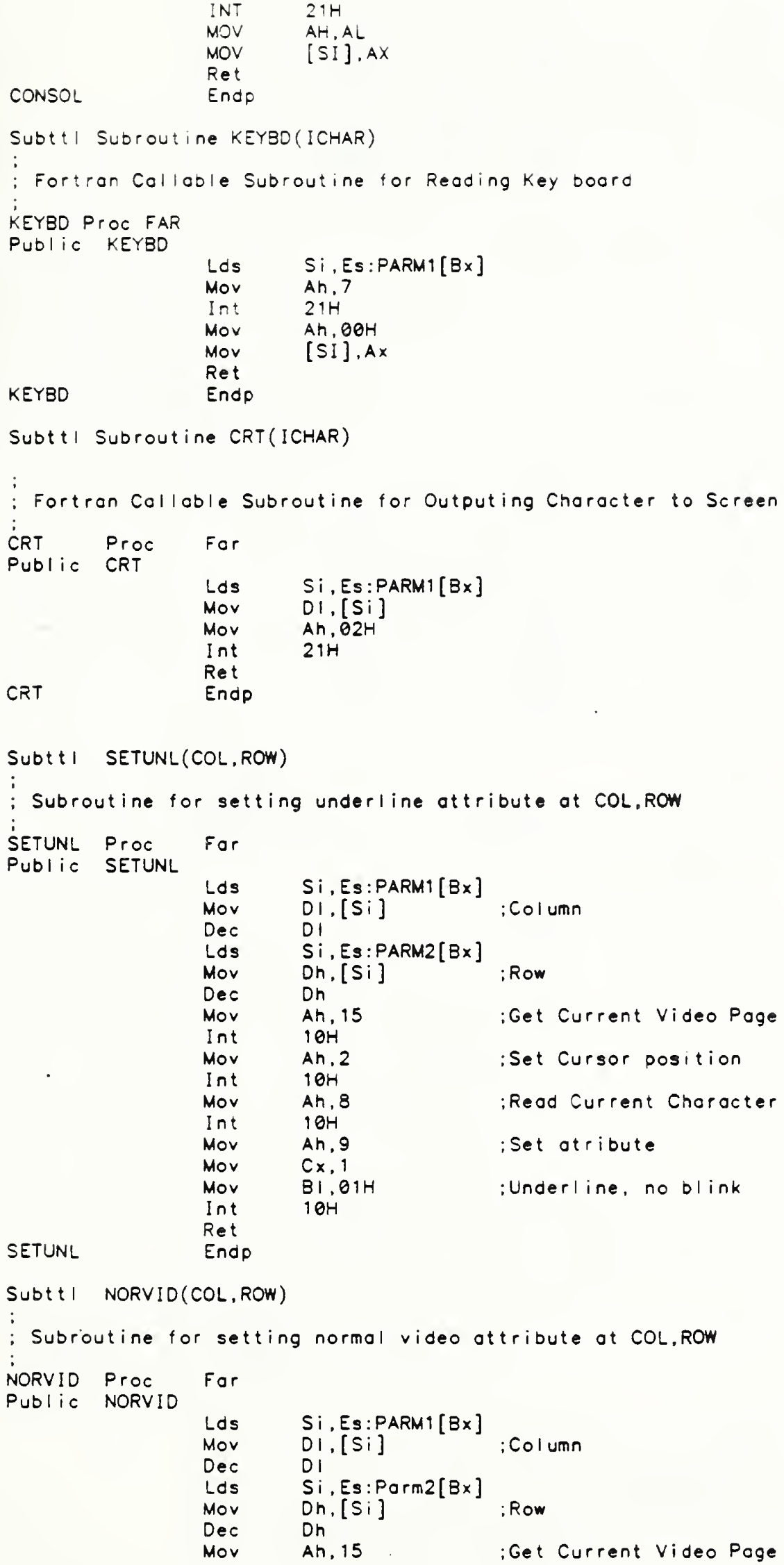




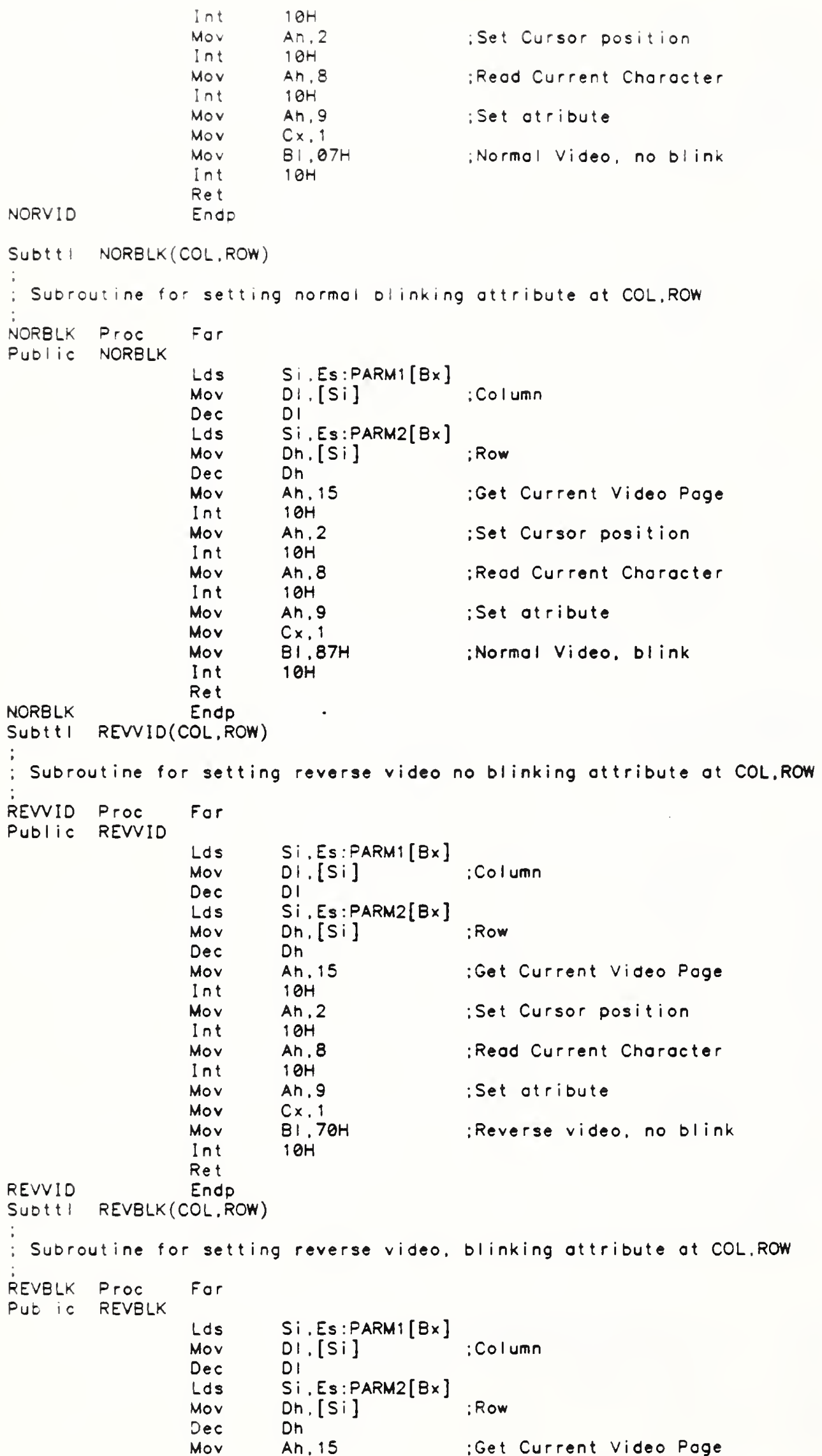




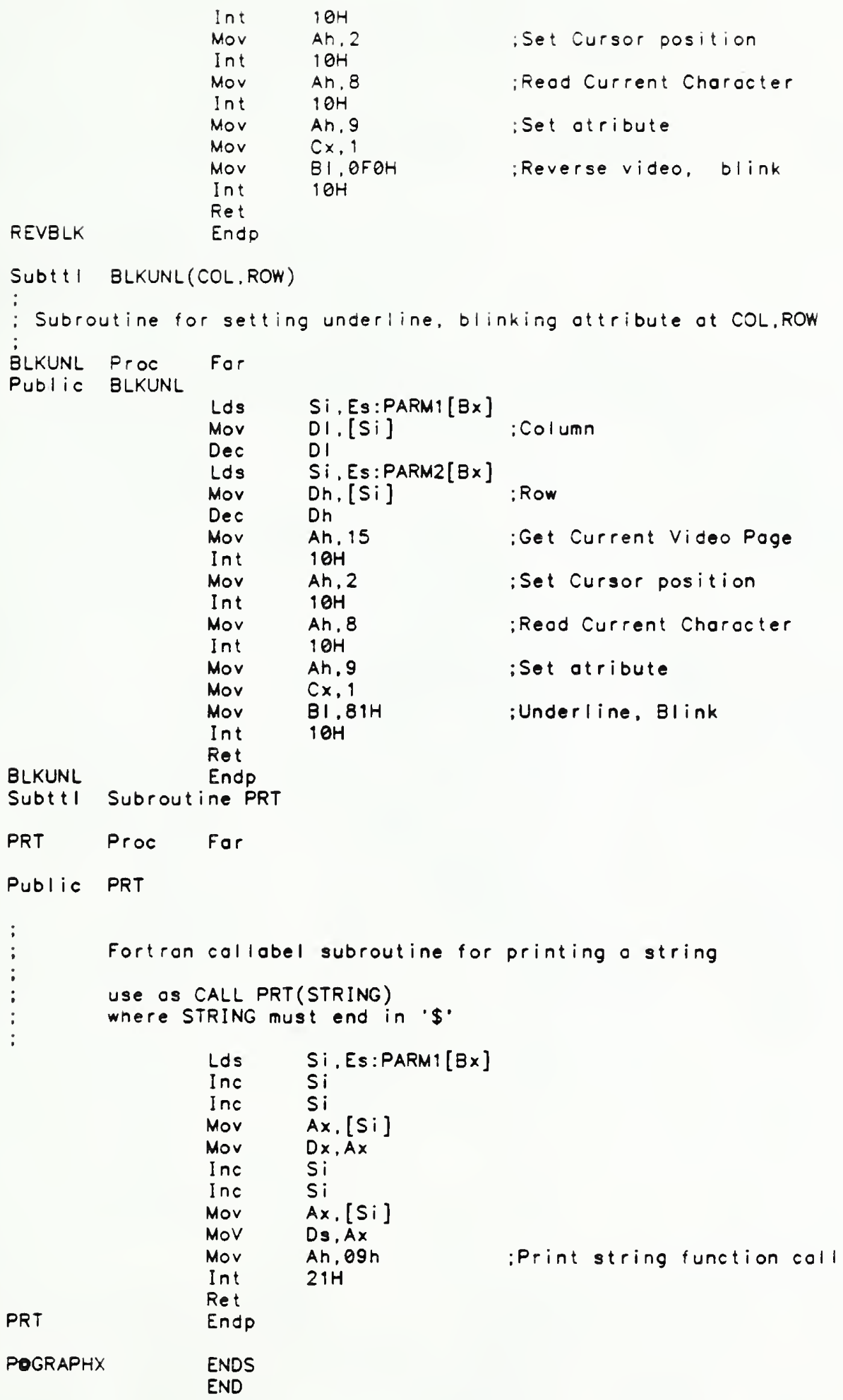


NBS.114A REV. 20AC)

U.S. DEPT. OF COMM.

BIBLIOGRAPHIC DATA

SHEET (See instructions)

1. PUBLICATION OR
REPORT NO.
NISTIR $88-4009$

2. Performing Organ. Report Nof 3. Publication Date

DEMMBER $1 \cong 88$

4. TITLE AND SUBTITLE

The Evaluation of Thermal Probe Method for Estimating the Heat

Loss from Underground Heat Distribution Systems

5. AUTHOR(S)

Jin B. Fang and Richard A. Grot

6. PERFORMING ORGANIZATION (If joint or other than NBS, see instructions)

NATIONAL BUREAU OF STANDARDS

DEPARTMENT OF COMMERCE

WASHINGTON, D.C. 20234

9. SPOASORING ORGANIZATION NAME ANO COMPLETE ADCRESS/SURE, CIY, STOTE, ZIF)

7. Contrace/Grant No.

U.S. Department of Energy

Building Services Division

Washington, DC 20585

10. SUPPLEMENTARY NOTES

Document describes a computer program; SF-185, FIPS Sofeware Summary, is attached.

11. ABSTRACT (A 200-word or less foctual summory of most significont information. If document includes a significont bibliogrophy or literoture survey, mention it here)

An automated, microcomputer controlled instrumentation system developed for in-situ measurements of the earth temperatures and soil thermal conductivities at different depths and for calculating the heat losses from the underground district heating pipes is described. Step-by-step use and operation procedures of the developed heat loss measuring system and computer software package are presented. The heat loss rates and locations of underground pipes are calculated from the measured values of soil thermal conductivity and the earth temperatures around the pipes using the nonlinear least squares method. The thermal probe technique was used to estimate the heat loss rates and the depths of buried steam supply and condensate return pipes installed at the James Madison University, Harrisonburg, Virginia.

12. KEY WORDS (Six to twelve entries; olphabeticol order; copitolize only proper nomes; ond seporote key words by semicolons) computer software; district heating and cooling; earth temperature; heat loss; instrumentation system; nonlinear least squares fitting; soil; steel pipe; thermal conductivity; underground heat distribution system.

13. AVAILABILITY

X] Unlimited

For Official Distribution. Do Not Release to NTIS

Order From Superintendent of Documents, U.S. Government Printing Office, Washington, D.C. 20402.

X. Order From National Technical Information Service (NTIS), Springfield, VA. 2216I

14. NO. OF PRINTED PAGES

125

15. Price

$\$ 18.95$ 




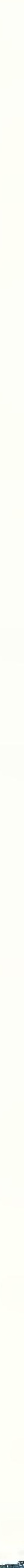





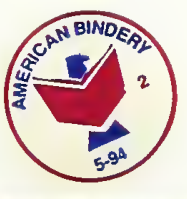


